WSRC-TR-2000-00486

SRT-RPP-2000-00047

BNF-003-98-0275

\title{
AN-107 (C) Simulant Bench-Scale LAW Evaporation with Organic Regulatory Analysis
}

Westinghouse Savannah River Company

Savannah River Site

Aiken, SC 29808

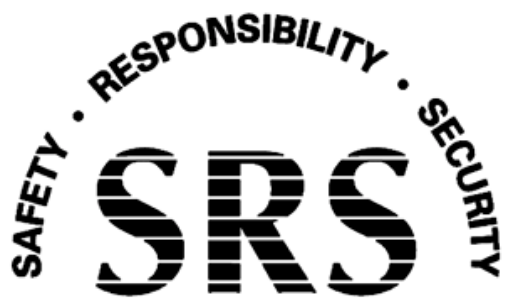

SAVANNAH RIVER SITE

Prepared for the U.S. Department of Energy under Contract No. DE-AC09-96SR18500 
This document was prepared in conjunction with work accomplished under Contract No.

DE-AC09-96SR18500 with the U.S. Department of Energy.

\section{DISCLAIMER}

This report was prepared as an account of work sponsored by an agency of the United States Government. Neither the United States Government nor any agency thereof, nor any of their employees, makes any warranty, express or implied, or assumes any legal liability or responsibility for the accuracy, completeness, or usefulness of any information, apparatus, product or process disclosed, or represents that its use would not infringe privately owned rights. Reference herein to any specific commercial product, process or service by trade name, trademark, manufacturer, or otherwise does not necessarily constitute or imply its endorsement, recommendation, or favoring by the United States Government or any agency

thereof. The views and opinions of authors expressed herein do not necessarily state or reflect those of the United States Government or any agency thereof.

This report has been reproduced directly from the best available copy.

Available for sale to the public, in paper, from: U.S. Department of Commerce, National Technical Information Service, 5285 Port Royal Road, Springfield, VA 22161, phone: (800)

553-6847, fax: (703) 605-6900, email: orders@ntis.fedworld.gov online ordering: http://www.ntis.gov/ordering.htm

Available electronically at http://www.doe.gov/bridge

Available for a processing fee to U.S. Department of Energy and its contractors, in paper, from: U.S. Department of Energy, Office of Scientific and Technical Information, P.O. Box 62, Oak Ridge, TN 37831-0062, phone: (865 ) 576-8401, fax: (865) 576-5728, email: reports@ adonis.osti.gov 
WSRC-TR-2000-00486

SRT-RPP-2000-00047

BNF-003-98-0275

\section{KEYWORDS:}

Hanford River Protection Project Low Activity Waste Melter Feed Evaporator Evaporation Regulatory Off-gas Analysis Volatile and Semi-volatile Organic, Pesticide

\section{AN-107 (C) Simulant Bench-Scale LAW Evaporation with Organic Regulatory Analysis}

SAVANNAH RIVER TECHNOLOGY CENTER

Hiroshi H. Saito

T. Bond Calloway, Jr.

Daro M. Ferrara

Alexander S. Choi

Thomas L. White

Luther V. Gibson, Jr. (BWXT-Y12, L.L.C.)

Mark A. Burdette (BWXT-Y12, L.L.C.)

Publication Date: February, 2001

Westinghouse Savannah River Company

Savannah River Site

Aiken, SC 29808

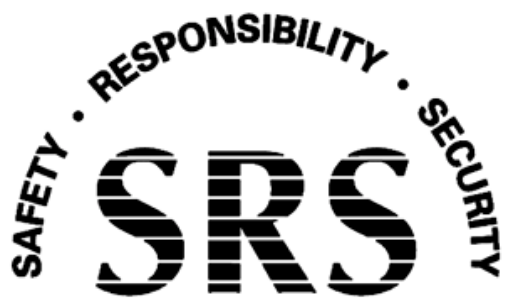

SAVANNAH RIVER SITE

Prepared for the U.S. Department of Energy under Contract No. DE-AC09-96SR18500 
DOCUMENT: $\quad$ WSRC-TR-2000-00486 (SRT-RPP-2000-00047, formerly BNF-003-98-0275)

TITLE:

AN-107 (C) Simulant Bench-Scale LAW Evaporation with Organic Regulatory Analysis

\section{APPROVALS}

Date:

Hiroshi H. Saito, Co-author (WPTS/SRTC)

Date:

T. Bond Calloway, Co-author ITS/SRTC)

Date:

Daro M. Ferrara, Co-author (ITS/SRTC)

Date:

Alexander S. Choi, Co-author (ITS/SRTC)

Date:

Thomas L. White, Co-author (ADS/SRTC)

Date:

Luther V. Gibson, Jr., Co-author (BWXT Y-12, L.L.C.)

Date:

Mark A. Burdette, Co-author (BWXT Y-12, L.L.C.)

Date:

Technical Reviewer

Date:

RPP Pretreatment or Vitrification Manager 


\section{Contents}

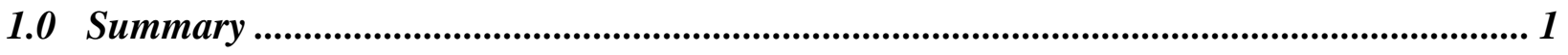

2.0 Introduction and Background ................................................................................... 1

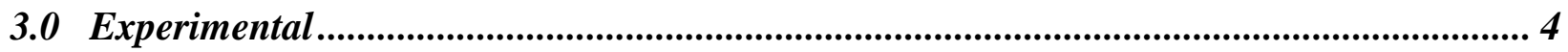

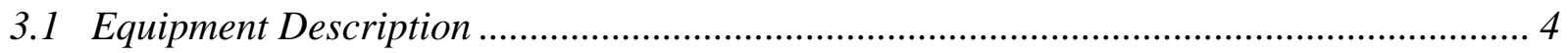

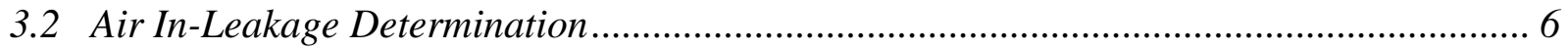

3.3 Gas Sampling Time Determination............................................................................... 7

3.4 Evaporator Entrainment ..................................................................................... 8

3.5 AN-107 Envelope C Simulant History …………….................................................. 9

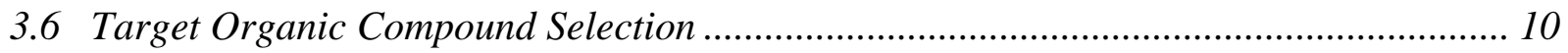

3.7 Spike Solution/Evaporator Feed System Development ................................................ 10

3.8 SW-846 Method Parameter Selection/Exceptions ………………………………........ 18

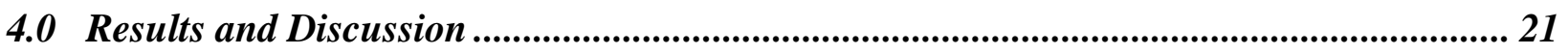

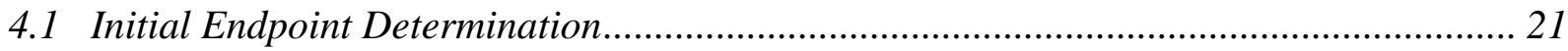

4.2 Execution of Experiment ...................................................................................... 22

4.3 Overall and Target Organics Mass Balance …………............................................... 27

4.4 Product Chemical Analysis Results .............................................................................. 30

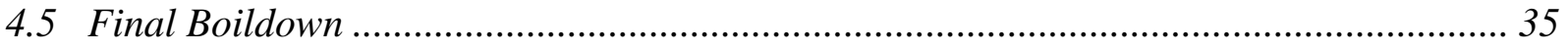

4.6 OLI Model Comparison ……………....................................................................... 39

5.0 Conclusion/Summary .............................................................................................................. 41

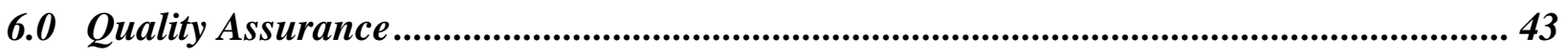

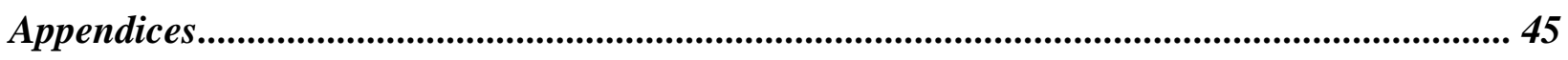

Appendix A - Envelope C (AN-107) Simulant Recipe ……………….................................... 45

Appendix B - Regulatory Analysis Raw Data Summary ………….......................................... 48

Appendix C - Target Organic Compound Mass Balances ..................................................... 65 


\subsection{Summary}

As part of a series of evaporation experiments, a Hanford Tank AN-107 Envelope C simulated waste was spiked with approximately $1 \mathrm{ppm}$ of 14 target volatile, semi-volatile and pesticide compounds, and was concentrated from approximately 5.5 to $8.0 \mathrm{M} \mathrm{Na}$ to determine the fate of organic species entering the Low Activity Waste Melter Feed Evaporator. These studies were conducted in support of the Hanford River Protection Project Waste Treatment Plant (RPPWTP). The information from these experiments will be used as input to the RPP-WTP environmental permits, risk assessments, and process flow sheet development. This experiment and an accompanying OLI model showed that: 1) volatile and light semi-volatile $(1,2,4-$ trichlorobenzene, naphthalene) organic compounds largely exit the evaporator system through the condensor vent gas at individual species concentrations up to $1000 \mathrm{ppm}, 2$ ) heavier semivolatile organic and pesticide compounds tend to remain in the evaporator concentrate, 3) AN107 simulant reaches a very sharp saturation point at about 10.1 M Na concentration, and 4) an OLI model can describe organics distribution over a wide molecular weight range from the evaporation of Hanford simulant, with a few exceptions. The final boildown experiment indicates the Envelope $\mathrm{C}$ simulant reaches saturation at $48.6 \mathrm{wt} \%$ (94.6 g total solids (TS)/100 g water, estimated $10.1 \mathrm{M} \mathrm{Na}$ ), and that initial insoluble solids are sodium oxalate followed by sodium carbonate prior to precipitation of sodium nitrate. This work also showed that evaporation of the pretreated Envelope $\mathrm{C}$ simulated waste did not cause scaling, did not require an anti-foaming agent, and behaves as a Newtonian fluid. Lastly, a novel waste simulant spiking and storage system was developed for the creation of stable Hanford waste simulants spiked with organic compounds.

\subsection{Introduction and Background}

The Hanford River Protection Project Waste Treatment Plant (RPP-WTP) pretreatment and immobilization process will decontaminate Envelope A, B \& C supernates using cesium and technetium ion exchange columns, after strontium and transuranics (Sr/TRU) are removed via a precipitation (Envelope $\mathrm{C}$ only) and filtration step. The decontaminated low activity waste (LAW) will be concentrated through the LAW Melter Feed Evaporator, a forced circulation evaporator. Glass formers will be added to the concentrated LAW and vitrified in a joule-heated, refractory-lined melter designed to operate at $1150^{\circ} \mathrm{C}$ (nominal). The design goal of the LAW Melter Feed Evaporator is to: 1) evaporate pretreated Envelope A, B, and C waste to 80\% of bulk solubility thereby preventing the formation of solids ${ }^{*}$, and 2) maximize the waste loading in the

\footnotetext{
* Bulk solubility of a multi-electrolyte solution is defined here as the mass of total dissolved solids in solution, when one or more of the major salt constituents first begins to precipitate. Small quantities of solids should not challenge the design basis for the LAW melter feed lag storage vessels. The LAW melter feed lag storage vessels are each equipped with pulsed-jet mixing units that are capable of suspending small quantities of solids. The LAW melter feed will be transferred from the lag storage vessels to the LAW vitrification building using
} 
melter feed by removing as much water as possible without over concentrating the slurry to the point that the material can not be transported to the melter, and to the point that inadequate distribution of the feed on the melt surface hinders melting.

The design of the Hanford RPP forced circulation evaporator is based upon the Hanford 242-A evaporator that is used to concentrate Hanford supernate wastes ${ }^{1,2}$. The Hanford 242-A evaporator is designed to operate at an absolute pressure of 40 to 80 torr $^{3}$. During Part A of the Tank Waste Remediation System (TWRS) Privatization contract, Savannah River Technology Center (SRTC) evaporated the Hanford LAW melter feed in crucibles at atmospheric pressure. No attempt was made in Part A to demonstrate the LAW Melter Feed Evaporator unit operation. During Part B1, actual Hanford radioactive samples, pretreated to remove Cs and Tc, were batch evaporated under prototypical pressure and temperature. SRTC has also performed evaporation experiments on simulated Hanford wastes.

The overall objective of this work is to develop preliminary operating data including expected concentration endpoints using a $\mathrm{C}$ waste envelope simulant. The data is to be used for the preliminary Hanford RPP flow sheet development and LAW Melter Feed Evaporator design. A scoping study by Monson ${ }^{4}$ and OLI model predictions were used as a basis to determine the maximum achievable concentration of Envelope $\mathrm{C}$ simulants without significant crystalline solids formation. A small bench scale evaporator $(1 \mathrm{~L})$ was fabricated and operated with simulated pretreated LAW solutions. Parameters that were monitored and /or measured included:

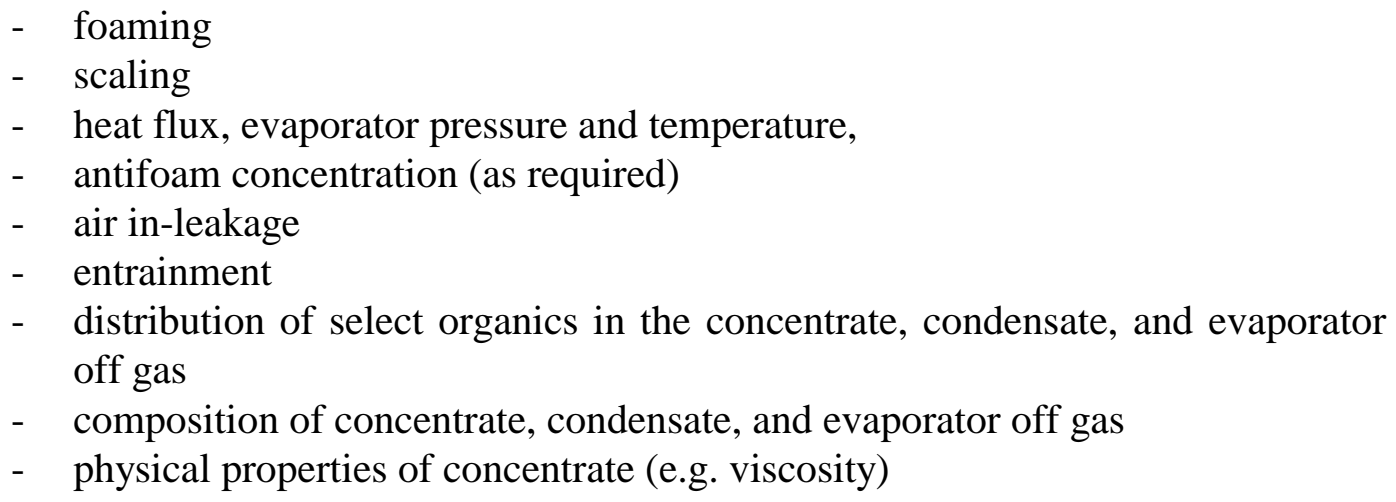

Corrosion testing is covered under another experimental program and will be conducted using actual Hanford radioactive wastes. The data developed during the simulant evaporation experiments will be used to refine an OLI Environmental Simulation Program (ESP) evaporation

centrifugal pumps which are to be designed to suspend solids and prevent settling in the underground pipeline. System Description for the LAW Melter Feed Lag Storage System (LP-140), SD-W375LP-PR00001, revision 3, April 3, 2000, BNFL Inc., Richland Washington.

${ }^{1}$ M. Currey, "LAW Melter Feed Evaporator", K0104_REP_013_PRC, BNFL Engineering Ltd, March 6, 1997.

${ }^{2}$ Verbal Conversation with M. E. Johnson concerning LAW Melter Feed Evaporator, January 19, 1999.

${ }^{3}$ M. D. Guthrie, "242-A Evaporator Campaign 97-1 Post Run Document”, HNF-SD-WM-PE-057, Waste Management Hanford, Richland WA 99352, August 15, 1997.

${ }^{4}$ Monson, P. R., "Envelopes A, B, and C Shaker/Bath Evaporation Saturation Studies", BNF-003-98-0189, SRTPTD-99-0062, Rev. 0, January 4, 2000. 
model that is being developed by SRTC. This task, in addition to the small scale scoping studies, will define experimental parameters to be used in the active LAW evaporations.

This bench-scale evaporation with C-simulant (AN-107) spiked with several target organic compounds is one in a series of runs outlined in a Technical Task Plan (TTP) by Calloway and Lambert ${ }^{5}$ examining evaporator operating parameters and evaporation endpoints for different Hanford RPP waste simulants under different feed conditions. The purpose of this experiment was to examine the regulatory off-gas emission impacts from the evaporation of a relatively organic-rich simulated waste containing a variety of volatile and semi-volatile organic compounds in addition to pesticides potentially present in actual Hanford RPP waste. An industrial-scale EPA (Environmental Protection Agency) SW-846 Methods 0010/0031 gas sampler was connected to the effluent of an operating bench-scale evaporator to collect and quantify emissions of regulated organic compounds as consistently as practically possible to the EPA SW-846 Methods. Based on the information gathered, evaporator off-gas permitting requirements will be determined.

Hence, the purpose of this work was to provide data as similar as possible to regulatory data on a bench-scale to serve as a guide for emissions permitting requirements for the actual industrialscale evaporator to be installed at Hanford.

\footnotetext{
${ }^{5}$ Calloway, T. B., Lambert, D. P., "Task Technical and Quality Assurance Plan for Bench Scale LAW Evaporation with Simulants”, BNF-003-98-0056, SRT-PTD-99-0018, Rev. 0, December 14, 1999.
} 


\subsection{Experimental}

\subsection{Equipment Description}

The bench-scale evaporator used in the experiment is shown in Figure 1. The evaporator is mainly of glass and Teflon ${ }^{\circledR}$ construction to minimize potential organic absorption/adsorption during operation. Only very slight losses are expected to the stainless steel-sheathed thermocouples/RTD's (Resistance Temperature Detectors) used to monitor the evaporator (T2), condensor (T3) and condensate (T4) temperatures, and the Incoloy ${ }^{\circledR}$ heating rod (with internal thermocouple T1) used as the heating element in this natural circulation evaporator. Stainless steel Cajon ${ }^{\circledR}$ fittings mounted in Teflon ${ }^{\circledR}$ plugs were used on the lids of the evaporator and condensate chambers to secure temperature and pressure (pressure gauge PG) measurement devices and some material addition/removal ports. Again, minimal losses of organic are expected due to minimal surface area and exposure to the interior headspace rather than direct contact with the liquid. When feed, condensate, or concentrate was introduced or removed from the system, liquids were routed through Teflon ${ }^{\circledR}$ lines and valves (V1-V3). To also minimize

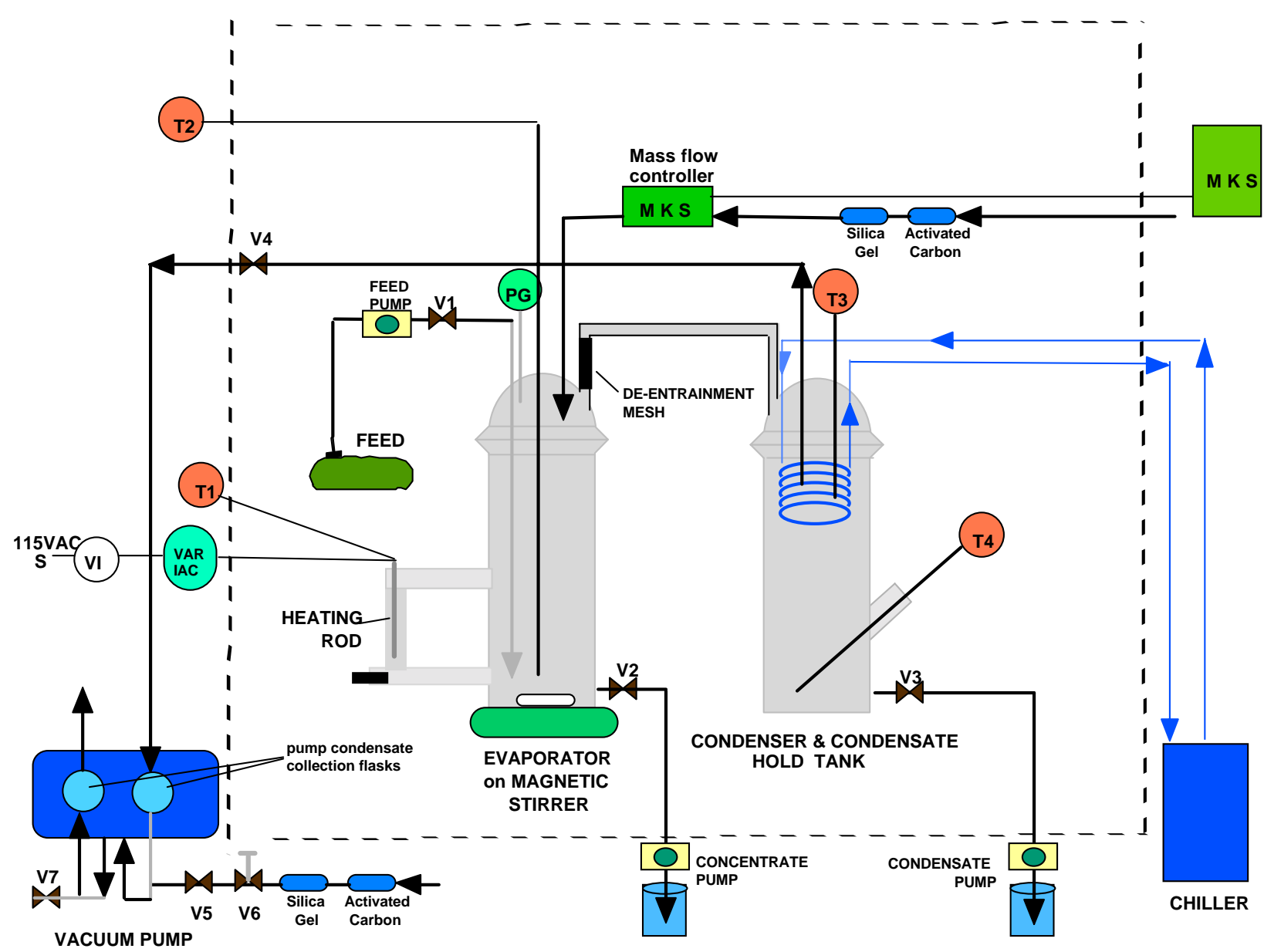

Figure 1. Evaporator System Schematic 
organic losses and simulant contamination, the ground glass joints were sealed with Teflon ${ }^{\circledR}$ tape, a Viton O-ring, or a Teflon ${ }^{\circledR}$-coated O-ring, rather than with conventional silicone vacuum grease. The internal volume of the evaporator was estimated to be approximately $5200 \mathrm{~mL}$ by filling the interior with water and measuring the water removed. The evaporator chamber and condensate hold tank are capable of holding nearly $2100 \mathrm{~mL}$ and $2000 \mathrm{~mL}$, respectively, before liquid reaches the seam with the lid. Natural leak rates of as low as $0.2 \mathrm{~mL} / \mathrm{min}$ (STP) were achieved with this system.

Continuous feed addition and concentrate removal was performed using Masterflex $\mathrm{L} / \mathrm{S}^{\circledR}$ pumps equipped with a segment of size 15 Viton $^{\circledR}$ tubing. The Viton ${ }^{\circledR}$ tubing was connected to the $1 / 8$ " OD teflon evaporator feed and concentrate lines by a Teflon ${ }^{\circledR}$ union and Teflon ${ }^{\circledR} 1 / 4$ " OD tubing secured with hose clamps. The condensate was removed in batches through $1 / 8^{\prime}$ OD Teflon ${ }^{\circledR}$ tubing connected to a Masterflex L/S ${ }^{\circledR}$ rigid PTFE tubing pump head equipped with $6 \mathrm{~mm}$ OD tubing. Feed material was introduced from $1 \mathrm{~L}$ Tedlar ${ }^{\circledR}$ (PVF, polyvinyl fluoride) bags to the feed line via size 14 Viton $^{\circledR}$ Masterflex ${ }^{\circledR}$ tubing, for reasons to be discussed later.

A measured air in-leakage was input into the evaporator using an MKS mass-flow controller to supplement the natural air-inleakage rate. The sum of the these two air flows (total evaporator off-gas) were pulled out of top of the condensate tank through 1/4" Teflon ${ }^{\circledR}$ tubing using a twostage Teflon ${ }^{\circledR}$ diaphragm pump (Vacuubrand, Inc., Model MZ-2C). To control the off-gas flow out of the evaporator, a bleed valve between the two pump stages was manually adjusted until a steady evaporator pressure was obtained. The measured evaporator in-leakage and pump bleed air were pretreated using moisture (silica gel) and carbon traps to minimize addition of target organics from the ambient air.

The total evaporator off-gas and pump bleed air were sent by Teflon ${ }^{\circledR}$ tubing to an Apex Inc. Model 602-V31 Super VOST (Volatile Organic Sampling Train) Sampling Kit (Figure 2)

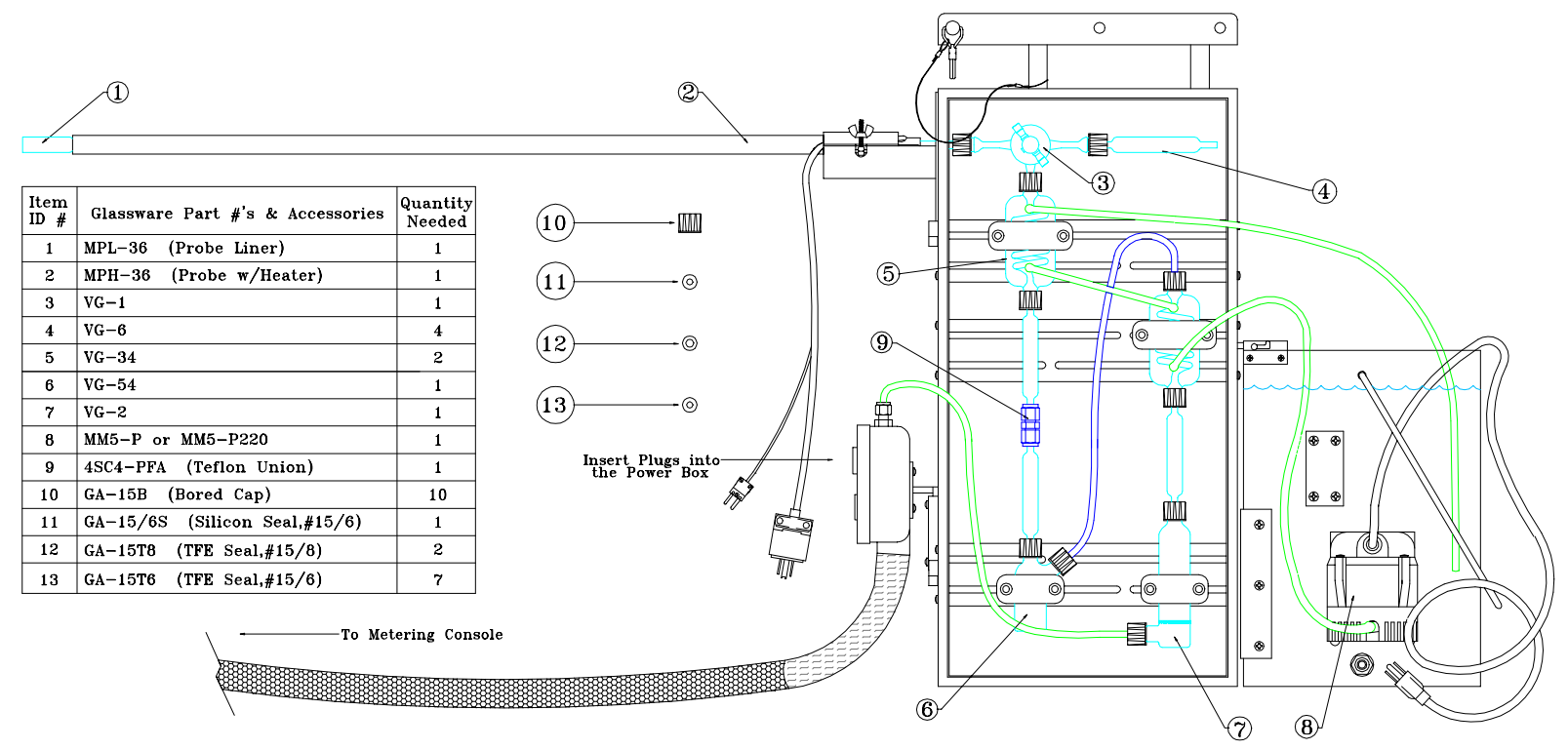

Figure 2. Off-gas Sampling System (SuperVOST Sampling Kit, Apex Instruments, Inc.) 
coupled with a Model 623 Metering Console. This sampling system is designed to withdraw from an emission source at an isokinetic sampling rate and collect target species in a multicomponent sampling train that includes packed beds of porous polymeric adsorbent resin. The VOST system in Figure 2 is setup for EPA SW-846 Method 0031, where the sampled gas typically enters the sampling module through a glass-lined probe heated to $130^{\circ} \mathrm{C} \pm 5^{\circ} \mathrm{C}$. The gas stream is cooled to $20^{\circ} \mathrm{C}$ by passage through a water-cooled condenser and volatile organic compounds are collected on a set of three sorbent traps (Tenax ${ }^{\circledR}-\mathrm{GC} / \mathrm{Tenax}{ }^{\circledR}-\mathrm{GC} / \mathrm{Anas}$ orb ${ }^{\circledR}-747$ ). The first and second traps contain $1.6 \mathrm{~g}$ of Tenax ${ }^{\circledR}-\mathrm{GC}$ each and the third trap (back trap) contains $5.0 \mathrm{~g}$ of Anasorb ${ }^{\circledR}-747$. The sorbent tubes are glass tubes with approximate dimensions of $10 \mathrm{~cm} \times 1.6 \mathrm{~cm}$ ID. The sampling module contains a condensate trap after the two Tenax ${ }^{\circledR}$ GC tubes, a second condenser immediately upstream of the Anasorb ${ }^{\circledR}-747$ tube, and silica gel to remove any moisture before entering the meter box. If required, traps may be analyzed separately to assess breakthrough or combined to improve detection limits.

For the capture of semi-volatile organic and pesticide compounds using Method 0010, the same sampling system was used where the Tenax and Anasorb sorbent tubes were replaced by a single $\mathrm{XAD}-2^{\circledR}$ tube. In typical application, a high-efficiency glass- or quartz-fiber filter is used to collect organic-laden particulate matter from the gas stream prior to sampling. The organic sampling module of the sampling train again consists of three sections, including a gas conditioning section, a sorbent trap, and a condensate knockout trap. In a typical Method 0010 stationary source emissions measurement application, the sorbent trap is sized to contain approximately $20 \mathrm{~g}$ of porous polymeric resin (Rohm and Haas XAD-2 or equivalent) and is jacketed to maintain the internal gas temperature not to exceed $20^{\circ} \mathrm{C}$. However for this regulatory study, the XAD-2 sorbent trap was sized identical to the sorbent traps used to perform Method 0031 based on the expected quantity of target species to be captured and for equipment interchangability.

In this experiment, the condensers above each column of sorbent tubes was connected to a chiller to maintain a temperature of $10^{\circ} \mathrm{C}$, rather than the ice bath shown at the right of Figure 2. The heated probe was also unnecessary as the entire pump gas effluent was sent directly into the gas sampler, and no in-line glass filter was used as no particulate matter in the off-gas was expected. The metering console was also equipped with a pump which maintained a slight vacuum $(<51$ $\mathrm{mm} \mathrm{Hg}$, or $<2 \mathrm{in.} \mathrm{Hg}$ ) on the gas sampling train to facilitate flow.

\subsection{Air In-Leakage Determination}

Gas flow in the evaporator was expected to be a major controlling variable influencing the rate of organic vapor transfer from the evaporator to the off-gas as well as the amount of liquid entrained from the evaporator to the condensate tank ${ }^{6}$. As the Hanford RPP tank waste supernatant liquids

\footnotetext{
${ }^{6}$ A. S. Choi, Preliminary Modeling Results of Preterated LAW Evaporator, BNF-003-98-0080 Rev. 0, Westinghouse Savannah River Company, June 1, 1999.
} 
are to be concentrated by vacuum evaporation, the primary contributor to gas flow would come from natural in-leakage of exterior ambient air into the vacuum evaporator system. To make this bench-scale experiment reflect an actual plant, a desired experimental air in-leakage rate into the bench-scale evaporator was determined by scaling down as a function of total internal volume from the expected full-scale system design. From a preliminary design, Ho and Washer ${ }^{7}$ had determined a maximum air in-leakage rate of $37 \mathrm{lb} / \mathrm{hr}$ air for a recirculation evaporator vessel, condenser, and associated piping with a $3681.6 \mathrm{ft}^{3}$ internal volume operating in the $21-89 \mathrm{~mm} \mathrm{Hg}$ pressure range. This translated to a $13.7 \mathrm{~m}^{3}$ air (STP)/hr per $104.3 \mathrm{~m}^{3}$ evaporator system internal volume at full-scale, or $11.5 \mathrm{~mL} / \mathrm{min}$ air (STP) for this approximately $5200 \mathrm{~mL}$ internal volume bench-scale evaporator.

For actual implementation of the $11.5 \mathrm{~mL} / \mathrm{min}$ air in-leakage rate, a natural leak rate for the evaporator was calculated from evaporator leak tests starting at evaporation operating pressure just prior to operation, and the remainder was made up using filtered/dehumidified air introduced through a calibrated mass flow controller.

\subsection{Gas Sampling Time Determination}

Evaporation run time was predominantly controlled by the minimum volume of condensate $(3 \mathrm{~L}$, in duplicate) required for regulatory analysis and the maximum evaporator condensate production rate $(3 \mathrm{~mL} / \mathrm{min})$ obtained by equipment testing using de-ionized water. As $6 \mathrm{~L}$ condensate each was required for regulatory semi-volatiles and pesticide analysis with additional time for volatiles and in-house sample generation, a minimum required evaporation run time of 73.5 hours was determined. Consultation with the Analytical Chemistry Organization Sampling and Support Department at the Y-12 National Security Complex ${ }^{8}$ indicated that Method 0031 was best suited for volatile organic compound (VOC) sampling and Method 0010 could be used for both semivolatiles and pesticide sampling.

While Method 0030 was viewed as sufficient for the volatile organic compounds spiked into the Envelope C (AN-107) Hanford waste simulant, the other commonly-used Method 0031 was selected over Method 0030 for two reasons: 1) the regulatory C-simulant evaporation was a preparatory run for regulatory off-gas sampling from the evaporation of actual Envelope C (AN102) Hanford waste immediately following, and 2) actual Hanford waste was suspected to contain VOC's that are more volatile, polar, and difficult to collect than those for which Method 0030 was designed. Method 0010 was commonly used for the collection of semi-volatile organic compounds, with pesticides of interest in this study having similar molecular weights. EPA SW846 Method 0031 calls for a withdrawal of a $20 \mathrm{~L}$ off-gas sample at a $1 \mathrm{~L} / \mathrm{min}$ flow rate, and Method 0010 requires a minimum $3 \mathrm{dscm}$ (dry standard cubic meters) or $3000 \mathrm{~L}$ (STP). With the

\footnotetext{
${ }^{7}$ Ho, J., Washer, M., "RPP-WTP: Stage B - Air Inleakage into LAW Pretreatment Evaporation Systems”, BNFL Document CALC-W375PT-PR00011, Rev. 1, October 27, 1999.

${ }^{8}$ Gibson, Jr., Luther V., Burdette, Mark A., Sampling and Support Department, Analytical Chemistry Organization, Y-12 National Security Complex (BWXT Y-12, L.L.C.), personal communications, January - June, 2000.
} 
total evaporator off-gas consisting of the $11.5 \mathrm{~mL} / \mathrm{min}$ air in-leakage, the maximum amount of gas sampling time for each method was clearly needed, and the 73.5 hour run time was arbitrarily split into two equal off-gas sampling periods for each method. This long sampling time combined with the large expected pump air-bleed volumetric flow rate needed to maintain evaporator pressure further supported the use of Method 0031, which also employs an Anasorb747 sorbent downstream of 2 Tenax-GC tubes which is known to be more "tenacious" in retaining organics than the Tenax and Tenax/charcoal combination used in Method 0030.

\subsection{Evaporator Entrainment}

Entrainment of evaporator tank liquids was undesirable due to potential artificially high condensate production rates, as well as high carry-over of metals and salts into the condensate and condenser vent (evaporator off-gas) stream. The bench-scale evaporator was built with basic anti-entrainment devices such as a "J"-shaped inlet port to the inverted U-tube connecting the evaporator and condensate tanks, and a small chamber between the "J"-shaped port and U-tube capable of holding a small amount of anti-entraiment mesh. With this initial arrangement, the evaporator was tested evaporating de-ionized water at $64 \mathrm{~mm} \mathrm{Hg}(-27.4 \mathrm{in} . \mathrm{Hg})$ and a nominal $40^{\circ} \mathrm{C}$ evaporator liquid temperature. In approximately 1.25 hours of steady state operation, approximately $39 \mathrm{~mL}$ of condensate formed in the traps of the Teflon ${ }^{\circledR}$ vacuum pump, translating to approximately $2.3 \mathrm{~L}$ of condensate in 73.5 hours. This was a potential problem for continuous operation as the pump traps can only hold about $1 \mathrm{~L}$ of condensate before pump operations would be forced to stop.

Assuming the pump trap condensates were due to entrainment, a calculation using the SoudersBrown expression ${ }^{9}$ was done showing that experimental evaporator vapor head velocities were likely below the calculated typical maximum allowable vapor velocity $(3.6 \mathrm{~m} / \mathrm{s})$, suggesting the vapor headspace in the experimental system may be small. Anti-entrainment using a stainless steel knitted mesh-packed inverted U-tube between the evaporator and condensate tank was chosen to counteract this possible effect. As anti-entrainment mesh performance improves with increasing vapor velocity, an attempt was made to match the expected upward vapor velocity in the evaporator vapor head in the preliminary Hanford RPP-WTP design to that in the inverted Utube of the bench-scale apparatus. Preliminary RPP-WTP design specifications of $4.52 \mathrm{~m}^{3} / \mathrm{hr}$ liquid condensate production from a $4.11 \mathrm{~m}(13.5 \mathrm{ft})$ diameter evaporator supplied by Washer ${ }^{10}$ suggested that for an equivalent quantity of steam generated at $40^{\circ} \mathrm{C}$ and $50 \mathrm{~mm} \mathrm{Hg}$ would create an upward vapor velocity of $2.04 \mathrm{~m} / \mathrm{s}$ or $6.7 \mathrm{ft} / \mathrm{s}$ (air in-leakage rate was negligible) entering an anti-entrainment mesh screen mounted in a full-scale evaporator vapor headspace. This upward vapor velocity is sufficient for $99+\%$ vapor-liquid separator efficiency for a knitted mesh

\footnotetext{
${ }^{9}$ Standiford, F. C., "Evaporation", Kirk-Othmer Encyclopedia of Chemical Technology, $4^{\text {th }}$ ed., Vol. 16, J. Wiley and Sons, Inc., New York, 1995.

${ }^{10}$ Washer, M., electronic mail communication, BNFL, Inc., Richland, WA, March 9, 2000.
} 
separator $\left(1.42 \mathrm{~m} / \mathrm{s}\right.$ or $5 \mathrm{ft} / \mathrm{s}$ minimum $\left.{ }^{11}\right)$. A calculational error and structurally viable U-tube diameters led to the selection of a $11 \mathrm{~mm}$ ID U-tube, packed with approximately $15 \mathrm{~cm}$ vertical height of rolled knitted stainless steel mesh. For a gas stream that produces $3 \mathrm{~mL} / \mathrm{min}$ liquid condensate and a saturated air stream at $40^{\circ} \mathrm{C}$ at $60 \mathrm{~mm} \mathrm{Hg}$ based on $11.5 \mathrm{~mL}$ (STP) air inleakage rate, corrected calculations show the vapor velocity entering the knitted stainless-steel anti-entrainment mesh was approximately $9.75 \mathrm{~m} / \mathrm{s}(32 \mathrm{ft} / \mathrm{s})$, more than sufficient to de-entrain the evaporator vapor stream. A subsequent de-ionized water evaporation test with the packed 11 mm ID U-tube and an uncooled impinger (equipped with an internal thermometer) between the evaporator condensate tank and the vacuum pump produced $5.2 \mathrm{~g}$ condensate in the impinger and no liquids in the pump trap after 1.5 hours steady state operation at $60 \mathrm{~mm} \mathrm{Hg}(-27.6 \mathrm{in} \mathrm{Hg})$ and $48^{\circ} \mathrm{C}$ nominal evaporator temperature. This amount was within $10 \%$ of the calculated quantity of water expected to condense from a $40^{\circ} \mathrm{C}$ water-saturated air stream after being cooled to the ambient room temperature $\left(28.5^{\circ} \mathrm{C}\right.$, measured), and was consistent with $\sim 255 \mathrm{~mL}$ pump trap liquid generation per 73.5 hours steady state operation.

\subsection{AN-107 Envelope C Simulant History}

The Hanford Tank AN-107 simulant used for this work is a product of the pilot-scale filtration study by Duignan $^{12}$ for concentration precipitated Envelope C waste. At SRTC's Thermal Fluids Laboratory, approximately 100 gallons of Envelope C simulant (107-AN) were synthesized using the recipe in Appendix A, including entrained solids at $0.5 \mathrm{wt} \%$ loading. This simulant was a non-toxic version that excluded addition of sodium chromate and lead nitrate. For Sr/TRU removal, the Hanford waste was diluted to $6 \mathrm{M} \mathrm{Na}$ before increasing free hydroxide concentration by $0.8 \mathrm{M}$ with $19 \mathrm{M} \mathrm{NaOH}$, strontium concentration by $0.075 \mathrm{M}$ using $1 \mathrm{M}$ $\mathrm{Sr}\left(\mathrm{NO}_{3}\right)_{2}$, and manganese concentration by $0.05 \mathrm{M}$ with $1 \mathrm{M} \mathrm{NaMnO}_{4}$ (recipe also in Appendix A). This precipitated AN-107 Envelope C simulant was then cross-flow filtered, producing a filtrate with a measured density of $1.276 \mathrm{~g} / \mathrm{mL}$ and analyte concentrations summarized in Tables 12 and 13. Dark solids produced by post-filtration precipitation were observed when the filtrate was transferred from the Thermal Fluids Laboratory drum. As much as possible through settling, the observed dark solids were not introduced into the evaporator to minimize potential line pluggage.

\footnotetext{
${ }^{11}$ Minton, P. E., Handbook of Evaporation Technology, pp. 153-7, Noyes Publications, Park Ridge, NJ, 1986.

${ }^{12}$ Duignan, M. R., "Final Report: Pilot-scale Cross-flow Ultrafiltration Test Using a Hanford Site Tank 241-AN-107 Waste Simulant - Envelope C + Entrained Solids + Strontium-Transuranic Precipitation," Savannah River Technology Center, BNF-003-98-0226, March 24, 2000.
} 


\subsection{Target Organic Compound Selection}

Of the original 20 organic Indicator Chemicals ${ }^{13}$ listed in RPP-WTP's Screening Level Risk Assessment ${ }^{14}$, SRTC recommended and the customer accepted removal of acrylonitrile, 1chloroethene, 1,1-dichloroethene and dichloromethyl ether due to rapid chemical breakdown in caustic Hanford RPP waste or off-gas sampling/analysis capability issues. Experimental toxicity hazard concerns led to the selection of bis(2-ethylhexyl)phthalate (BEHP), a 2,3,7,8-TCDD toxicity equivalent, as the indicator for both $\mathrm{PCB}$ and dioxin/furan chemical groups based on thermal stability and vapor pressure criteria. Ultimately, the following 14 target organic compounds (Table 1) were selected to be representative compounds for volatile and semi-volatile organics and pesticides suspected to be present in Hanford RPP wastes:

\begin{tabular}{|l|l|l|l|}
\hline Chemical & Formula & $\begin{array}{l}\text { Molecular } \\
\text { Weight }\end{array}$ & Chemical Group \\
\hline Benzene & $\mathrm{C}_{6} \mathrm{H}_{6}$ & 78.11 & Volatile Organic \\
\hline Toluene & $\mathrm{C}_{7} \mathrm{H}_{8}$ & 92.13 & Volatile Organic \\
\hline 4-methyl-2-pentanone (MIBK) & $\mathrm{C}_{6} \mathrm{H}_{12} \mathrm{O}$ & 100.16 & Volatile Organic \\
\hline Chlorobenzene & $\mathrm{C}_{6} \mathrm{H}_{5} \mathrm{Cl}$ & 112.56 & Volatile Organic \\
\hline 1,2,3-trichloropropane & $\mathrm{C}_{3} \mathrm{H}_{5} \mathrm{Cl}_{3}$ & 147.43 & Volatile Organic \\
\hline 1,2-dibromoethane & $\mathrm{C}_{2} \mathrm{H}_{4} \mathrm{Br}_{2}$ & 187.88 & Volatile Organic \\
\hline 1,2,4-trichlorobenzene & $\mathrm{C}_{6} \mathrm{H}_{3} \mathrm{Cl}_{3}$ & 181.46 & Light Semi-volatile Organic \\
\hline Naphthalene & $\mathrm{C}_{10} \mathrm{H}_{8}$ & 128.16 & Light Semi-volatile Organic \\
\hline Pyrene & $\mathrm{C}_{16} \mathrm{H}_{10}$ & 202.24 & Semi-volatile Organic \\
\hline Benzo(a)pyrene (BaP) & $\mathrm{C}_{20} \mathrm{H}_{12}$ & 252.32 & Semi-volatile Organic \\
\hline Pentachlorophenol & $\mathrm{C}_{6} \mathrm{Cl}_{5} \mathrm{OH}$ & 266.35 & Semi-volatile Organic \\
\hline Hexachlorobenzene & $\mathrm{C}_{6} \mathrm{Cl}_{6}$ & 284.8 & Semi-volatile Organic \\
\hline $\begin{array}{l}\text { Bis(2-ethylhexyl)phthalate } \\
\text { (BEHP) }\end{array}$ & $\mathrm{C}_{24} \mathrm{H}_{38} \mathrm{O}_{4}$ & 390.54 & $\begin{array}{l}\text { PCB/Dioxin/Furan Equivalent } \\
\text { (Semi-volatile) }\end{array}$ \\
\hline Aldrin & & & Pesticide (Semi-volatile Organic) \\
\hline
\end{tabular}

Table 1. 14 Target Organic Compounds Spiked Into the Envelope C (AN-107) Simulant

\subsection{Spike Solution/Evaporator Feed System Development}

To feed the 14 target organic compounds with the AN-107 Envelope $\mathrm{C}$ simulant into an evaporator, two issues had to be overcome: 1) a method to "spike" or add the organics into the aqueous caustic solution, and 2) a storage and feeding mechanism to minimize volatile organic losses to headspace during the estimated 73.5 hour evaporator run. In addition, a realistic and practical target organic concentration also had to be determined. Based on the development descibed below, spiked feed solutions were made by injecting $1.3 \mathrm{~mL}$ of $1000 \mathrm{mg} / \mathrm{L}$ concentration (each target organic compound) spiking solution into pre-prepared Tedlar ${ }^{\circledR}$ (polyvinylfluoride, PVF) bags containing $1 \mathrm{~L}$ by mass (1262 g) Hanford RPP AN-107 Envelope $\mathrm{C}$-simulant on the day prior to use in the evaporator run the following day. The spiked bags were

13 Johnson, M. E., “TWRS Privatization Contract No. DE-AC06-96RL13308 - Low Activity Waste Evaporator Modeling and Simulant Solution Evaporation", BNFL Letter No. 002709, BNFL Inc., 4/29/99

${ }^{14}$ Edwards, D. W., "Draft Work Plan for Screening Level Risk Assessment for the TWRS-P Facility", BNFL, Inc., RPT-W375-EN00001, Rev. C, May 7, 1999, 
stored in a covered secondary container at ambient conditions on a benchtop until use, with every attempt made to use them within the 24-32 hour aging period. The bag of C-simulant with target organics was laid covered with dark cloth flat on the benchtop in the laboratory hood, and the contents were withdrawn by connecting Viton ${ }^{\circledR}$ Masterflex ${ }^{\circledR}$ tubing to the bag hose valve and controlling the withdrawal volumetric flowrate with the pump.

As the customer requested similar mass concentrations (ppm level) for each compound, solubility reference data indicated the need for a solvent as the 14 components could not be dissolved within each other to be directly introduced into the simulated Hanford waste. Joint work with Supelco, Inc. was performed to develop a $70 \%$ hexane $/ 30 \%$ acetone mixture containing 1000 $\mathrm{mg} / \mathrm{L}$ of each target organic compound. However discussions with BWXT Services, Inc. (of BWX Technologies, Inc.) indicated that large quantities of hexane would interfere with the volatiles analysis due to similar elution times to the target compounds. Other possibilities were considered weighing the following factors:

i) Maximize gas sample volumes for the target volatile organic compounds while minimizing total run time. This necessitated the need to produce one spiked $\mathrm{C}$ simulant to allow regulatory liquid pesticide samples to be generated during volatiles gas sampling and intermittent volatiles liquid sampling. Semi-volatiles gas and liquid sampling would occur simultaneously afterward.

ii) Minimize solvent addition to the C-simulant. As the 14 target compounds were not expected to produce a single liquid sample without the use of a solvent, alternative solvents with high solubilities for all 14 target organics were few. Other solvents such as methanol, long-chain aliphatic alcohols and Tetraglyme ${ }^{\circledR}$ were considered but were eliminated due to solubility low limits or objectives i and iii.

iii) Avoid solvent interferences to the gas sample analyses. Long-chain alcohols and Tetraglyme ${ }^{\circledR}$ were thought to possibly allow for dissolution of all 14 target organic compounds, but were also expected to cause signal interference with the quantification of other target semi-volatiles.

iv) Avoid separate runs for volatiles and semi-volatiles/pesticide. This was not thought to be representative of actual RPP-WTP liquid wastes which would be encountered in the field. The required workload in order to develop and test two separate spiking solutions would double, and then run both for the requisite gas sampling times would conflict with objective i.

Ultimately, acetone was selected as the solvent through which to add the 14 target volatiles, semi-volatiles and pesticide organic compounds. The primary advantage of acetone was the high expected solubility of the resulting enolate formed in caustic solutions. BWXT Services, Inc. did express concern about detector overload and acetone contamination of their analytical equipment. However shutdown of the detector was determined to be the method to avoid detector overload. 
With an SRTC Analytical Development Section (ADS) gas chromatograph connected to a purge and trap system, Young ${ }^{15}$ showed that acetone contamination levels can be reduced to $15 \mu \mathrm{g} / \mathrm{L}$ acetone by subsequently running only 5 water blanks after initially injecting an aqueous solution containing $800,000 \mu \mathrm{g} / \mathrm{L}$ acetone. Young also felt that the Tekmar systems employed by BWXT Services, Inc. should purge acetone better than the SRTC ADS system. In the event that a long series of water blanks would not purge the BWXT equipment, a provision was made for analytical equipment refurbishing.

After determining the spiking solvent, testing of organic solubility in the C-simulant began. Based on dye experiments by Dworjanyn ${ }^{16}$ examining the presence of benzene droplets in tetraphenylborate-treated SRS tank waste, a similar study was performed by adding $1 \mathrm{wt} \%$ Sudan Red 7B dissolved in acetone into the Hanford RPP simulant. $1.25 \mathrm{~mL}$ of the dye solution was added to $1 \mathrm{~L}$ simulant, a quantity of solution equivalent to spiking to $1 \mathrm{ppm}$ using $1000 \mathrm{mg} / \mathrm{L}$ in acetone. The resulting solution of uniform color strongly indicated that the spiking solution containing $1000 \mathrm{mg} / \mathrm{L}$ of the 14 target organic compounds in acetone would be a viable method to introduce the chemicals of interest into the AN-107 Envelope C simulant.

Subsequently, batch spiking tests using acetone spike solutions were performed to target levels of $0.6,1.0$, and $3 \mathrm{ppm}$ to find a predictable and consistent concentration for the target compounds. $0.8,1.3$, and $3.8 \mathrm{~mL}$, respectively, were added to $1 \mathrm{~L}$ simulant in a $2 \mathrm{~L} \mathrm{Teflon}^{\circledR}$ beaker for each test, and mixing was accomplished using a $23 / 8$ " OD Teflon ${ }^{\circledR}$ four-blade pitched-blade turbine mounted on a Lightnin LabMaster mixer set at $400 \mathrm{rpm}$. Mixing was done for $31 / 2$ minutes, except one $4 \frac{1}{1} 4$ minute test, compared to a 3 second theoretical mixing time for three volume turnovers. Zero headspace samples were taken immediately after mixing for SRTC analysis (Table 2). The $1 \mathrm{ppm}$ target levels were found experimentally to be readily generated with produced concentrations matching calculated/expected concentrations best, in comparison to batch-mixing tests also performed at 0.62 and $3.01 \mathrm{ppm}$ target compound concentrations. The target concentration of $1 \mathrm{ppm}$ was selected also as it was expected to represent regulated target organic compound concentrations encountered in actual Hanford Tank AN-107 liquid waste.

\begin{tabular}{|l|c|c|c|c|c|c|}
\hline \multirow{2}{*}{ Target Compound } & \multicolumn{2}{|c|}{$0.63 \mathrm{ppm}$ target } & \multicolumn{2}{|c|}{$1.03 \mathrm{ppm}$ target } & \multicolumn{2}{c|}{$3.01 \mathrm{ppm}$ target } \\
\cline { 2 - 7 } & Conc. $(\mathrm{ppm})$ & Recovery (\%) & Conc. (ppm) & Recovery (\%) & Conc. (ppm) & Recovery (\%) \\
\hline benzene & 0.301 & 48 & 0.533 & 52 & $\mathbf{4 . 7 3 0}$ & 157 \\
\hline 4-methyl-2-pentanone (MIBK) & 0.256 & 41 & 0.591 & 57 & $\mathbf{3 . 6 5 3}$ & 121 \\
\hline toluene & 0.320 & 51 & 0.563 & 55 & 1.890 & 63 \\
\hline 1,2-dibromoethane & $<\mathbf{0 . 0 4}$ & $<6$ & $\mathbf{0 . 0 1 7}$ & 2 & $\mathbf{0 . 0 1 4}$ & 0 \\
\hline chlorobenzene & 0.311 & 49 & 0.537 & 52 & 1.987 & 66 \\
\hline 1,2,3-trichloropropane & $\mathbf{0 . 0 7 9}$ & 13 & $\mathbf{0 . 0 9 5}$ & 9 & $\mathbf{0 . 1 1 7}$ & 4 \\
\hline 1,2,4-trichlorobenzene & 0.135 & 21 & 0.515 & 50 & 1.983 & 66 \\
\hline hexachlorobenzene & 0.397 & 63 & 0.777 & 75 & 2.617 & 87 \\
\hline naphthalene & 0.127 & 20 & 0.508 & 49 & 1.903 & 63 \\
\hline aldrin & 0.397 & 63 & 0.769 & 75 & 2.617 & 87 \\
\hline pyrene & 0.428 & 68 & 0.793 & 77 & 2.696 & 90 \\
\hline bis(2-ethylhexyl)phthalate (BEHP) & $\mathbf{0 . 6 5 8}$ & 104 & $\mathbf{1 . 1 1 0}$ & 108 & $\mathbf{3 . 0 9 3}$ & 103 \\
\hline benzo(a)pyrene (BaP) & 0.420 & 67 & 0.872 & 85 & 2.934 & 97 \\
\hline pentachlorophenol & $<\mathbf{0 . 2} \mathbf{p p m}$ & $<32$ & $<\mathbf{0 . 2} \mathbf{p p m}$ & $<19$ & $<\mathbf{0 . 2} \mathbf{p p m}$ & $<7$ \\
\hline
\end{tabular}

Table 2. Spiking Level Test Results: Target Organic Compound Concentrations in Envelope C (AN-107) Simulant

\footnotetext{
${ }^{15}$ Young, J. E., unpublished results, March, 2000.

${ }^{16}$ Dworjanyn, L. O., "Benzene Release - Status Report”, WSRC-RP-97-903, Rev. 0, November 4, 1997.
} 
Numbers that are italicized bold in Table 2 are deviations far from the expected. A literature review shows that the low levels of 1,2-dibromoethane and 1,2,3-trichloropropane (halogenated aliphatics) are likely due to hydrolysis with the caustic in the simulant, as indicated by a 16 day half-life for 1,2-dibromo-3-chloropropane at significantly milder conditions ( $\mathrm{pH}=10$ compared to $\mathrm{pH}=\sim 13$ of this simulant $)^{17}$. Slightly low aldrin levels may also be due to slow hydrolysis ${ }^{18}$. Bis(2-ethylhexyl)phthalate losses were expected by saponification ${ }^{19}$, but any loss appears to have been more than offset by leaching from the plastic pipettes used to extract the samples from the Teflon ${ }^{\circledR}$ beaker. Leaching is expected since bis(2-ethylhexyl)phthalate is used as an softening additive in plastics. Low pentachlorophenol concentrations are probably due to the loss of the phenolic hydrogen in the caustic solution, which would not permit liquid-liquid extraction into the organic methylene chloride phase used in the SRTC analytical method.

A related issue was the loss of analytes onto Viton ${ }^{\circledR}$ tubing mounted in the Masterflex ${ }^{\circledR}$ pumps used to feed material and remove concentrate. For the experiment, the target $1 \mathrm{ppm}$ solution produced in the previous experiment was used after aging 10 days and storage in a polyethylene bottle with of order 50-100 mL headspace above the solution. A zero-headspace sample was taken before pumping three-fourths of the bottle contents into another $1 \mathrm{~L}$ polyethylene bottle at $10 \mathrm{~mL} / \mathrm{min}$, the projected feed flow rate, through approximately 3 feet $(\sim 1 \mathrm{~m})$ of \#16 Viton ${ }^{\circledR}$ Masterflex ${ }^{\circledR}$ hose. A second zero-headspace sample was taken by pipette immediately after pumping was stopped. The results (Table 3) indicate that large masses of volatiles were not lost, with the larger percentage losses for 1,2-dibromoethane, 1,2,3-trichloropropane, and chlorobenzene due to low initial concentrations. Semi-volatile mass losses were significant but relatively low at $17-25 \%$ in comparison to the SRTC analysis quoted $10 \%$ error. In the actual steady-state experiment, overall analyte losses were expected to be lower than in Table 3 since about half of the length of Viton tubing would be used, and sorption sites on the tubing would likely be occupied relatively early in the long run.

\begin{tabular}{|l|c|c|c|c|}
\hline Target Compound & Before $(\mathrm{ppm})$ & After $(\mathrm{ppm})$ & Change $(\mathrm{ppm})$ & \% Loss \\
\hline Benzene & 0.068 & 0.054 & 0.014 & 21.3 \\
\hline 4-Methyl-2-Pentanone (MIBK) & 0.716 & 0.628 & 0.088 & 12.2 \\
\hline Toluene & 0.014 & 0.013 & 0.001 & 7.0 \\
\hline 1,2-dibromoethane & 0.013 & 0.000 & 0.013 & 100.0 \\
\hline Chlorobenzene & 0.019 & 0.013 & 0.006 & 32.8 \\
\hline 1,2,3-trichloropropane & 0.020 & 0.004 & 0.016 & 78.0 \\
\hline 1,2,4-trichlorobenzene & 0.000 & 0.000 & & \\
\hline hexachlorobenzene & 0.698 & 0.539 & 0.159 & 22.7 \\
\hline naphthalene & 0.000 & 0.000 & & \\
\hline aldrin & 0.698 & 0.539 & 0.159 & 22.7 \\
\hline pyrene & 0.650 & 0.492 & 0.158 & 24.4 \\
\hline bis(2-ethylhexyl)phthalate (BEHP) & 1.348 & 1.110 & 0.238 & 17.6 \\
\hline benzo(a)pyrene (BaP) & 0.785 & 0.571 & 0.214 & 27.3 \\
\hline pentachlorophenol & 0.000 & 0.000 & & \\
\hline
\end{tabular}

Table 3. Target Organic Compound Concentrations in Envelope C (AN-107) Simulant before and after pumping through $\sim 1 \mathrm{~m}$ Viton ${ }^{\circledR}$ tubing at $10 \mathrm{~mL} / \mathrm{min}$

\footnotetext{
${ }^{17}$ Milano, J.C., Guibourg, A., Vernet, J.L., Wat. Res., 22, 1553, 1988.

${ }^{18}$ Schuphan, I., Sajko, B., Ballschmiter, K.Z., Naturforsch. B., 27, 147, 1972.

${ }^{19}$ Wolf, N.L., Steen, W.C., Burns, L.A., Chemosphere, 9, 403, 1980.
} 
The last major issue was to find a preparation and storage method yielding stable concentrations of analytes. Using the $1 \mathrm{ppm}$ target solution in the batch mixing and viton-tubing losses experiments, typical volatilization rates potentially encountered during the experiment and from actual waste in Hanford RPP tanks could be gauged. Again, headspace was of order 50-100 mL above the $1 \mathrm{~L}$ solution for the first 10 days, and was considered the "best case" scenario should continuous pumping of spiked batches of bottled feed be used. For the following twenty days, headspace increased to approximately $300-400 \mathrm{~mL}$ as only about $3 / 4$ of the test solution was transferred in the Viton tubing loss study. The data in the last column of Table 4 was also corrected for mass losses to tubing during the Viton tubing test discussed above.

\begin{tabular}{|l|c|c|c|}
\hline \multirow{2}{*}{ Target Compound } & \multicolumn{3}{|c|}{ Concentrations (ppb) } \\
\cline { 2 - 4 } & Initial & 10 days & 30 days $^{*}$ \\
\hline benzene & 533 & 68 & 0 \\
\hline 4-methyl-2-pentanone (MIBK) & 591 & 716 & 0 \\
\hline toluene & 563 & 14 & 0 \\
\hline 1,2 -dibromoethane & 17 & 13 & 0 \\
\hline chlorobenzene & 537 & 19 & 0 \\
\hline $1,2,3$-trichloropropane & 95 & 20 & 0 \\
\hline 1,2,4-trichlorobenzene & 515 & 0 & 1 \\
\hline hexachlorobenzene & 777 & 698 & 791 \\
\hline naphthalene & 508 & 0 & 2 \\
\hline aldrin & 769 & 698 & 795 \\
\hline pyrene & 793 & 650 & 662 \\
\hline bis(2-ethylhexyl)phthalate (BEHP) & 1110 & 1348 & 1887 \\
\hline benzo(a)pyrene (BaP) & 872 & 785 & 1197 \\
\hline pentachlorophenol & 0 & 0 & 0 \\
\hline * adjusted for Viton tubing losses at 10 days, and bottle only 3/4 full from 10-30 days \\
\hline
\end{tabular}

Table 4. Batch Storage Test Results: Target Organic Compound Concentrations in Envelope $\mathrm{C}(\mathrm{AN}-107)$ Simulant from 0 to 30 days

The data (Table 4) shows that volatiles except 4-methyl-2-pentanone and the lighter semivolatiles (naphthalene, 1,2,4-trichlorobenzene) are lost quickly, while semi-volatile concentrations generally remain unchanged. This trend is also expected in actual Hanford tank waste. Hence, a spiking and storage system without headspace was desirable for the experiment.

In-line mixing was thought to be a promising approach to avoid both headspace and storage of spiked feed solution before entry into the evaporator. Unspiked feed simulant exiting from a Masterflex pump contacting spiking solution fed from a syringe pump before entering an in-line static tube mixer and the evaporator feed line was the tested concept. A syringe pump was desired to eliminate volatiles loss from the spiking solution to headspace under vacuum conditions. During calibration of the syringe pump against a -27.6 in $\mathrm{Hg}$ vacuum, the Teflon ${ }^{\circledR}$ seal on the barrel of the Hamilton Gastight ${ }^{\circledR}$ syringe was not able to prevent ambient air from leaking in at a rate below $12.1 \mu \mathrm{L} / \mathrm{min}$, the maximum spiking solution rate for $1 \mathrm{ppm}$ loading at $\sim 10 \mathrm{~mL} / \mathrm{min}$ simulant feed rates. The $20 \mathrm{~mL}$ syringe pump of a TOA Electronics Ltd. AutoBuret $^{\circledR}$ (Model ABT-511) automatic dispenser was also tested against vacuum with the same result. Since the syringe barrel seals appear to work best against pressure, the in-line mixing method of spiking organics into the feed solution prior to injection into the evaporator was abandoned. 
SRTC proposed and tested the use of $1 \mathrm{~L}$ Tedlar $^{\circledR}$ bags, used for collection of EPA Method 1311 Toxicity Characteristic Leaching Procedure (TCLP) volatile extracts, as a means to store variable quantities of spiked feed material with almost zero-headspace. In the initial aging study, $1 \mathrm{~L}$ simulant by mass (1262 g) and $1.3 \mathrm{~mL} 1000 \mathrm{mg} / \mathrm{L}$ spiking solution were mixed using a Teflon ${ }^{\circledR}$ beaker and impeller, before being pumped into the Tedlar ${ }^{\circledR}$ bag by a Masterflex ${ }^{\circledR}$ pump using Viton ${ }^{\circledR}$ tubing. The Tedlar ${ }^{\circledR}$ bag was stored at ambient temperature on the benchtop, and zeroheadspace samples withdrawn periodically by draining bags via the bag hose valve into teflonlined cap glass sample vials. Sample analyses (Table 5) showed relatively uniform losses, suggesting there may be sorption losses to the bag interior surface, chemical degradation, or photolytic degradation. For the retention calculation, the bolded 7-day concentrations were replaced by the 3-day concentrations since the bolded values far exceeded the downward trend observed in the first 3 days of aging.

\begin{tabular}{|c|c|c|c|c|c|c|}
\hline & \multicolumn{5}{|c|}{ Actual Detected Concentrations (ppb) } & \multirow{2}{*}{$\begin{array}{l}\% \text { Initial } \\
\text { retained }\end{array}$} \\
\hline Target Compound & Initial ${ }^{*}$ & 1 Day & 2 Day & 3 Day & 7 Day & \\
\hline benzene & 212 & 290 & 172 & 196 & 161 & 76.3 \\
\hline 4-methyl-2-pentanone (MIBK) & 439 & 556 & 313 & 361 & 263 & 59.8 \\
\hline toluene & 447 & 784 & 384 & 376 & 212 & 47.4 \\
\hline 1,2-dibromoethane & 0 & 251 & 0 & 0 & 0 & \\
\hline chlorobenzene & 431 & 768 & 345 & 313 & 172 & 40.0 \\
\hline 1,2,3-trichloropropane & 0 & 0 & 0 & 0 & 0 & \\
\hline 1,2,4-trichlorobenzene & 234 & 257 & 176 & 109 & 102 & 43.6 \\
\hline hexachlorobenzene & 746 & 583 & 562 & 428 & 722 & 57.4 \\
\hline naphthalene & 192 & 291 & 178 & 124 & 89 & 46.5 \\
\hline aldrin & 777 & 610 & 583 & 433 & 679 & 55.7 \\
\hline pyrene & 861 & 697 & 583 & 460 & 700 & 53.4 \\
\hline bis(2-ethylhexyl)phthalate (BEHP) & 1619 & 1328 & 1223 & 1127 & 1530 & \\
\hline benzo(a)pyrene $(\mathrm{BaP})$ & 904 & 766 & 674 & 566 & 896 & 62.6 \\
\hline pentachlorophenol & 0 & 0 & 0 & 0 & 0 & \\
\hline & & & $\begin{array}{l}\text { er to } \\
\text { es }\end{array}$ & & & \\
\hline
\end{tabular}

Table 5. Tedlar Bag Aging Test Initial Results: Target Organic Compound Concentrations in Envelope $\mathrm{C}(\mathrm{AN}-107)$ Simulant from storage up to 1 week (organics pre-mixed into solution in a separate container prior to being pumped into the Tedlar bag)

To determine the mechanism for analyte loss, the aging experiment was repeated for a period of three days where the spiked sample bag was protected from light by storage in a box on the laboratory benchtop. Additionally to maximize target organic compound concentrations, the solution was prepared by pumping in nearly $1 \mathrm{~L}$ by mass (1239 g) AN-107 simulant and injecting $1.3 \mathrm{~mL}$ spiking solution directly into the bag via the septum-lined syringe port. Compared to the initial test results in Table 5, Figures 3 and 4 show that the more volatile organic compound concentrations and percentage of initial retained are improved after 72 hours in all cases except toluene, and that volatiles concentrations are temperature dependent as shown by the significant drop after 32 hours when the laboratory warmed from $\sim 22^{\circ} \mathrm{C}$ to $30^{\circ} \mathrm{C}$. Hence, chemical degradation of the volatile target organic compounds appears to be the dominating factor for losses observed. Besides bis(2-ethylhexyl)phthalate (DEHP) concentrations being higher than theoretical likely due to extraction from the Tedlar ${ }^{\circledR}$ bag, the semi-volatiles concentrations (Figure 5) appear essentially constant over the experimental period despite significant scatter in the data, suggesting that semi-volatile photolytic degradation was the significant factor in the first experiment. Error bars in Figures 3-5 are standard deviations (one sigma) calculated from 
WSRC-TR-2000-00486

SRT-RPP-2000-00047

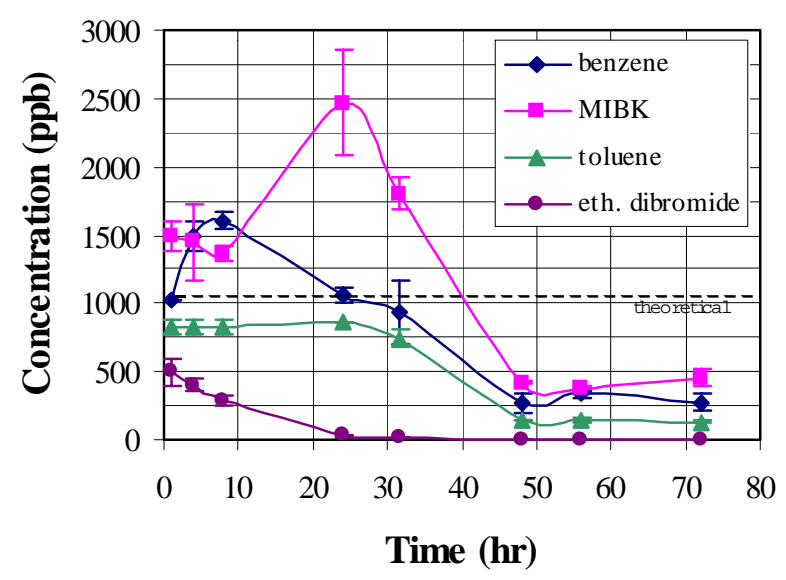

Figure 3. Tedlar Bag Aging Test Results: Volatile Organic Compound Concentrations vs. Time, stored at ambient conditions in box. (Organics spiked and mixed in pre-filled Tedlar bag)

analysis of duplicate samples, and higher than theoretical values are thought to be due to signal interferences.

Based on Figures 3-5, an aging period of 2432 hours for a $1 \mathrm{~L}$ bag of simulant after spiking with $1.3 \mathrm{~mL}$ of spiking solution was selected as most of the compounds are largely retained in the $\mathrm{C}$-simulant for up to 32 hours (relative changes of less than approximately $15 \%$ ). Notable exceptions are 1,2-dibromoethane which mostly degrades to a low asymptotic value after 24 hours, and 1,2,3-trichloropropane and naphthalene which statistically may be equivalent at 24 and 32 hours aging time. Table 6, drawn from data in Figures 3-5, lists the concentrations at initial (1 hour aging to allow sufficient diffusion of spiking solution) and at 24-32 hours aging.

Based on this analysis, spiked feed solutions were made by injecting $1.3 \mathrm{~mL}$ of $1000 \mathrm{mg} / \mathrm{L}$ concentration (each target organic compound) spiking solution into pre-prepared Tedlar ${ }^{\circledR}$ bags containing 1 L by mass (1267 - 1287 g) Hanford RPP AN-107 Envelope C-simulant on the day prior to use in the evaporator run the following day. The spiked bags were stored in a covered secondary container at ambient conditions on a benchtop until use, with every attempt made to use them within the 24-32 hour aging period. The bag of C-simulant with target organics was laid covered with dark cloth flat on the benchtop in the laboratory hood, and the contents were withdrawn by connecting size 14 Viton $^{\circledR}$ Masterflex ${ }^{\circledR}$ tubing to the bag hose valve and controlling the withdrawal volumetric flowrate with the pump. 


\begin{tabular}{|l|c|c|}
\hline \multirow{2}{*}{ Target Compound } & \multicolumn{2}{|c|}{ Concentration (ppm) } \\
\cline { 2 - 3 } & After 1 hr. & After 24-32 hrs. \\
\hline benzene & 1.019 & $0.933-1.058$ \\
\hline 4-methyl-2-pentanone (MIBK) & 1.489 & $1.803-2.469$ \\
\hline toluene & 0.823 & $0.741-0.862$ \\
\hline 1,2-dibromoethane & 0.502 & $0.016-0.029$ \\
\hline chlorobenzene & 0.862 & $0.721-0.784$ \\
\hline 1,2,3-trichloropropane & 0.752 & 0.776 \\
\hline 1,2,4-trichlorobenzene & 0.662 & $0.415-0.553$ \\
\hline hexachlorobenzene & 0.940 & $0.842-1.136$ \\
\hline naphthalene & 0.686 & $0.353-0.474$ \\
\hline aldrin & 0.940 & $0.831-1.136$ \\
\hline pyrene & 0.980 & $0.866-1.215$ \\
\hline bis(2-ethylhexyl)phthalate (BEHP) & $\mathbf{1 . 4 5 0}$ & $\mathbf{1 . 2 5 4 - 1 . 6 4 6}$ \\
\hline benzo(a)pyrene (BaP) & 0.980 & $0.964-1.2544$ \\
\hline pentachlorophenol & $<0.2 \mathrm{ppm}$ & $<0.2 \mathrm{ppm}$ \\
\hline
\end{tabular}

Table 6. Tedlar Bag Aging Test Results: Target Organic Compound Concentrations in Envelope $C(A N-107)$ Simulant from 1 hour and 24-32 hours after spiking. Solution storage in box at ambient $\left(\sim 22^{\circ} \mathrm{C}\right)$ to 32 hours. (Organics spiked and mixed in pre-filled Tedlar bag)

Overall, the average aging times from spiking to the beginning and the end of bag use were 29.28 and 31.15 hours, respectively. Due to an unexpected delay at the start of operations, the first 10 bags for steady state operation did age significantly longer, 37-51 hours until start of use, but were refrigerated overnight and allowed to slowly warm to room temperature to mitigate the effects of the added aging. Analytical data of these feed samples shows no significant losses of the target organic compounds due to the additional aging and refrigeration. If these refrigerated samples are removed from the analysis, the average aging times from spiking to the beginning and end of bag use were reduced to 24.76 and 26.4 hours, respectively. Given that average aging times were within the specified 24-32 hour aging period, no significant deviations due to aging were expected or found.

The aging studies discussed above show that the SRTC analyses for these 14 volatile and semivolatile organic species are generally consistent and reproducible to the cited $10 \%$ analytical random error, with a few potential considerations. Bis(ethylhexyl)phthalate concentrations will generally tend to be high due to extraction from the Tedlar ${ }^{\circledR}$ bag or polyethylene bottle. Similarly, 4-methyl-2-pentanone concentrations may possibly be affected due to its use as a solvent for applying protective films. Lastly, the results in Figure 5 indicate that the SRTC semi-volatile results can sometimes result in systematically high values for all species, likely due to organic solvent evaporation after liquid-liquid extraction of the target compounds prior to analysis. 


\subsection{SW-846 Method Parameter Selection/Exceptions}

The customer requested that duplicate liquid samples be taken in all cases where possible. The EPA SW-846 Methods call for a $40 \mathrm{~mL}$ zero-headspace liquid sample for each volatiles analysis, and $3 \times 1 \mathrm{~L}$ samples each for liquid sample semi-volatiles and pesticide analysis $(1 \mathrm{~L}$ each for sample, method spike, and method spike duplicate). Hence, regulatory analysis required for each the evaporator feed, condensate, and concentrate samples the following volumes in Table 7:

\begin{tabular}{|l|l|}
\hline Organic Analysis Type & Sample Volume \\
\hline Volatiles (VOA) & $2 \times 40 \mathrm{~mL}$ \\
\hline Semi-volatiles (SVOA) & $6 \times 1 \mathrm{~L}$ \\
\hline Pesticide & $6 \times 1 \mathrm{~L}$ \\
\hline
\end{tabular}

Table 7. Regulatory Analysis Liquid Sample Volumes per the EPA SW-846 Methods

All regulatory liquid samples and associated blanks were collected, stored, and shipped "as-is" in I-Chem ${ }^{\circledR}$ Certified Series 300 environmental sample amber glass bottles or clear vials that were laboratory-certified to meet US EPA analyte specifications. The only possible exceptions were a few volatiles analysis liquid samples whose volumes were insufficient due to the uncertainty in generation, such as pump trap liquids and off-gas sampler condensates, where samples were "topped off" with reagent water to create zero-headspace samples. In these cases, pre- and postdilution masses were recorded, and the resulting higher detection limits from the analytical laboratory (BWXT Services, Inc.) were accepted.

Reagent blanks and trip blanks were poured in a separate "clean" laboratory to minimize effects of laboratory contamination, while field blanks were poured in the laboratory where the evaporator and off-gas sampling system were set up. All blank volumes were matched to required sample volumes $(1 \mathrm{~L}$ for semi-volatiles and pesticide analysis, $40 \mathrm{~mL}$ for volatiles analysis), except a few cases where blank volumes were larger than regulatory sample volumes due to less than expected sample volumes. The water and 50\% v/v methylene choride/methanol reagent blanks were samples of freshly prepared material taken just prior to experimentation. Trip blanks were only required for volatiles analysis, and water was chosen as the representative material since water was less likely to pick up material from the sample container (covered by field blank).

$1 \mathrm{M} \mathrm{NaOH}$ solution was chosen as the field blank solution to represent the feed and concentrate samples since caustic and neutral solutions air contamination behavior could possibly be different, and caustic solution is more likely to leach any contamination from the sample containers. The $1 \mathrm{M}$ concentration was chosen to represent the $0.56 \mathrm{M}$ free $\mathrm{OH}^{-}$and $1.41 \mathrm{M}$ total $\mathrm{OH}^{-}$concentrations found from duplicate feed analyses. The concentrate hydroxide concentrations were expected to be roughly $20-30 \%$ higher than the feed concentrations. $1 \mathrm{M}$ $\mathrm{NaOH}$ solution was also used for the condensate sample field blanks as a "worst case", with the high alkalinity more likely to extract contaminants than a neutral $\mathrm{pH}$ solution, to minimize blank volume shipped. Feed field blanks were collected at the beginning of each off-gas sampling run again as a "worst case" just in case there was any air contact before introduction into the evaporator. Feed solution air contact was considered highly unlikely since the feed solution was 
being fed directly from a Tedlar bag through hosing directly to the evaporator inlet without intentional exposure to ambient air. By contrast, concentrate samples were collected continuously and condensate samples semi-continuously into open narrow-neck bottles, and hence field blanks were taken in parallel to the extent possible to adequately capture any day-today atmospheric contamination variations.

AN-107 C-simulant spiked with acetone at a level comparable to that in the actual feed was selected to incorporate effects of any leaching of organic and inorganic components from the evaporator during the regulatory analysis run. Since caustic solutions were again thought to more likely leach components from the evaporator system, contact of the process blank liquid with only the evaporator tank was believed to be adequate. Hence, liquid process blanks were taken by simply filling the evaporator tank with acetone-spiked simulant at $-27.6 \mathrm{in} \mathrm{Hg}$ and pumping the solution out through the concentrate line into the appropriate sample containers.

Single volatile and semi-volatile/pesticide off-gas samples were taken since SW-846 Method gas sample volume requirements were anticipated to be difficult to meet, as mentioned previously. Since a vacuum pump bleed air flow rate of $\sim 400 \mathrm{~mL} / \mathrm{min}$ was expected to enter the off-gas sampler with the $11.5 \mathrm{~mL} / \mathrm{min}$ natural and set air in-leakage, a decision was made to collect $20 \mathrm{~L}$ of combined air in-leakage/bleed air as the process blank, and any detectable quantities of target analytes to be scaled by off-gas sample volume. To be representative of an actual evaporator run, the process blank off-gas sample was taken with an empty evaporator at -27.6 in $\mathrm{Hg}$ vacuum pressure. The volatile and semi-volatile/pesticide off-gas process blanks were taken before any other liquid such as the process blank liquids was introduced to the system to minimize potential contamination of the off-gas sampling sorbent tubes. Prior to assembly, the evaporator glassware was washed with dishwashing detergent and hot water, and dried. Subsequently, the evaporator interior was further cleaned through evaporator testing using de-ionized water and unspiked Envelope $\mathrm{C}$ simulant, before being drained for the regulatory run. The off-gas sampling glassware was cleaned and dried per the stricter EPA SW-846 Method 0010 for semi-volatiles.

Off-gas sample field blanks were taken according to their related EPA SW-846 Methods, Method 0031 and 0010, through pre-sampling leak checks. Method 0031 volatiles trip blanks were prepared by simply packaging for shipment stored tubes as received from the Southwest Research Institute (SWRI). As BWXT Services, Inc. did not have the sorbent tube conditioning capabilities, SWRI was asked to prepare and condition Tenax, Anasorb, and XAD-2 tubes used for this experiment. The sorbent tubes used in the off-gas sampling and as blanks were all employed within 14 days of conditioning.

All filled liquid samples and spent sorbent tubes were immediately sealed and stored in a $4^{\circ} \mathrm{C}$ refrigerator to cool before being packaged and shipped for analysis at BWXT Services, Inc. Tenax, Anasorb, and XAD-2 sorbent tubes sealed with endcaps were individually bagged, sealed with a signed custody seal, bagged again in batches, and shipped in coolers containing ice separate from the liquid samples. Liquid samples were sealed with a signed custody seal, individually bagged, and placed in 2 gallon cylindrical coolers separated by "bubble wrap" before ice was added. These 2 gallon coolers were then packaged in 10 gallon drums lined with shock 
absorbent material, before shipment. All samples were shipped from SRTC to BWXT Services, Inc. by Federal Express overnight delivery.

Method 0031, "Sampling Method for Volatile Organic Compounds (SMVOC)", is applicable to volatile organic compounds that have a boiling point between $-15^{\circ} \mathrm{C}$ and $121^{\circ} \mathrm{C}$. Method 0031 is generally not applicable to polar water-soluble and reactive volatile organic compounds, and requires support of laboratory data to demonstrate sampling and analysis method efficiencies for application to volatile organic compounds with boiling points less than $0^{\circ} \mathrm{C}$. The method is applicable to the determination of volatile organic compounds in the gaseous effluent of stationary sources with an upper concentration limit of 1.5 parts per million (ppm), and is designed to be operated between 0.25 and $1 \mathrm{~L} / \mathrm{min}$. In a typical measurement application on a stationary source effluent, the traps are typically replaced every $20 \mathrm{~min}$ at an operating rate of 1 $\mathrm{L} / \mathrm{min}$, and, every $40 \mathrm{~min}$ at $0.5 \mathrm{~L} / \mathrm{min}$. In the application of Method 0031 in this regulatory study, the entire off-gas stream (approximately $0.4 \mathrm{~L} / \mathrm{min}$ ) was directed through the sampling module from a vacuum pump that had condensate beakers to remove some of the liquid that could condense within the vacuum pump and harm it. The liquid condensed upstream of the sampling module was collected and analyzed. Based on the anticipated mass loading of volatile organics on the traps, it was judged that the total volume of gas sample could be extended beyond the $20 \mathrm{~L}$ of a typical effluent measurement. It was also judged that Method 0031 was the best single method to quantify the wide range of volatile organics specified in this investigation.

Method 0010, "Modified Method 5 Sampling Train", is applicable to the determination of semivolatile (boiling point $>100^{\circ} \mathrm{C}$ ) Principal Organic Hazardous Organic Compounds (POHCs) from incineration systems. The gas sampling rate is typically 0.5-1.0 dry standard cubic feet per minute $(\mathrm{dscfm})$ or $14-28 \mathrm{~L} / \mathrm{min}$, to collect a minimum 3 dry standard cubic meters (dscm) or 105.9 dscf. In the application of Method 0010 in this regulatory study, the lower flow rate of the entire off-gas stream (approximately $0.4 \mathrm{~L} / \mathrm{min}$ ) was thought to not affect sampling efficiency, and the XAD-2 sorbent trap was sized identical to the sorbent traps used to perform Method 0031 based on the total material expected to be captured during semi-volatiles/pesticide off-gas sampling. As the volume of gas to be sampled (of order $950 \mathrm{~L}$ ) was less than the minimum specified sampling volume, sampling duration was again extended beyond that of a typical effluent measurement from a stationary emission source.

For the regulatory analyses, one major deviation widening the acceptable analyte recoveries to $20-130 \%$ was accepted and approved by the customer ${ }^{20}$, based on input from BWXT Services, Inc. on expected low recoveries of certain species in the target list of compounds.

${ }^{20}$ Ferrara, D., Groseclose, R., Ray, R., Crawford, C., Calloway, T. B.,“ Task Technical, Analytical Study, and Quality Assurance Plan in Support of BNFL Part B - "'Regulatory' Sample Analyses from A, B, C, and LC Studies at SRTC", BNF-003-98-0082, January, 1999. 


\subsection{Results and Discussion}

\subsection{Initial Endpoint Determination}

To determine the saturation point for the C-simulant spiked with the 14 target volatiles, semivolatiles, and pesticide, an OLI model was formulated by $\mathrm{Choi}^{21}$. Inconsistencies between the Csimulant analytical data led to conflicts such as in balancing excess anions, and in resolving predicted initial solution density to total solids. Of particular concern was an analytically high fluoride concentration that could rapidly lead to formation of a sodium phosphate-fluoride double salt in the simulated waste. After repeating several analyses and using theoretical calculations to correct some analytical results, the "best" model inputs were determined to be $1.276 \mathrm{~g} / \mathrm{mL}$ density (matches analytical data), 5.8 M Na (vs. 5.5 M Na by AA and ICP-ES), and $31 \mathrm{wt} . \%$ total solids (vs. 32.5 wt.\% by oven method, $35 \%$ by microwave method).

Based on these "best" model inputs, a saturation point of over $11 \mathrm{M} \mathrm{Na}, 52.2$ wt.\% total solids, and $1.51 \mathrm{~g} / \mathrm{mL}$ density was predicted. Trace quantities of precipitated sodium oxalate was also predicted. As this final sodium concentration was viewed to be high, 5.5 M Na C-simulant was boiled down in the laboratory where samples were taken after calculated concentration to $8.7 \mathrm{M}$ $\mathrm{Na}, 9.4 \mathrm{M} \mathrm{Na}$, and 10.3 M Na. After these concentrated C-simulant samples were cooled, white solids were observed in the first two samples and the last sample was mostly precipitated salt. As the original $5.5 \mathrm{M} \mathrm{Na} \mathrm{C}$-simulant was also opaque with white solids (approximately 0.8 wt.\%), visual determination of the endpoint through back-addition of produced condensate to the concentrated samples generated was impossible. As the operation of the evaporator was thought to be unaffected by the suspended solids in the simulant up to $10 \mathrm{M} \mathrm{Na}$ and due to the undetermined end-point, concentrating to the current Hanford RPP-WTP design flowsheet specification of $8.0 \mathrm{M} \mathrm{Na}$ was determined as the best basis.

By assuming $80 \%$ saturation $\left(25^{\circ} \mathrm{C}\right)$ at $8 \mathrm{M} \mathrm{Na}$, the evaporator feed will be concentrated from 32.5 to 41.9 wt.\% solids as determined experimentally by back-addition of condensate to the 9.4 $\mathrm{M}$ Na sample produced during the boildown study. Choi's OLI model ${ }^{22}$ run concentrating to $8 \mathrm{M}$ Na predicted $40.6 \%$ total solids. Required water removal per liter of feed was estimated by two methods: simple arithmetic (assuming ideal mixing behavior) and based on experimental total solids quantities above.

Simple arithmetic suggests that the following quantity of condensate must be generated (or water removed from the feed) per liter of $5.5 \mathrm{M} \mathrm{Na}$-simulant fed to the evaporator to produce an $8 \mathrm{M}$ Na concentrate:

$$
\begin{aligned}
1 \mathrm{~L} \text { feed }(1-5.5 \mathrm{M} \mathrm{Na} / 8 \mathrm{M} \mathrm{Na}) & =0.3125 \mathrm{~L} \text { condensate } \\
& =312.5 \mathrm{~mL} \text { condensate }(\text { per liter feed })
\end{aligned}
$$

\footnotetext{
${ }^{21}$ Choi, A. S., forthcoming report for Hanford Tank AN-107 Envelope C-simulant evaporation OLI modeling, 2001.

${ }^{22}$ Choi, A. S., ibid.
} 
The ideal mixing assumption indicates generation of a $1.40 \mathrm{~g} / \mathrm{mL}$ and $43 \mathrm{wt} . \%$ total solids in the 8.0 M Na concentrate.

Using the experimentally measured $5.5 \mathrm{M} \mathrm{Na}$ simulant density and the experimentally determined total wt.\% solids results obtained (the $8.0 \mathrm{M} \mathrm{Na}$ total solids was obtained from the drying of a solution produced from somewhat approximate boildown and condensate backaddition experiments), the following condensate production was determined as necessary per liter of feed:

\begin{tabular}{|l|r|}
\hline \multicolumn{2}{|c|}{ Water removal (per liter feed) based on } \\
experimental data \\
\hline \multicolumn{2}{|c|}{} \\
\hline $5.5 \mathrm{M} \mathrm{Na:}$ Density (g/mL) & 1.276 \\
\hline $5.5 \mathrm{M}$ Na: Tot. wt.\% solids & 32.5 \\
\hline Total salt per liter feed $(\mathrm{g})$ & 414.7 \\
\hline Total water per liter feed $(\mathrm{g})$ & 861.3 \\
\hline & 41.9 \\
\hline 8.0 M Na: Total wt.\% solids & 989.7 \\
\hline Resulting 8.0 M Na solution mass $(\mathrm{g})$ & 575.0 \\
\hline Water remaining (g) & 286.3 \\
\hline \multicolumn{2}{|c|}{} \\
\hline Required water removal $(\mathrm{g})$ & \\
\hline
\end{tabular}

Table 8. Required water removal per liter $5.5 \mathrm{M} \mathrm{Na}$ feed based on initial boildown experiment

The similarity of the two calculated quantities suggest the C-simulant may exhibit ideal mixing behavior. The initial calculated number to which the experimental run schedule was made (312.5 $\mathrm{mL}$ condensate produced per $1 \mathrm{~L}$ simulant) was selected for use in this experiment, given the somewhat rough nature of the calculated water removal based on the boildown/condensate backaddition work and the uncertain nature of the true saturation point.

The difference between the OLI model prediction of saturation at $11.4 \mathrm{M} \mathrm{Na}$ concentration and the experimental boildown result of approximately $10.3 \mathrm{M} \mathrm{Na}$ based on the volume of condensate produced at saturation strongly indicates the necessity of a second final boildown experiment (Section 4.5) to confirm this result and to produce samples of larger quantities for further analysis (density, total solids, etc.).

\subsection{Execution of Experiment}

Approximately 100 gallons of simulated Envelope C (107-AN) supernate with entrained solids were synthesized using the recipe in Appendix A, precipitated with $\mathrm{NaOH} / \mathrm{Sr}\left(\mathrm{NO}_{3}\right)_{2} / \mathrm{NaMnO}_{4}$, and cross-flow filtered in the Thermal Fluids Laboratory. As noted, this simulant was a nontoxic version that excluded addition of sodium chromate and lead nitrate. The resulting filtrate had a density of $1.276 \mathrm{~g} / \mathrm{mL}$. Using a Masterflex ${ }^{\circledR}$ pump with Viton ${ }^{\circledR}$ tubing operating at 50-100 $\mathrm{mL} / \mathrm{min}, 60 \mathrm{~L}$ of simulant was pumped into $601 \mathrm{~L}$ Tedlar ${ }^{\circledR}$ bags a few days prior to use in the 
evaporator. A notable difficulty was that post-precipitation solids often encountered in AN-107 simulants restricted flow into the hose valves on the $1 \mathrm{~L}$ bags. This problem was eliminated by initially mixing the simulant, and allowing the post-precipitation solids to settle for 30-60 minutes prior to pumping simulant from near the top of the liquid. Bags were spiked with the target organic compounds 24-32 hours prior to anticipated use, with schedules being continually adjusted for any operational difficulties.

On the first day (June 4, 2000), semi-volatile and volatiles off-gas process blanks were taken before the liquid process blank samples taken. Due to air flow control difficulty, an empty evaporator operating at $82 \mathrm{~mm} \mathrm{Hg}(-26.7 \mathrm{in} . \mathrm{Hg})$ steady-state vacuum was run for approximately 50 and 43 minutes, respectively, to collect $20 \mathrm{~L}$ of treated laboratory air as a basis to reflect any effect of laboratory air leaking or introduced into the evaporator. Air flow for the process blanks was controlled through a needle valve before entering a silica gel and a carbon trap (to remove water and trace organics) and subsequently entering the evaporator through the evaporator feed line to maximize air contact within the apparatus interior. In both cases, no condensate was generated in the off-gas sampler, and only a small quantity of pump trap liquids $(\sim 1 \mathrm{~mL})$ was generated in the outlet pump flask, the latter of the two pump trap bulbs. The leak rate for the volatiles off-gas field blank was approximately 5\% higher than the Method 0031 specification, but only resulted in detection of slight quantities of toluene (374 ng), 1,2,4-trichlorobenzene (22 ng), and naphthalene (45 ng).

Beginning the second day of experiments (June 5, 2000), an evaporator leak check was performed for 1 hour and 40 minutes, yielding a natural leak rate of $0.35 \mathrm{~mL} / \mathrm{min}$. A simulant spiked with $800 \mathrm{ppm}$ acetone was prepared in a carboy and then pulled into the $-27.8 \mathrm{in}$. $\mathrm{Hg}$ evaporator tank through the feed line in $1600 \mathrm{~mL}$ batches. Some initial difficulties starting and priming the concentrate pump were solved by temporarily raising evaporator pressure to -12 in. $\mathrm{Hg}$, and some bubbling of air through the process blank solution did result. After concentrate pump flow and $-27.6 \mathrm{in}$. Hg evaporator pressure were established, the requisite volume $(\sim 6.5 \mathrm{~L})$ of process blank samples were generated within $5 \frac{1}{2}$ hours of solution generation. The pump priming difficulties resulted in detectable quantities of benzene, 4-methyl-2-pentanone, hexachlorobenzene, pentachlorophenol, and bis(ethylhexyl)phthalate in the volatile and first semi-volatile process blank samples. However, these quantities were deemed negligible since the quantities were less than the minimum reportable quantity, except bis(ethylhexyl)phthalate which was only $6 \mathrm{ppb}$ above the $10 \mathrm{ppb}$ minimimum reportable quantity. Additionally, the quantities of semi-volatiles fell below detectable in the following two process blank samples. In preparation for the steady-state experiment, the evaporator was emptied using the concentrate pump leaving a 50-75 mL heel of the process blank solution at the base of the evaporator tank.

Feed from prepared Tedlar bags \#8, \#7, and \#9 (bags \#1 to \#6 were used for feed samples) were added to the evaporator during the $6 \frac{1}{2}$ hour initial boildown of the evaporator tank to a target 8.0 $\mathrm{M} \mathrm{Na}$ from the initial 5.5 M Na. Feed was added in batches until approximately $2100 \mathrm{~mL}$ (not including concentrate samples) was boiled down to the steady state level of $1450 \mathrm{~mL}$. Assuming ideal mixing behavior, the approximate $710 \mathrm{~mL}$ condensate produced from nearly $2150 \mathrm{~mL}$ feed material produced a calculated 8.2 $\mathrm{M}$ Na solution. The initial boildown mass balance was closed to within $6.5 \%$ based on volume of spiked feed material fed $(1.276 \mathrm{~g} / \mathrm{ml}$ measured density), 
volume of condensate produced (1 $\mathrm{g} / \mathrm{ml}$ density assumed), evaporator tank level $(1.42 \mathrm{~g} / \mathrm{ml}$ density assumed based on OLI model results), and mass of concentrate samples removed. Evaporator operation targets for both boildown and steady state operation are shown in Table 9:

\begin{tabular}{|l|ccc|ccc|}
\hline Operation Parameter & \multicolumn{3}{|c|}{ Operational Target } & \multicolumn{3}{|c|}{ Typical Operational Range } \\
\hline Evaporator tank level & 1450 & $\pm 150 \mathrm{~mL}$ & \multicolumn{1}{c|}{1450} & $\pm 150 \mathrm{~mL}$ & \\
\hline Vacuum pressure & 60 & $\pm 8 \mathrm{~mm} \mathrm{Hg}$ & (P) & 60 & $\pm 8 \mathrm{~mm} \mathrm{Hg}$ & $(\mathrm{P})$ \\
& -27.6 & $\pm 0.3 \mathrm{in} \mathrm{Hg}$ & -27.6 & $\pm 0.3 \mathrm{in} \mathrm{Hg}$ & \\
\hline Evaporator tank temperatures & 50 & $\pm 3^{\circ} \mathrm{C}$ & $(\mathrm{T} 1)$ & 60 & $\pm 2^{\circ} \mathrm{C}$ & $(\mathrm{T} 1)$ \\
& & & & 50 & $\pm 2^{\circ} \mathrm{C}$ & $(\mathrm{T} 2)$ \\
\hline Condenser temperature & 40 & $\pm 1^{\circ} \mathrm{C}$ & (T3) & 40 & $\pm 1^{\circ} \mathrm{C}$ & $(\mathrm{T} 3)$ \\
\hline
\end{tabular}

Table 9. Evaporator Operational Targets and Typical Ranges.

Higher than target evaporator tank (T2) and heating rod temperatures (T1) were required to maintain a $3 \mathrm{~mL} / \mathrm{min}$ condensate production rate necessary for a 74.5 hour steady state run time. After completing the initial boildown, the evaporator operation was immediately converted to steady state by turning on both the feed $(9.6 \mathrm{~mL} / \mathrm{min}$ target $)$ and concentrate $(6.6 \mathrm{~mL} / \mathrm{min}$ target $)$ pumps to pre-determined settings obtained by pumping deionized water to and from the evaporator system at $59 \mathrm{~mm} \mathrm{Hg}(-27.6 \mathrm{in} . \mathrm{Hg})$. Soon afterwards, the vacuum pump effluent (evaporator air in-leakage and pump bleed air) was directed to the Apex off-gas sampler setup for volatiles off-gas sampling. Regulatory samples and samples for in-house (SRTC) analysis were scheduled to be taken according to the timeline in Figure 6. Arrows signify volatiles zeroheadspace samples and "H"-shape symbols represent the expected time to fill $1 \mathrm{~L}$ IChem bottles. In-house samples are labeled as such in the Figure. Semi-volatiles and pesticide regulatory feed samples were not included on this figure as these were scheduled to be taken prior to the beginning of each off-gas sampling period. Off-gas sampler regulatory samples and field blanks were also not included in this Figure. Refer to the Run Plan ${ }^{23}$ (BNF-003-98-0234, Rev. 0) for spreadsheets tabulating the sample schedule and sample details.

As pump flows can vary with time, the evaporator was run at steady state successfully maintaining reasonably constant evaporator tank volumes for the first 20 hours until solids were observed, indicating that the simulant in the evaporator was becoming too concentrated. The concentrate line was backflushed to dislodge accumulated solids by naturally pulling in previously produced concentrate product. The concentrate withdrawal rate was increased to reduce tank levels sufficiently before the feed flow rate was increased and concentrate removal was reduced to dilute the evaporator tank contents. This strategy was pursued for 12 hours until a concentrate density measurement was taken and the $1.35 \mathrm{~g} / \mathrm{mL}$ result indicated a dilute concentrate, compared to the $1.40 \mathrm{~g} / \mathrm{mL}$ density of a sample taken 14 hours previous (a spot check at 28 hours steady-state operation showed $1.41 \mathrm{~g} / \mathrm{mL}$ ). The concentrate and feed pumps were then shutoff and the evaporator tank contents were boiled down again for approximately 80 minutes until a concentrate density of $1.40 \mathrm{~g} / \mathrm{mL}$ was obtained by pycnometer. Steady state evaporation was resumed and pump flow rates re-calibrated for the final 4 hours of volatiles off-

${ }^{23}$ Saito, H., Calloway, T. B., "Bench Scale LAW Evaporation of Simulants With Target Organic Indicators - Run 7E Run Plan - Rev. 0”, BNF-003-98-0234, Rev. 0, June 4, 2000. 
gas sampling which was done for a total of 37 hours 37 minutes collecting sample from $928.5 \mathrm{~L}$ of evaporator condenser vent gas $(11.5 \mathrm{~mL} / \mathrm{min})$ and pump bleed air $(400 \mathrm{~mL} / \mathrm{min})$. The mass balance for liquids was closed to within $4.5 \%$ (Table 10) for the total volatiles off-gas sampling period of steady-state evaporator operation. No condensate in the volatiles off-gas sampling train was recovered, although the chilled condensate collection flask did have an unrecoverable thin film of condensed vapor on the walls. Vacuum pump trap liquid volume for this portion of the run $(236.9 \mathrm{~g})$ was thought to be atypically high since the silica gel trap used to clean pump bleed air was found to have settled at the end of the run, leaving a void space for inefficiently treated air to enter the pump flasks and condense moisture.

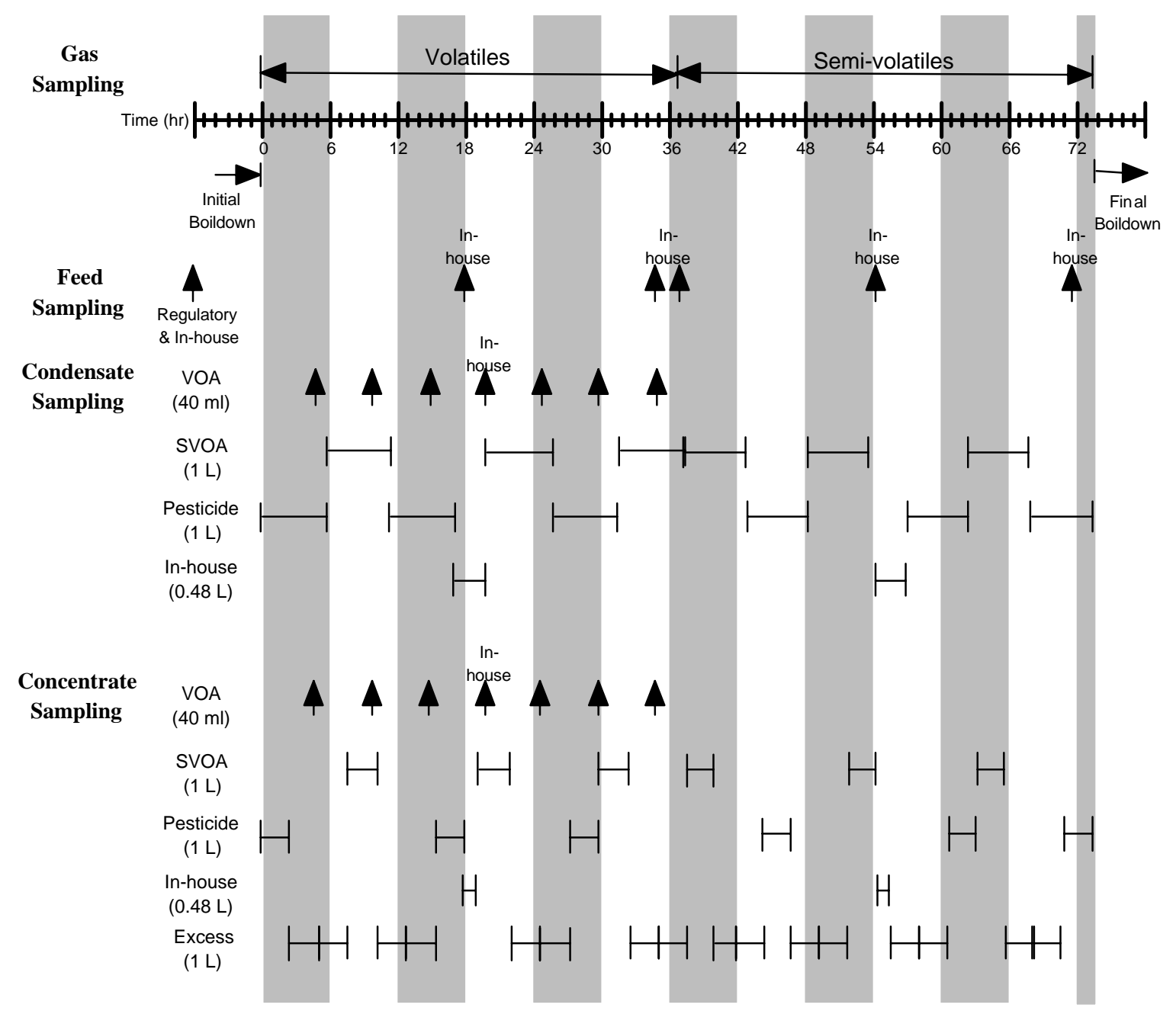

Figure 6. Regulatory sample and in-house analysis sample withdrawal schedule.

To minimize run time and to remove any potential effects from evaporation shutdown and restart, an "on-the-fly" transition from volatiles off-gas sampling (Method 0031) to semivolatiles/pesticide off-gas sampling (Method 0010) was attempted and accomplished in less than 35 minutes on June 7, 2000. During this period, the evaporator outlet was valved off from the vacuum pump and the off-gas sampling operation was stopped. As the transition was initially 
expected to be shorter, evaporator heating, air-inleakage, and the concentrate pump operation continued while feed introduction was stopped. The vacuum pump was stopped, pump trap bulbs replaced, and the silica gel trap for the pump bleed air emptied and refilled with fresh dessicant. Simultaneously, pump trap liquid volatiles were poured to create zero-headspace samples for regulatory analysis, and a preprepared and leak-checked semi-volatiles gas sampling train was attached to the pump outlet line. The vacuum pump was then restarted to lower the pressure which had crept up due to the continuing air-inleakage, and the feed pump turned on with the concentrate pump turned off to regain a sufficient volume in the evaporator tank. Once evaporator operating conditions were stabilized, the vacuum effluent was valved to the semivolatiles off-gas sampling train, and Method 0010 sampling was began when off-gas sampler operations were stabilized.

By comparison to the evaporator operation during Method 0031 execution, steady-state was more easily achieved during Method 0010 semi-volatiles/pesticide off-gas sampling due to the more frequent concentrate density checks performed by pycnometer. Target steady-state operation was maintained for 12 hours before the evaporator began running a bit dilute with a concentrate density of $1.38 \mathrm{~g} / \mathrm{mL}$. Feed pump flow rates were gradually reduced due to increasing evaporator tank levels, and the concentrate density rose to $1.39 \mathrm{~g} / \mathrm{mL}$ over the next 5 hours. Various inhouse condensate and concentrate samples were collected before another concentrate spot-check showed a drop in density to $1.38 \mathrm{~g} / \mathrm{mL}$ due to rising evaporator tank levels 3 hours later. The feed and concentrate pumps were turned off, and a 25-minute boildown was performed to concentrate from a calculated 7.2 M Na concentration. After the target $1.40 \mathrm{~g} / \mathrm{mL}$ concentrate density was recovered, both pumps were restarted and reset to target flow rates. Another 9 hours later, a last concentrate density check and very stable evaporator operation suggested continued desired steady-state evaporator operation. A $1.38 \mathrm{~g} / \mathrm{mL}$ density of the final boildown starting material suggests that the evaporator ran somewhat dilute towards the end of the last 6 hours of Method 0010 sampling. Ending in the early morning of June 9, 2000, semi-volatiles/pesticide off-gas sampling was done for a total of 34 hours 50 minutes collecting sample from $953.9 \mathrm{~L}$ of evaporator condenser vent gas $(11.5 \mathrm{~mL} / \mathrm{min})$ and pump bleed air $(445 \mathrm{~mL} / \mathrm{min})$. The mass balance for liquids was closed to within $1.7 \%$ (Table 10) for the total volatiles and semivolatiles/pesticide off-gas sampling periods of steady-state evaporator operation.

A small amount of condensate $(1.25 \mathrm{~g})$ in the semi-volatiles/pesticide off-gas sampling train was recovered for analysis. Vacuum pump trap liquid volume for this portion of the run $(72.9 \mathrm{~g})$ was lower than for the volatiles run $(236.9 \mathrm{~g})$, as expected, due to a more efficiently packed silica gel trap to treat the pump bleed air. The mid-run in-house condensate and concentrate samples were taken at slight dilution (1.39 $\mathrm{g} / \mathrm{mL}$ concentrate density) from target steady state operating conditions.

Review of the regulatory process, field, trip and reagent blank data shows that contamination was a minor issue in 22 of the approximately 72 blanks (Appendix B, A. Raw Data), with most detected analytes being only slightly above detection limits or at levels far below those detected in associated samples. The remainder did not show detectable quantities. Many of these "positive" results never impacted results since "positive" trip blanks were discounted due to nondetectable levels in associated field blanks, and one case was a water reagent blank for dilution 
that was never needed. As a result, only about 10 sample results had to be adjusted slightly as a result of detected contamination. Sample results that were adjusted are identified in a subsequent section (Appendix B, B. Validated and Corrected Data).

While preparations were made to add Dow US-1520 anti-foam in the case of evaporator tank liquid foaming during evaporation, anti-foam use was not necessary as foaming was not encountered either during the nearly 75 hour steady-state operation or during the final boildown experiment.

\subsection{Overall and Target Organics Mass Balance}

Mass and volume balances for the volatiles and semi-volatiles/pesticide sampling portions of the run were completed and are summarized in Table 10. Mass of spiked feed material fed into the evaporator and mass of concentrate and condensate extracted were recorded throughout the experiment. Remaining condensate and concentrate in the evaporator were estimated by multiplying estimated volumes determined from equipment graduations and assumed densities such as $1 \mathrm{~g} / \mathrm{mL}$ for condensate and the most recent concentrate density measurement. By this method, a mass balance was maintained throughout the experiment. Based on the mass balance results, a volume balance was performed using the assumed densities listed at the bottom of Table 10.

\begin{tabular}{|l|c|c|c|c|}
\hline Sampling Period/Event & Mass Fed $(\mathrm{g})$ & $\begin{array}{c}\text { Condensate } \\
\text { Generated }(\mathrm{g})\end{array}$ & $\begin{array}{c}\text { Concentrate } \\
\text { Generated }(\mathrm{g})\end{array}$ & $\begin{array}{c}\text { Mass Balance } \\
\text { Closure (\%) }\end{array}$ \\
\hline Volatiles Off-gas & 24704 & 6475 & 19343 & 4.5 \\
\hline $\begin{array}{l}\text { Semi-volatiles/Pesticide } \\
\text { Off-gas }\end{array}$ & 24881 & 6107 & 18531 & 1.0 \\
\hline Total & 49585 & 12582 & 37874 & 1.7 \\
\hline
\end{tabular}

\begin{tabular}{|l|c|c|c|c|}
\hline Sampling Period/Event & $\begin{array}{c}\text { Volume Fed } \\
(\mathrm{mL})\end{array}$ & $\begin{array}{c}\text { Condensate } \\
\text { Generated }(\mathrm{mL})\end{array}$ & $\begin{array}{c}\text { Concentrate } \\
\text { Generated }(\mathrm{mL})\end{array}$ & $\begin{array}{c}\text { Volume Balance } \\
\text { Closure }(\%)\end{array}$ \\
\hline Volatiles Off-gas & 19361 & 6475 & 13816 & 4.8 \\
\hline $\begin{array}{l}\text { Semi-volatiles/Pesticide } \\
\text { Off-gas }\end{array}$ & 19499 & 6107 & 13236 & 0.8 \\
\hline Total & 38860 & 12582 & 27052 & 2.0 \\
\hline Assumed density & 1.276 & 1 & 1.4 & ---- \\
\hline
\end{tabular}

Table 10. Experiment Mass and Volume Balance Results: Overall and by Sampling Event.

The material for each sampling period was accounted for to within 5\% of the mass fed. The densities assumed for the volume balances are from experimental measurements of the feed before experiments and of the concentrate during the experiment. As mentioned earlier, a concentrate density of $1.40 \mathrm{~g} / \mathrm{mL}$ was the target, but deviations in the actual concentrate densities will affect the volume balance only slightly.

When occasionally necessary, the raw regulatory analytical data obtained from BWXT Services, Inc. was corrected for the almost negligible contamination as quantified in the trip, field, and 
process blanks generated in parallel to the regulatory samples. The SRTC Quality Assuranceapproved regulatory raw analytical data and corrected quantities are tabulated in Appendix B (refer to BWXT Services, Inc. report numbers 0006015 VOC AQUEOUS, VOC SOLID, SVOC, and PEST in reference [24] for the raw data package). The corrected regulatory analytical data was then combined with the experimental mass balance data to understand the fate of the 14 target organic compounds fed into the evaporator. Table 11 lists the calculated quantity and standard deviation of each target organic compound entering or leaving through each evaporator stream for the overall experiment (See Appendix C for calculations).

Given the 20-130\% acceptable analyte recoveries specified for this work, acceptable mass balances (-30 to 80\% mass closure) were obtained for all species except for 1,2-dibromoethane, 1,2,3-trichloropropane and pentachlorophenol whose quantities are small (likely due to hydrolysis) and large analytical errors are expected. Similar material balances were performed individually for both the volatiles and semi-volatiles/pesticide off-gas sampling periods and were not found to change the results or trends significantly.

\begin{tabular}{|c|c|c|c|c|c|c|c|c|c|}
\hline & Chemical & $\begin{array}{c}\text { Mass } \\
\text { Fed (ug) }\end{array}$ & $\begin{array}{c}\text { Condensat } \\
\mathrm{e}\end{array}$ & Concentrate & $\begin{array}{l}\text { Sorbent } \\
\text { Tube }\end{array}$ & $\begin{array}{l}\text { Pump } \\
\text { Traps }\end{array}$ & $\begin{array}{c}\text { Off-gas } \\
\text { Line Rinse }\end{array}$ & TOTAL & $\begin{array}{c}\text { Mass } \\
\text { Closure (\%) }\end{array}$ \\
\hline \multirow{9}{*}{ 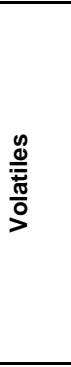 } & Benzene & 55550 & 405 & $174^{\star}$ & 49896 & $15^{*}$ & 0 & 50491 & 9.11 \\
\hline & 4-methyl-2-pentanone (MIBK) & 99928 & $2063^{*}$ & $1833^{*}$ & 66401 & $373^{*}$ & 0 & 70670 & 29.28 \\
\hline & Std. Dev & 9068 & 1644 & 1099 & & & & 1977 & 6.72 \\
\hline & Toluene & 41386 & 326 & $235^{\star}$ & 22736 & $10^{*}$ & 0 & 23307 & 43.68 \\
\hline & Std. Dev & 346 & & 50 & & & & 50 & 43.27 \\
\hline & Chlorobenzene & 45660 & 554 & $166^{*}$ & 17811 & $11^{*}$ & 0 & 18542 & 59.39 \\
\hline & Std. Dev & 5770 & & 27 & & & & 27 & 5.13 \\
\hline & 1,2,3-trichloropropane & 38471 & $2139^{*}$ & $6222^{*}$ & 0 & $34^{*}$ & 0 & 8395 & 78.18 \\
\hline & Std. Dev & & 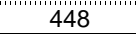 & "3085 & & & & 3117 & "8.10" \\
\hline \multirow{10}{*}{ 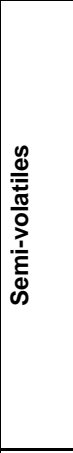 } & Hexachlorobenzene & 31574 & 22 & $22522^{*}$ & 0 & $0^{*}$ & 940 & 23483 & 25.62 \\
\hline & Std. Dev & 10443 & 26 & 3847 & & & & 3847 & '27.45" \\
\hline & Pentachlorophenol & 2332 & 0 & 4058 & 0 & $0^{*}$ & 0 & 4058 & -74.04 \\
\hline & Std. Dev & 1124 & & 716 & & & & 716 & 89.36 \\
\hline & Pyrene & $36140^{*}$ & 1699 & $20425^{\star}$ & 0 & $28^{*}$ & 719 & 22870 & 36.72 \\
\hline & Std. Dev & 0 & "417'"' & 2353 & & & & 2390 & 6.61 \\
\hline & $\begin{array}{l}\text { Bis(ethylhexyl)phthalate } \\
\text { (BEHP) }\end{array}$ & 40220 & 38 & $24618^{*}$ & 0 & 0 & 0 & 24656 & 38.70 \\
\hline & Std. Dev & 275 & 75 & 2231 & & & & 2232 & 5.57 \\
\hline & Benzo[a]pyrene (BaP) & $56735^{\star}$ & 0 & $31449^{*}$ & 0 & $0^{*}$ & 0 & 31449 & 44.57 \\
\hline & Std. Dev & 7859 & & 4975 & & & & 4975 & 11.66 \\
\hline $\begin{array}{l}\text { Pest- } \\
\text { icide }\end{array}$ & Aldrin & $40285^{\star}$ & 315 & $31449^{*}$ & 0 & $18^{*}$ & 0 & 31782 & 21.11 \\
\hline
\end{tabular}

Table 11. Overall Experiment Mass Balance for Each Target Organic Compound

Table 11 shows that the target organic volatiles and the more volatile semi-volatiles $(1,2,4-$ trichlorobenzene and naphthalene) largely exit the evaporator through the evaporator off-gas, generally leaving small quantities in the concentrate and slightly greater quantities in the

${ }^{24}$ Ferrara, D. M., "Data Package for AN-107 Env. C-simulant Regulatory Evaporation", WSRC-TR-2000-00528, SRT-RPP-2000-00062, 2001. 
produced condensate. The remaining semi-volatiles were found to predominantly remain in the evaporator concentrate with slight quantities being captured in the condensate. No significant quantities of the less-volatile semi-volatiles were detected in the off-gas sampling train, although a few percent of the fed hexachlorobenzene and pyrene were found to have condensed in the evaporator off-gas line.

The yellow/italic cells in Table 11 signify that there is analytical uncertainty (lack of accuracy) in the values due to data qualification by BWXT Services, Inc. or by SRTC Quality Assurance Department. Regulatory feed analyses for 4-methyl-2-pentanone (methyl iso-butyl ketone, MIBK), 1,2-dibromoethane, and pentachlorophenol were qualified as inaccurate, which could explain the discrepancies in the material balances observed. The same is true for hexachlorobenzene in the condensate. The quantity of 1,2,3-trichloropropane fed into the evaporator during the experiment is a calculated quantity based on the aging studies discussed earlier. The actual quantity is expected to be between the $800 \mu \mathrm{g} / \mathrm{L}$ minimum detection limit cited by BWXT Services from their sample analysis, and $140 \mu \mathrm{g} / \mathrm{L}$ obtained by belated analysis of an in-house sample. BWXT Services also expects that the lack of recovery of 1,2,3trichloropropane in the off-gas sampling tubes is due to chemical degradation on the sorbent material or during extraction. Pesticide numbers colored yellow were deemed uncertain as insufficient sample was set aside for these analyses. MIBK totals are thought to be higher than the theoretical input due to extraction of this compound, often used for plastic coatings, from the Tedlar bags.

The regulatory data from BWXT Services, Inc. were used to the maximum extent possible. But analytical problems and issues required that some of the data be replaced by analytical results from SRTC in-house analysis of identical samples, or that regulatory data be used that were qualified as inaccurate or "uncertain" by the Quality Assurance Department at either SRTC or the vendor laboratory. Regulatory semi-volatiles and pesticide analytical results for both feed and concentrate samples were replaced by SRTC in-house analytical results. The EPA SW-846 Methods require that semi-volatiles and pesticide samples be acidified to $\mathrm{pH}=2$ prior to analysis. However the vendor laboratory noted that the samples bubbled on acidification and that lower than expected target semi-volatile organic compound concentrations were obtained. It is believed that the added acid is reacting with the abundant nitrite in the Hanford AN-107 simulated waste to form the highly reactive nitrous acid which is oxidizing and consuming the target organics. As the SRTC analytical method concentrates the analytes through the use of liquid-liquid extraction with methylene chloride, the in-house results for both feed and concentrate semi-volatiles and pesticides were deemed more accurate and were used in the analysis, except pentachlorophenol. It is believed that sample acidification helps reprotonate the deprotonated phenolic group for quantification, while a deprotonated pentachlorophenol in the caustic simulated waste would not be extractable by methylene chloride.

The volatiles off-gas numbers were deemed uncertain for two primary reasons. First, low surrogate recoveries, average $8 \%$ for Anasorb sorbent tubes and an acceptable but low 34\% average for Tenax sample tubes, were initially reported. A regulatory sample Tenax and the Anasorb tube had to be methanol-extracted since the quantities of target components on the first thermally-desorbed Tenax tube overloaded the analytical equipment detector. As the low 
quantities of spike material (50 $\mu \mathrm{g}$ each component) combined with permananent sorption losses onto the sorbent material were thought to be causing the reported low recoveries, recovery testing using the maximum quantity of analyte observed on each regulatory sample tube (3000 $\mu \mathrm{g}$ on Tenax, $30000 \mu \mathrm{g}$ on Anasorb) was performed by BWXT Services, Inc. The recoveries obtained with these larger spiked quantities improved to $15 \%$ for Anasorb and $88 \%$ for Tenax (refer to BWXT Services, Inc. Report No. 0011102 VOC TENAX AND ANASORB $^{25}$ for raw data package). The low average surrogate recovery for Anasorb are due to $<11 \%$ recoveries of benzene, toluene, and chlorobenzene by methanol extraction. The recovered quantities of volatiles cited in Table 11 were not adjusted for reported recoveries, as is standard practice ${ }^{26}$. Second, due to the sorbent tube analysis difficulties, the obtained analytical volatiles quantities for one volatiles Tenax sample tube is known to be approximate and low due to detector overload. As a result, all sorbent tube recovered quantities were deemed approximate, although reasonable material balances were obtained and the target organic compound distribution trends appear unaffected.

An important note from BWXT Services, Inc. was that all Anasorb and one sample Tenax tube were solvent extracted to yield the analytical results. Hence, the process, field, and trip blank Tenax tube results were thermally desorbed for analysis and those results (where significant) were not affected by the aforementioned difficulties.

\subsection{Product Chemical Analysis Results}

Tables 12 and 13 show the analytical results from SRTC analysis of the feed and evaporation products. Density was obtained by pycnometer, total solids by staged oven drying at 90,105 , 120,135 , and $150^{\circ} \mathrm{C}$ (if needed due to large sample size), and insoluble solids by vacuum filtration using a $0.22 \mu \mathrm{m}$ pore-size cellulose filter followed by staged drying with the total solids analysis samples. Metals concentrations were obtained by induced coupled plasma-emission spectroscopy (ICP-ES), with $\mathrm{Cs}, \mathrm{K}$, and $\mathrm{Na}$ analyzed by atomic absorption (AA) or by induced coupled plasma-mass spectrometry (ICP-MS). Anion concentrations were obtained by ion chromatography (IC-Anion), total and free hydroxide wet chemical analysis, and total inorganic carbon/total organic carbon (TIC/TOC) analysis. The concentrate data presented below are thought to be slightly dilute compared to the overall run average concentrations as the evaporator concentrate density at the time of sampling was $1.38 \mathrm{~g} / \mathrm{mL}$ compared to the experimental target $1.40 \mathrm{~g} / \mathrm{mL}$ specified by the OLI model.

\footnotetext{
${ }^{25}$ Ferrara, D. M., op. cit., WSRC-TR-2000-00528, SRT-RPP-2000-00062, 2001.

${ }^{26}$ Gibson, Jr., L.V., Sampling and Support Department, Analytical Chemistry Organization, Y-12 National Security Complex (BWXT Y-12, L.L.C.), electronic mail, October 16, 2000.
} 


\begin{tabular}{|c|c|c|c|c|c|}
\hline Property/Analyte & \multicolumn{2}{|c|}{ Feed } & Condensate & Calculated DF & Concentrate \\
\hline Density & \multicolumn{2}{|c|}{1.276} & & & 1.382 \\
\hline Total Solids (wt.\%) & \multicolumn{2}{|c|}{32.5} & & & $42.9^{*}$ \\
\hline Insoluble Solids (wt.\%) & \multicolumn{2}{|c|}{$\sim 0.3$} & & & $0.39^{*}$ \\
\hline & & & \\
\hline $\mathrm{Ag}(\mathrm{mg} / \mathrm{L})$ & & & $<0.056$ & & $<0.28$ \\
\hline $\mathrm{Al}(\mathrm{mg} / \mathrm{L})$ & 236 & 223 & $<0.048$ & $>4800$ & 328 \\
\hline$B(\mathrm{mg} / \mathrm{L})$ & 23 & 22 & $<0.042$ & $>540$ & 28.7 \\
\hline $\mathrm{Ba}(\mathrm{mg} / \mathrm{L})$ & $<0.1$ & & $<0.004$ & & $<0.2$ \\
\hline $\mathrm{Ca}(\mathrm{mg} / \mathrm{L})$ & 160 & 143 & $<0.008$ & $>18900$ & 202 \\
\hline $\mathrm{Cd}(\mathrm{mg} / \mathrm{L})$ & & $<0.14$ & $<0.004$ & & $<0.2$ \\
\hline Co $(\mathrm{mg} / \mathrm{L})$ & & & $<0.01$ & & $<0.5$ \\
\hline $\mathrm{Cr}(\mathrm{mg} / \mathrm{L})$ & 0.5 & $<0.74$ & $<0.01$ & $>62$ & $<0.5$ \\
\hline $\mathrm{Cs}(\mathrm{mg} / \mathrm{L})$ & \multicolumn{2}{|c|}{$\begin{array}{r}9.24 \\
\text { (AA) } \\
\end{array}$} & $\begin{array}{l}0.000019 \\
\text { (ICP-MS) }\end{array}$ & 486000 & \\
\hline $\mathrm{Cu}(\mathrm{mg} / \mathrm{L})$ & 13 & 13 & $<0.01$ & $>1300$ & 17.5 \\
\hline $\mathrm{Fe}(\mathrm{mg} / \mathrm{L})$ & 34 & 35 & $<0.01$ & $>3450$ & 47.0 \\
\hline $\mathrm{K}(\mathrm{mg} / \mathrm{L}, \mathrm{AA})$ & 2563 & 1119 & & & \\
\hline $\mathrm{La}(\mathrm{mg} / \mathrm{L})$ & 1.5 & & & & \\
\hline $\mathrm{Li}(\mathrm{mg} / \mathrm{L})$ & & & $<0.02$ & & $<1$ \\
\hline $\mathrm{Mg}(\mathrm{mg} / \mathrm{L})$ & $<0.1$ & $<0.084$ & $<0.018$ & & $<0.9$ \\
\hline $\mathrm{Mn}(\mathrm{mg} / \mathrm{L})$ & 11 & 24 & $<0.002$ & $>8750$ & 22.4 \\
\hline Mo (mg/L) & & 20 & $<0.02$ & $>1000$ & 30.2 \\
\hline $\mathrm{Na}(\mathrm{mg} / \mathrm{L})$ & 125258 & 131057 & $<2$ & $>64100$ & 184200 \\
\hline $\mathrm{Na}(\mathrm{mg} / \mathrm{L}, \mathrm{AA})$ & 121043 & 128128 & & & \\
\hline $\mathrm{Nb}(\mathrm{mg} / \mathrm{L})$ & & & $<0.1$ & & $<5$ \\
\hline $\mathrm{Ni}(\mathrm{mg} / \mathrm{L})$ & 315 & 283 & $<0.014$ & $>21400$ & 427 \\
\hline $\mathrm{P}(\mathrm{mg} / \mathrm{L})$ & 280 & 299 & $<0.14$ & $>2070$ & 376 \\
\hline $\mathrm{Pb}(\mathrm{mg} / \mathrm{L})$ & $<1$ & $<2$ & $<0.14$ & & $<7$ \\
\hline $\mathrm{Si}(\mathrm{mg} / \mathrm{L})$ & 8 & 9.2 & 0.09 & 96 & 19.8 \\
\hline $\mathrm{Sn}(\mathrm{mg} / \mathrm{L})$ & & & $<0.052$ & & $<2.6$ \\
\hline $\mathrm{Sr}(\mathrm{mg} / \mathrm{L})$ & 80 & 73 & $<0.0004$ & $>191000$ & 106 \\
\hline $\mathrm{Ti}(\mathrm{mg} / \mathrm{L})$ & & & $<0.028$ & & $<1.4$ \\
\hline $\mathrm{V}(\mathrm{mg} / \mathrm{L})$ & & & $<0.026$ & & $<1.3$ \\
\hline $\mathrm{Zn}(\mathrm{mg} / \mathrm{L})$ & 18 & 17 & $<0.074$ & $>236$ & 24.8 \\
\hline $\mathrm{Zr}(\mathrm{mg} / \mathrm{L})$ & 2 & 1.7 & $<0.01$ & $>185$ & 1.9 \\
\hline $\mathrm{Na}(\mathrm{M})$ & 5.45 & 5.70 & $<0.00009$ & & 8.01 \\
\hline $\mathrm{Na}(\mathrm{M})$ - predicted & 5.58 & asis) & & & 7.89 \\
\hline Tot. Solids (wt\%)-pred. & 32.5 & asis) & & & 42.5 \\
\hline
\end{tabular}

Table 12. Bulk property and cationic concentration (ICP-ES, unless otherwise specified) data with calculated DF for Envelope $\mathrm{C}$ simulant feed and evaporation products.

Calculation of decontamination factors (DF) using Table 12 and 13 data, where DF = feed concentration/condensate concentration, allows for evaluation of evaporator operation during the experiment. In addition to the below detection limit condensate ICP-ES and IC-Anion analyte concentrations, the high decontamination factors for $\mathrm{Cs}, \mathrm{OH}^{-}$and $\mathrm{Sr}$ show that de-entrainment of droplets from the evaporator tank to the condensate tank by the packed stainless steel mesh was excellent. Minimum calculated DF's were calculated using analytical feed data and the minimum detection limits cited for the condensate data. Low feed concentrations and relatively high minimum detection limits are likely responsible for the low DF's calculated for $\mathrm{Cr}, \mathrm{Zn}, \mathrm{Zr}$, formate, oxalate and phosphate, and to a lesser degree for other species with calculated DF's in the 800-10000 range. However, the low DF for Si suggests that individual species verification is necessary and that high DF may not occur for all species. 


\begin{tabular}{|c|c|c|c|c|c|}
\hline Analyte & \multicolumn{2}{|c|}{ Feed } & Condensate & Calculated DF & Concentrate \\
\hline Chloride (mg/L) & 1308 & 2477 & $<2$ & $>946$ & 1559 \\
\hline Fluoride $(\mathrm{mg} / \mathrm{L})$ & 2864 & 2455 & $<2$ & $>1330$ & 3177 \\
\hline Formate $(\mathrm{mg} / \mathrm{L})$ & 7179 & 6636 & $<10$ & $>691$ & 10105 \\
\hline Nitrate $(\mathrm{mg} / \mathrm{L})$ & 145186 & 137961 & $<10$ & $>14200$ & 188331 \\
\hline Nitrite $(\mathrm{mg} / \mathrm{L})$ & 38751 & 36145 & $<10$ & $>3750$ & 42364 \\
\hline Oxalate $(\mathrm{mg} / \mathrm{L})$ & 1578 & 1306 & $<10$ & $>144$ & 1647 \\
\hline Phosphate (mg/L) & 1529 & 2349 & $<10$ & $>194$ & 2148 \\
\hline Sulfate $(\mathrm{mg} / \mathrm{L})$ & 5273 & 5297 & $<5$ & $>1060$ & 5913 \\
\hline & & & & & \\
\hline Total $\mathrm{OH}^{-}(\mathrm{M})$ & 1.395 & 1.421 & & & 2.059 \\
\hline Free $\mathrm{OH}^{-}(\mathrm{M})$ & 0.553 & 0.561 & $\begin{array}{c}2.51 \times 10^{-6} \\
(\mathrm{pH}=8.4)\end{array}$ & 222000 & 0.987 \\
\hline Total Inorganic C (mg/L) & & & & & 15046 \\
\hline Total Organic C (mg/L) & & & & & 17328 \\
\hline
\end{tabular}

Table 13. IC-Anion, Total/Free Hydroxide and TIC/TOC analytical results with calculated DF for Envelope $\mathrm{C}$ simulant feed and evaporation products.

\begin{tabular}{|c|c|c|c|c|c|}
\hline Property/Analyte & \multicolumn{2}{|c|}{$\begin{array}{c}\text { Measured } \\
\text { Feed (basis) }\end{array}$} & $\begin{array}{l}\text { Measured } \\
\text { Concentrate }\end{array}$ & $\begin{array}{c}\text { Volume Additivity } \\
\text { Concentrate Prediction }\end{array}$ & $\begin{array}{l}\% \text { Difference } \\
\text { vs. Measured }\end{array}$ \\
\hline $\mathrm{Al}(\mathrm{mg} / \mathrm{L})$ & 236 & 223 & 328 & 325 & 0.9 \\
\hline $\mathrm{B}(\mathrm{mg} / \mathrm{L})$ & 23 & 22 & 28.7 & 31.9 & 11.0 \\
\hline $\mathrm{Ca}(\mathrm{mg} / \mathrm{L})$ & 160 & 143 & 202 & 215 & 6.2 \\
\hline $\mathrm{Cu}(\mathrm{mg} / \mathrm{L})$ & 13 & 13 & 17.5 & 18.4 & 5.2 \\
\hline $\mathrm{Fe}(\mathrm{mg} / \mathrm{L})$ & 34 & 35 & 47.0 & 48.8 & 3.9 \\
\hline $\mathrm{Mn}(\mathrm{mg} / \mathrm{L})$ & 11 & 24 & 22.4 & 24.8 & 10.6 \\
\hline Mo $(\mathrm{mg} / \mathrm{L})$ & & 20 & 30.2 & 28.3 & 6.2 \\
\hline $\mathrm{Na}(\mathrm{mg} / \mathrm{L})$ & 125258 & 131057 & 184200 & 181460 & 1.5 \\
\hline $\mathrm{Si}(\mathrm{mg} / \mathrm{L})$ & 8 & 9.2 & 19.8 & 12.2 & 38.5 \\
\hline $\mathrm{Sr}(\mathrm{mg} / \mathrm{L})$ & 80 & 73 & 106 & 108 & 2.2 \\
\hline $\mathrm{Zn}(\mathrm{mg} / \mathrm{L})$ & 18 & 17 & 24.8 & 24.8 & 0.1 \\
\hline $\mathrm{Zr}(\mathrm{mg} / \mathrm{L})$ & 2 & 1.7 & 1.9 & 2.6 & 37.9 \\
\hline & & & & & \\
\hline $\mathrm{Na}(\mathrm{M})$ & & & 8.01 & 7.90 & 1.5 \\
\hline Tot. Solids (wt\%) & & & 42.9 & 42.5 & 0.9 \\
\hline Total Mass Processed (g) & & & 37874 & Conc. Factor & \\
\hline $\begin{array}{c}\text { Total Volume Processed } \\
(\mathrm{mL})\end{array}$ & & & 27445 & 1.42 & \\
\hline Assumed Density $(\mathrm{g} / \mathrm{mL})$ & & & 1.38 & ---- & \\
\hline
\end{tabular}

Table 14. Actual concentrate metal concentrations versus prediction by volume additivity (ideal mixing behavior), and percent difference from measured.

The overall mass balance data (Table 10) indicate that the feed was concentrated by a factor of 1.42 (bottom of Table 14), assuming ideal mixing and that the condensate is pure water. Combining this concentration factor with evaporator feed data in Tables 12 and 13 also allows for a comparison of the predicted species concentrations in the concentrate assuming ideal mixing behavior with analytical concentrate data for the Hanford Tank AN-107 Envelope Csimulant salt solution. Given the estimated $10 \%$ random error in the analytical data, the actual and predicted concentrate metals and total solids concentrations (Table 14) match very well, being within $12 \%$ for the majority of analytes except $\mathrm{Si}$ and $\mathrm{Zr}$, and suggests the Envelope $\mathrm{C}$ simulant behaves similarly to an ideal mixture in this concentration range. 
By the same calculation method, the predicted anion concentrations (Table 15) were not found to compare as well, with the majority of analyzed species being overpredicted by at least $20 \%$ except fluoride, formate, nitrate, total hydroxide and total organic carbon. As verified by comparing feed analytical data to the simulant recipes, the SRTC method used for IC-Anion analysis was not specific ion selective and signal interferences were found to lead to high estimates for chloride, fluoride, and phosphate due to co-elution with formate, acetate, gluconate and other organic compounds present in the Envelope $\mathrm{C}$ simulant. Oxalate predictions are possibly high due to the precipitation of sodium oxalate as detected in the Final Boildown initial concentrate insoluble solids (see Final Boildown section), although the small quantities of insoluble solids are expected to have been included in the sample used for IC-Anion analysis.

\begin{tabular}{|c|c|c|c|c|c|}
\hline Analyte & \multicolumn{2}{|c|}{ Feed } & Concentrate & Concentrate Prediction & $\%$ Difference \\
\hline Chloride (mg/L) & 1308 & 2477 & 1559 & 2680 & 71.9 \\
\hline Fluoride $(\mathrm{mg} / \mathrm{L})$ & 2864 & 2455 & 3177 & 3766 & 18.5 \\
\hline Formate $(\mathrm{mg} / \mathrm{L})$ & 7179 & 6636 & 10105 & 9780 & 3.2 \\
\hline Nitrate $(\mathrm{mg} / \mathrm{L})$ & 145186 & 137961 & 188331 & 200456 & 6.4 \\
\hline Nitrite (mg/L) & 38751 & 36145 & 42364 & 53023 & 25.2 \\
\hline Oxalate $(\mathrm{mg} / \mathrm{L})$ & 1578 & 1306 & 1647 & 2042 & 24.0 \\
\hline Phosphate (mg/L) & 1529 & 2349 & 2148 & 2745 & 27.8 \\
\hline Sulfate $(\mathrm{mg} / \mathrm{L})$ & 5273 & 5297 & 5913 & 7483 & 26.6 \\
\hline Total $\mathrm{OH}^{-}(\mathrm{M})$ & 1.395 & 1.421 & 2.059 & 1.994 & 3.2 \\
\hline Free $\mathrm{OH}^{-}(\mathrm{M})$ & 0.553 & 0.561 & 0.987 & 0.789 & 20.1 \\
\hline & & & 15046 & 24795 & \\
\hline $\begin{array}{c}\text { Total Inorganic C (mg/L) } \\
\text { Total Organic C }(\mathrm{mg} / \mathrm{L})\end{array}$ & & & $\begin{array}{l}15046 \\
17328\end{array}$ & $\begin{array}{l}24795 \\
15674\end{array}$ & $\frac{64.8}{9.5}$ \\
\hline
\end{tabular}

Table 15. Actual concentrate anion concentrations versus prediction by volume additivity (ideal mixing behavior).

The good comparisons for major and/or highly soluble species such as nitrate, total hydroxide, formate and total organic carbon suggest analytical error which could account for up to $20 \%$ of the difference is not a major factor, although error in nitrite indicates the contrary. The unaccounted for sulfate $(1570 \mathrm{mg} / \mathrm{L})$ is sufficient to add $0.1 \mathrm{wt} \%$ insoluble solids that was not detected by X-ray diffraction of insoluble solids.

Tables 16 and 17 compare the simulant analytical data to the analytical data obtained for actual Hanford Tank AN-107 waste that has been pre-treated to the completion of Tc-99 removal by ion exchange (Fiskum ${ }^{27}$ ) to assess simulant quality. The first column in Tables 16 and 17 are the analytical data from Table 3.5 of Fiskum's report which is at a sodium concentration consistent with post-ion exchange solutions. The following two columns are calculated concentrations for each species in the Hanford waste at the concentrations used for the simulant steady state evaporator, assuming ideal mixing and that no species are lost to the condensate.

\footnotetext{
${ }^{27}$ Fiskum, S. K., Kurath, D. E., Rapko, B. M., "Development and Demonstration of a Sulfate Precipitation Process for Hanford Waste Tank 241-AN-107", PNWD-3050, BNFL-RPT-029, Rev. 0, Battelle, Pacific Northwest Division, Richland, WA, August, 2000.
} 
WSRC-TR-2000-00486

SRT-RPP-2000-00047

\begin{tabular}{|c|c|c|c|c|c|}
\hline & \multicolumn{5}{|c|}{ Concentration in $\mathrm{mg} / \mathrm{L}$} \\
\hline & \multicolumn{3}{|c|}{ Actual AN-107 Post Tc IX Material } & \multicolumn{2}{|c|}{ AN-107 Simulant } \\
\hline & Fiskum Data & $5.58 \mathrm{M} \mathrm{Na}$ Feed & $8.01 \mathrm{M} \mathrm{Na}$ Conc. & $5.58 \mathrm{M} \mathrm{Na}$ Feed & 8.01 M Na Conc. \\
\hline $\mathrm{Al}$ & 2340 & 2704 & 3882 & 230 & 328 \\
\hline $\mathrm{B}$ & 19 & 22 & 32 & 23 & 28.7 \\
\hline $\mathrm{Ca}$ & 172 & 199 & 285 & 152 & 202 \\
\hline $\mathrm{Cd}$ & 27 & 31 & 45 & $<0.14$ & $<0.2$ \\
\hline $\mathrm{Cr}$ & 43.0 & 50 & 71 & 0.5 & $<0.5$ \\
\hline $\mathrm{Cu}$ & 13 & 15 & 22 & 13 & 17.5 \\
\hline $\mathrm{Fe}$ & 8.6 & 10 & 14 & 35 & 47 \\
\hline$\overline{\mathrm{Mn}}$ & 1.4 & 1.6 & 2.3 & 18 & 22.4 \\
\hline Mo & 16.0 & 18 & 27 & 20 & 30.2 \\
\hline $\mathrm{Na}$ & 111000 & 128283 & 184148 & 128158 & 184200 \\
\hline $\mathrm{Ni}$ & 210 & 243 & 348 & 299 & 427 \\
\hline $\mathrm{P}$ & 302.0 & 349 & 501 & 290 & 376 \\
\hline $\mathrm{Pb}$ & 58 & 67 & 96 & $<2$ & $<7$ \\
\hline $\mathrm{Si}$ & 32 & 37 & 53 & 8.6 & 19.8 \\
\hline $\mathrm{Sr}$ & 130 & 150 & 216 & 77 & 106 \\
\hline $\mathrm{Zn}$ & 7.6 & 8.8 & 13 & 18 & 24.8 \\
\hline $\mathrm{Zr}$ & 2.9 & 3.4 & 5 & 1.9 & 1.9 \\
\hline
\end{tabular}

Table 16. Expected metals concentrations in Hanford AN-107 waste versus observed metals concentrations in the AN-107 simulant.

\begin{tabular}{|c|c|c|c|c|c|}
\hline & \multicolumn{5}{|c|}{ Concentration in $\mathrm{mg} / \mathrm{L}$} \\
\hline & \multicolumn{3}{|c|}{ Actual AN-107 Post Tc IX Material } & \multicolumn{2}{|c|}{ AN-107 Simulant (Averaged values) } \\
\hline & Fiskum Data & 5.6 M Na Feed & 8.01 M Na Conc. & 5.6 M Na Feed & 8.01 M Na Conc. \\
\hline $\mathrm{Na}(\mathrm{M})$ & 4.83 & 5.58 & 8.01 & 5.58 & 8.01 \\
\hline & & & & & \\
\hline Fluoride & 3500 & 4045 & 5806 & 2660 & 3177 \\
\hline Nitrate & 112000 & 129439 & 185807 & 141574 & 188331 \\
\hline Nitrite & 28800 & 33284 & 47779 & 37448 & 42364 \\
\hline Phosphate & 1400 & 1618 & 2323 & 1939 & 2148 \\
\hline Sulfate & 4020 & 4646 & 6639 & 5285 & 5913 \\
\hline Oxalate & 1400 & 1618 & 2323 & 1442 & 1647 \\
\hline
\end{tabular}

Table 17. Expected anion concentrations in Hanford AN-107 waste versus observed anion concentrations in the $\mathrm{AN}-107$ simulant.

The low cadmium, chromium and lead in the AN-107 simulant is because these components were not added to this "non-toxic" version. Good matches are found for boron, copper, molybdenum, nitrate and nitrite, with less favorable matches found for phosphate and sulfate. The Hanford waste is higher in aluminum, calcium, phosphorous, silicon, strontium, zirconium, fluoride and oxalate. The higher concentrations of iron, manganese, nickel, and zinc in the simulant suggest some dissolution of stainless steel components used during processing.

\begin{tabular}{|l|l|c|c|}
\hline \multirow{2}{*}{ Material } & \multicolumn{2}{|c|}{ Viscosity $(\mathrm{cP})$} \\
\cline { 3 - 4 } Simulated AN-107 & Feed $(5.6 \mathrm{M} \mathrm{Na})$ & $25^{\circ} \mathrm{C}$ & $50^{\circ} \mathrm{C}$ \\
\cline { 2 - 4 } & Concentrate $(8.0 \mathrm{M} \mathrm{Na})$ & 4.6 & 1.9 \\
\hline \multirow{2}{*}{ Hanford AN-107 } & $6 \mathrm{M} \mathrm{Na}$ & 8.3 & 3.9 \\
\cline { 2 - 4 } & $8 \mathrm{M} \mathrm{Na}$ & 8 & 4 \\
\hline
\end{tabular}

Table 18. Comparison of $\mathrm{AN}-107$ simulant feed and concentrate viscosity and 
actual Hanford $\mathrm{AN}-107$ waste at 25 and $50^{\circ} \mathrm{C}$.

Other data obtained relevant for evaporator operation is evaporator feed (5.6 $\mathrm{M} \mathrm{Na}$ ) and concentrate $(8.0 \mathrm{M} \mathrm{Na})$ viscosity shown in Table 18 at the ambient feed and the evaporator concentrate effluent temperatures. Viscosity, measured by a RV20 Haake rheometer (M5 measuring head with NV sensor), was found to decrease with temperature as expected, with the slightly greater percentage drop in the feed material likely due to increased dissolution of insoluble solids in the less concentrated salt solution. The increase in the viscosity with salt concentration may be due to slightly increased insoluble solids likely present in the concentrate, although this was not verifiable experimentally due to relatively high scatter in the insoluble solids determinations. The simulant at 5.6 and $8.0 \mathrm{M} \mathrm{Na}$ was found to be a Newtonian fluid, as was the actual Hanford waste at similar concentrations ${ }^{28}$. Although insoluble solids (IS) concentrations are not reported, the higher viscosities for the Hanford waste samples may be due to slightly greater IS content than in the simulant as evidenced by $60 \%$ by volume insoluble solids observed in the $9.7 \mathrm{M} \mathrm{Na}$ actual waste sample compared to $40 \%$ by volume (5.0 wt $\%$ ) insoluble solids content in $10 \mathrm{M} \mathrm{Na}$ simulated waste.

\subsection{Final Boildown}

Five days following the completion of the 75 hour steady-state evaporation, the remaining evaporator tank contents were boiled down to find the maximum $\mathrm{Na}$ concentration of the C-simulant concentrate before flow characteristics significantly deteriorate. The evaporator was again operated at -27.6 in $\mathrm{Hg}$ vacuum with a total natural and calibrated air-inleakage of $11.5 \mathrm{~mL} / \mathrm{min}$. From an initial $1630 \mathrm{~mL}$ evaporator tank volume, $30 \mathrm{~mL}$ concentrate samples were taken every 15 minutes, or every $48 \mathrm{~mL}$ of condensate produced at 3.2 $\mathrm{mL} / \mathrm{min}$ production rate, until the concentrate could not be pumped out through the $1 / 8$ " Teflon ${ }^{\circledR}$ concentrate line during the withdrawal of the fifth sample. Exhibiting a sharp transition, the evaporator concentrate within a 1-2 minute period went from a green semi-translucent liquid to a very viscous greenish-white gel. The top picture

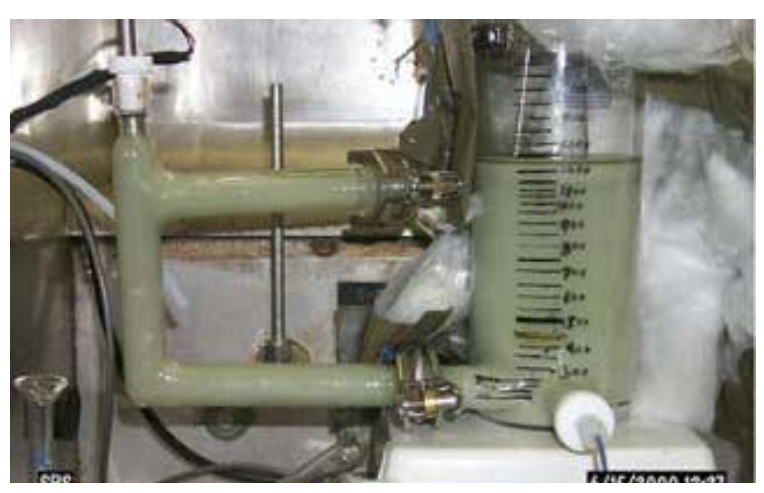

Figure 7. Boildown concentrate samples, first to last, with final concentrate in rear; final concentrate in evaporator.

\footnotetext{
${ }^{28}$ Bredt, P. R., Swoboda, R. G., "Rheological Studies on Pretreated Feed and Melter Feed from AW-101 and AN107”, BNFL-RPT-034, PNWD-3034, Rev. 0, Battelle, Pacific Northwest Division, Richalnd, WA, April, 2000.
} 
in Figure 7 shows the contrast between samples obtained prior to bulk saturation (front row, left to right, initial $\sim 8.0 \mathrm{M} \mathrm{Na}$ concentrate sample to progressively more concentrated) and the "near saturated" samples obtained (back row, right two bottles), and the bottom picture shows more clearly the color of the saturated solution in the evaporator. The stir bar in the evaporator tank was apparently only mixing the lower fourth of the tank contents after bulk saturation, and no recirculation was observed in the evaporator arm containing the heating rod. The final evaporator tank volume was $\sim 1250 \mathrm{~mL}$ after evaporator heating was discontinued, with $350 \mathrm{~mL}$ condensate produced. As in the steady-state operation, no antifoam was used in this experiment.

To obtain a sample of this bulk saturated concentrate that was removeable by pump, $36 \mathrm{~g}$ condensate was back-added by suction through the concentrate line to dilute the concentrate slightly, and agitation was increased to the maximum. However, viscosity of the gel-like concentrate limited dilution to the lower fourth of the evaporator, leaving the slurry in the heating arm and the bulk of the evaporator unaffected. Using the vacuum in the evaporator, mixing was accomplished by additionally sparging laboratory air in through the concentrate and feed lines as well as from the seal around the heating rod eventually creating a "pumpable" slurry. The final evaporator volume was $\sim 1290 \mathrm{~mL}$, and sparging had reduced the vacuum to $-23.4 \mathrm{in} \mathrm{Hg}$. The vacuum was then released, and the near-saturated concentrate was pumped out of the evaporator system.

Selected samples from the final boildown experiment were sent for total and insoluble solids, density, ICP-ES and XRD (X-ray diffraction) analysis (Table 19). The total solids analytical results indicates that the $\mathrm{AN}-107$ Envelope $\mathrm{C}$ simulated waste reaches bulk saturation at 48.6 $\mathrm{wt} \%$, which is equivalent to $94.6 \mathrm{~g}$ total salt (TS) per $100 \mathrm{~g}$ water at an estimated $10.1 \mathrm{M} \mathrm{Na}$ $\left(50^{\circ} \mathrm{C}\right)$. This extent of concentration before "first" solids formation is slightly exceeded by that for AN-105 Envelope A simulant ${ }^{29}$ (99 g TS/100 g water, $7.5 \mathrm{M} \mathrm{Na}$ at $50^{\circ} \mathrm{C}$ ), and is slightly higher than for AZ-101 Envelope B simulant ${ }^{30}$ (88-90 g TS/100 g water, 9.9-10.1 M Na at 50 ${ }^{\circ} \mathrm{C}$ ). The insoluble solids data and second experiment confirmed the sharp change in salt solution characteristics upon reaching bulk saturation, with measured insoluble solids content increasing approximately by a factor of 10 over a very slight change (calculated $\sim 0.1 \mathrm{M} \mathrm{Na}$ ) in salt concentration. X-ray diffraction data indicates that initial insoluble solids at $5.5 \mathrm{M} \mathrm{Na}$ are largely sodium oxalate, with sodium carbonate decahydrate appearing by $9.6 \mathrm{M}$ Na before the bulk salt, sodium nitrate, precipitates at the saturation point near $10.1 \mathrm{M} \mathrm{Na}$. Sodium nitrate and nitrite detected below saturation is a result of dried simulant that was the interstitial liquid in the insoluble solids filter cake.

\footnotetext{
${ }^{29}$ Calloway, Jr., T.B., "Evaporation of Hanford Envelope A Simulant (AN-105)", WSRC-TR-2000-00300, SRTRPP-2000-00010, Rev. 0, August, 2000.

${ }^{30}$ Calloway, Jr., T.B., Choi, A.S., Monson, P.R., "Evaporation of Hanford Envelope B Simulant (AZ-101) Preliminary Report”, BNF-003-98-0166, Rev. 1, January 6, 2000.
} 
WSRC-TR-2000-00486

SRT-RPP-2000-00047

\begin{tabular}{|c|c|c|c|c|c|c|c|c|}
\hline Property/Analyte & \multicolumn{2}{|c|}{ Initial Sample } & $\begin{array}{c}\text { Sample } \\
\text { \#2 }\end{array}$ & \multicolumn{2}{|c|}{ Sample \#4 } & Sample \#5 & \multicolumn{2}{|c|}{$\begin{array}{l}\text { Near-saturation } \\
\text { Sample }\end{array}$} \\
\hline Density & \multicolumn{2}{|c|}{1.380} & & \multicolumn{2}{|c|}{1.427} & & \multicolumn{2}{|c|}{1.437} \\
\hline Total Solids (wt.\%) & \multicolumn{2}{|c|}{42.9} & 45.4 & \multicolumn{2}{|c|}{46.8} & 48.6 & \multicolumn{2}{|c|}{48.6} \\
\hline $\begin{array}{c}\text { Insoluble Solids (wt.\%) } \\
\text { (std. dev.) }\end{array}$ & & & $\begin{array}{c}0.39 \\
(0.26) \\
\end{array}$ & & & $\begin{array}{c}0.43 \\
(0.02) \\
\end{array}$ & \multicolumn{2}{|c|}{$\begin{array}{c}4.99 \\
(0.15) \\
\end{array}$} \\
\hline $\begin{array}{l}\text { XRD-Identified } \\
\text { Insoluble Salts }\end{array}$ & \multicolumn{2}{|c|}{$\begin{array}{l}\text { Sodium Oxalate } \\
\text { Sodium Nitrate }\end{array}$} & & \multicolumn{2}{|c|}{$\begin{array}{l}\text { Sodium Oxalate } \\
\text { Sodium } \\
\text { Carbonate } \\
\text { Sodium Nitrite } \\
\text { Sodium Nitrate }\end{array}$} & & \multicolumn{2}{|c|}{$\begin{array}{l}\text { Sodium Oxalate } \\
\text { Sodium Carbonate } \\
\text { Sodium Nitrite } \\
\text { Sodium Nitrate }\end{array}$} \\
\hline \multicolumn{9}{|l|}{ ICP-ES Data } \\
\hline $\mathrm{Al}(\mathrm{mg} / \mathrm{L})$ & 328 & 317 & & 364 & 364 & & 385 & 390 \\
\hline $\mathrm{B}(\mathrm{mg} / \mathrm{L})$ & 32 & 32 & & 36 & 36 & & 38 & 38 \\
\hline $\mathrm{Ba}(\mathrm{mg} / \mathrm{L})$ & $<0.12$ & $<0.12$ & & $<0.12$ & $<0.12$ & & $<0.12$ & $<0.12$ \\
\hline $\mathrm{Ca}(\mathrm{mg} / \mathrm{L})$ & 202 & 199 & & 228 & 227 & & 241 & 242 \\
\hline $\mathrm{Cd}(\mathrm{mg} / \mathrm{L})$ & $<0.14$ & $<0.14$ & & $<0.14$ & $<0.14$ & & $<0.14$ & $<0.14$ \\
\hline $\mathrm{Cr}(\mathrm{mg} / \mathrm{L})$ & $<1$ & $<1$ & & $<1$ & $<1$ & & $<1$ & $<1$ \\
\hline $\mathrm{Cu}(\mathrm{mg} / \mathrm{L})$ & 17 & 16 & & 19 & 18 & & 19 & 19 \\
\hline $\mathrm{Fe}(\mathrm{mg} / \mathrm{L})$ & 36 & 35 & & 42 & 41 & & 46 & 45 \\
\hline $\mathrm{La}(\mathrm{mg} / \mathrm{L})$ & 1 & 1 & & 2 & 2 & & 2 & 2 \\
\hline $\mathrm{Li}(\mathrm{mg} / \mathrm{L})$ & $<1$ & $<1$ & & $<1$ & $<1$ & & $<1$ & $<1$ \\
\hline $\mathrm{Mg}(\mathrm{mg} / \mathrm{L})$ & $<0.84$ & $<0.84$ & & $<0.84$ & $<0.84$ & & $<0.84$ & $<0.84$ \\
\hline $\mathrm{Mn}(\mathrm{mg} / \mathrm{L})$ & 2 & 2 & & 2 & 2 & & 3 & 3 \\
\hline Mo (mg/L) & 30 & 30 & & 35 & 33 & & 37 & 36 \\
\hline $\mathrm{Na}(\mathrm{mg} / \mathrm{L})$ & 192591 & 191150 & & 222691 & 221667 & & 207326 & 216559 \\
\hline $\mathrm{Ni}(\mathrm{mg} / \mathrm{L})$ & 424 & 414 & & 473 & 474 & & 501 & 507 \\
\hline $\mathrm{P}(\mathrm{mg} / \mathrm{L})$ & 405 & 396 & & 463 & 447 & & 440 & 451 \\
\hline $\mathrm{Pb}(\mathrm{mg} / \mathrm{L})$ & $<6.8$ & $<6.8$ & & $<6.8$ & $<6.8$ & & $<6.8$ & $<6.8$ \\
\hline Si (mg/L) & 23 & 22 & & 29 & 28 & & 32 & 31 \\
\hline $\mathrm{Sn}(\mathrm{mg} / \mathrm{L})$ & $<1.3$ & $<1.3$ & & $<1.3$ & $<1.3$ & & $<1.3$ & $<1.3$ \\
\hline $\mathrm{Sr}(\mathrm{mg} / \mathrm{L})$ & 110 & 109 & & 125 & 124 & & 130 & 130 \\
\hline $\mathrm{Ti}(\mathrm{mg} / \mathrm{L})$ & 0.2 & $<0.02$ & & $<0.02$ & 0.1 & & $<0.02$ & $<0.02$ \\
\hline $\mathrm{V}(\mathrm{mg} / \mathrm{L})$ & $<1.4$ & $<1.4$ & & $<1.4$ & $<1.4$ & & $<1.4$ & $<1.4$ \\
\hline $\mathrm{Zn}(\mathrm{mg} / \mathrm{L})$ & 24 & 24 & & 27 & 26 & & 29 & 29 \\
\hline $\mathrm{Zr}(\mathrm{mg} / \mathrm{L})$ & $<3.7$ & $<3.7$ & & $<3.7$ & $<3.7$ & & $<3.7$ & $<3.7$ \\
\hline $\mathrm{K}(\mathrm{mg} / \mathrm{L})$ & 1740 & 1700 & & 1943 & 1952 & & 2074 & 2103 \\
\hline $\mathrm{S}(\mathrm{mg} / \mathrm{L})$ & 2279 & 2237 & & 2539 & 2457 & & 2688 & 2654 \\
\hline $\mathrm{Ag}(\mathrm{mg} / \mathrm{L})$ & $<5$ & $<5$ & & $<5$ & $<5$ & & $<5$ & $<5$ \\
\hline $\mathrm{Na}(\mathrm{M})$ & 8.38 & 8.31 & & 9.69 & 9.64 & & \multicolumn{2}{|c|}{$(9.22)$} \\
\hline $\mathrm{Na}(\mathrm{M})$ - predicted & \multicolumn{2}{|c|}{8.35 (basis) } & 8.92 & \multicolumn{2}{|c|}{9.65} & 10.08 & \multicolumn{2}{|c|}{10.16} \\
\hline Tot. Solids (wt\%)-pred. & \multicolumn{2}{|c|}{42.9 (basis) } & 45.0 & & & 49.0 & & \\
\hline
\end{tabular}

Table 19. Final Boildown Sample Analytical Results.

Predicted values for $\mathrm{Na}$ concentration and total solids were calculated based on condensate production data using as a basis: 1) SRTC data for Na obtained by ICP-ES, 2) total solids obtained by oven-drying for an initial boildown sample taken before evaporator heat input, 3) assuming volumes are additive (ideal mixing), and 4) assuming condensate produced is pure water. Predicted and average actual $\mathrm{Na}$ concentrations were within $0.2 \%$ for Sample \#4, but did not match well for the near saturation sample due to sampling error. The 9.2 $\mathrm{M}$ Na average value obtained for the near saturation sample is low because only the filtrate of the sample, known to precipitate solids after filtration, was analyzed. A repeat analysis of the near saturation sample was attempted omitting filtration and using a heated sample to dissolve insoluble solids prior to drawing an aliquot for analysis, but nearly identical sodium concentrations (207861 and 215038 $\mathrm{mg} / \mathrm{L}$ ) were obtained likely because of solids recrystallization inside the sampling pipette. Given the uncertainties in the initial values used in the calculations due to sample splattering described 
below and the measured condensate volumes, the predicted and actual total solids also compared well (less than $0.6 \mathrm{wt} \%$ difference), with the predicted value initially lower before tending high.

The insoluble solids results reflect the observation that the change to bulk saturation (between Sample \#5 and "Near Saturation" sample) is very sudden, occurring within $\sim 10-20 \mathrm{~mL}$ of condensate produced. Despite the uncertainty in the duplicate measurements, the quantity of settled insoluble solids visually observed in Figure 7 combined with the data for select samples in Table 19 indicate that the measured insoluble solids content is very possibly already above the target evaporation endpoint of $0.1 \mathrm{wt} \%$ insoluble solids simply from steady state concentration to 8.3 $\mathrm{M} \mathrm{Na}$. If this is true, this work has demonstrated that evaporation operations were not significantly impacted due to higher than $0.1 \mathrm{wt} \%$ insoluble solids.

Insoluble solids measurements were obtained by vacuum filtration of a known mass of sample through a pre-weighed $0.22 \mu \mathrm{m}$ cellulose filter, and oven drying the filter cake. Insoluble solids analytical results for the initial sample and sample \#4 are not listed in Table 19 due to wide scatter caused by an overly aggressive drying procedure initially used, which led to splattering of neighboring total solids samples onto the insoluble solids samples as well as possible splattering of the insoluble samples themselves. The initial approach, using sample 4 with the initial and near saturation samples, was based on earlier sample analysis completed on the same simulant at similar concentrations, where a three-day schedule of heating at 105,120 , and $145^{\circ} \mathrm{C}$ for 24 hours each was found to be sufficient. Probably due to smaller simulant quantities used in the second attempt, the near saturated concentrate samples showed the most significant splatter visually, yielding a measured total solids content of only $42.6 \mathrm{wt} \%$ similar to the initial sample. This suggests that voilent boiling of a viscous near-saturated concentrate caused the sample loss, suggesting that the total solids for sample 4 and initial sample results may be affected but to a lesser degree. However this splattering led to wide scatter in the insoluble solids results whose tests could not be repeated due to limited sample. Hence, samples 2 and 5 were selected as surrogates for the initial sample and sample 4, and the analysis was repeated for the near saturation sample. For this second attempt, a very conservative approach was used within initial heating to dryness at $90^{\circ} \mathrm{C}$ for 24 hours, followed by 24 hours at $105^{\circ} \mathrm{C}, 31$ hours at $120^{\circ} \mathrm{C}$, and drying to constant weight at $135^{\circ} \mathrm{C}(46$ hours). The insoluble solids samples were dried with the total solids samples, with some samples requiring an additional 48-60 hours of additional drying at $135^{\circ} \mathrm{C}$. This latter approach yielded more consistent data.

Another detail embedded in the insoluble solids data is a correction for solids produced from the drying of interstitial liquids in the filter cake as well as in filter paper used to capture the sample. A procedure was devised at SRTC by Charles Coleman, where a correction for the interstitial liquids could be estimated by wetting pre-weighed filter paper with the filtrate produced from insoluble solids filtration. The dried filtrate on the wetted paper mass could be used to subtract from the dried insoluble solids filter cake on filter paper. However when executing this procedure with the highly concentrated salt solutions generated during the final boildown, the filtrate was found to precipitate solids continually with time yielding a scatter of several fold sometimes yielding a correction larger than the sample mass itself. As a result, an average of three reasonable correction masses from the most dilute samples, initial sample and sample 2, was used as a correction for the interstitial liquid contribution in all cases. It is recognized that 
interstitial liquid contributions are likely to rise with increasing insoluble solids content, but insufficient data was available to account for this effect.

Table 20 compares the observed near-saturation concentrate anion concentration and predictions calculated by assuming ideal mixing and a pure water condensate produced from concentrating the 5.6 M Na feed. Similar to the 8.0 M Na data for the concentrate produced during steady state evaporation (Table 15), 1) agreement was good for the very soluble species nitrate and formate, and 2) other observed concentrations are 25-82\% low compared to predictions. As Table 12 and 13 showed, no significant amount of the measured species were carried over into the condensate indicating that SRTC IC-Anion measurements tend to underestimate anion quantities in Hanford simulants significantly as the salt concentration increases beyond $8.0 \mathrm{M} \mathrm{Na}$.

\begin{tabular}{|c|c|c|c|c|c|c|}
\hline Analyte & \multirow{2}{*}{\multicolumn{2}{|c|}{$\begin{array}{c}\text { Feed } \\
5.58\end{array}$}} & $\begin{array}{c}\text { Concentrate } \\
\text { Prediction }\end{array}$ & \multicolumn{2}{|c|}{ Concentrate } & $\begin{array}{c}\text { Average } \\
\% \text { Difference }\end{array}$ \\
\hline $\mathrm{Na}(\mathrm{M})$ & & & 10.16 & $10.16(\epsilon$ & ated) & \\
\hline Chloride (mg/L) & 1308 & 2477 & 3446 & 1724 & 1740 & 50 \\
\hline Fluoride (mg/L) & 2864 & 2455 & 4842 & 3561 & 3599 & 26 \\
\hline Formate (mg/L) & 7179 & 6636 & 12577 & 11020 & 11412 & 11 \\
\hline Nitrate (mg/L) & 145186 & 137961 & 257775 & 236007 & 236839 & 8 \\
\hline Nitrite (mg/L) & 38751 & 36145 & 68185 & 51839 & 53619 & 23 \\
\hline Oxalate (mg/L) & 1578 & 1306 & 2626 & 509 & 455 & 82 \\
\hline Phosphate (mg/L) & 1529 & 2349 & 3531 & 1118 & 1271 & 66 \\
\hline
\end{tabular}

Table 20. Actual concentrate anion concentrations versus prediction by volume additivity (ideal mixing behavior).

Despite these limitations in the data, Table 19 does indicate that the assumptions of volume additivity (ideal mixing) and pure water condensate can predict reasonably well basic bulk solution properties for AN-107 simulant evaporation.

\subsection{OLI Model Comparison}

After resolving the model input charge balance to simulant analytical data, Choi $^{31}$ initially employed OLI models to predict the endpoint where total insoluble solids would exceed 0.2 $\mathrm{wt} \%$. The constructed model predicted saturation at over $11 \mathrm{M} \mathrm{Na}$ where sodium nitrate would precipitate, matching reasonably well with the experimental $10.1 \mathrm{M} \mathrm{Na}$ final boildown concentration where the simulated waste suddenly transformed into a viscous gel-like slurry.

Choi subsequently added into the model the 14 target organic compounds to predict their distribution between the produced condensate, concentrate and off-gas during steady state evaporation from 5.8 M Na to $8.0 \mathrm{M} \mathrm{Na}$ (See Appendix C for summary of model output). Table 21 provides a comparison of the experimental values and the OLI model predicted values for

\footnotetext{
${ }^{31}$ Choi, A. S., forthcoming report for Hanford Tank AN-107 Envelope C-simulant evaporation OLI modeling, 2001.
} 
distribution of the 14 target organic compounds between the condensate, concentrate, and off-gas phases.

\begin{tabular}{|c|c|c|c|c|c|c|c|c|}
\hline & \multirow{2}{*}{\multicolumn{6}{|c|}{$\%$ of total feed }} & \multirow{4}{*}{$\begin{array}{c}\text { Condensor } \\
\text { Vent } \\
\text { (ug/g) }\end{array}$} \\
\hline & & & & & & & & \\
\hline & & \multicolumn{3}{|c|}{ EXPERIMENTAL DATA } & \multicolumn{3}{|c|}{ OLI Model Prediction } & \\
\hline & Target Organic & Condensate & Concentrate & Off-gas & Condensate & Concentrate & Off-gas & \\
\hline \multirow{6}{*}{ 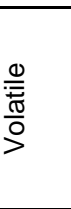 } & Benzene & 0.7 & $0.3^{*}$ & 89.8 & 0.4 & 0.0 & 99.5 & 723 \\
\hline & 4-methyl-2-pentanone (MIBK) & $2.1^{*}$ & $1.8^{*}$ & 66.8 & 11.9 & 0.2 & 87.9 & 963 \\
\hline & Toluene & 0.8 & $0.6^{*}$ & 55.0 & 0.4 & 0.0 & 99.6 & 330 \\
\hline & 1,2-dibromoethane & 18.6 & $2.0^{*}$ & 331.7 & 3.5 & 0.1 & 96.4 & 135 \\
\hline & Chlorobenzene & 1.2 & $0.4^{*}$ & 39.0 & 0.9 & 0.0 & 99.1 & 258 \\
\hline & 1,2,3-trichloropropane & $5.6^{*}$ & $16.2^{*}$ & 0.1 & 4.9 & 0.1 & 95.1 & 0 \\
\hline \multirow{7}{*}{ 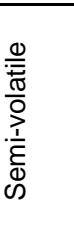 } & 1,2,4-trichlorobenzene & 4.4 & $6.6^{*}$ & 86.1 & 0.9 & 0.0 & 99.0 & 315 \\
\hline & Naphthalene & 16.9 & $3.1^{*}$ & 79.3 & 2.8 & 0.0 & 97.2 & 274 \\
\hline & Hexachlorobenzene & 0.1 & $71.3^{*}$ & 3.0 & 0.0 & 100.0 & 0.0 & 0 \\
\hline & Pentachlorophenol & 0.0 & 174.0 & 0.0 & 77.8 & 19.4 & 2.8 & 0 \\
\hline & Pyrene & 4.7 & $56.5^{*}$ & 2.1 & 88.3 & 6.0 & 5.6 & 0 \\
\hline & Bis(ethylhexyl)phthalate (BEHP) & 0.1 & $61.2^{*}$ & 0.0 & 12.6 & 87.4 & 0.0 & 0 \\
\hline & Benzo(a)pyrene & 0.0 & $55.4^{*}$ & 0.0 & 0.0 & 100.0 & 0.0 & 0 \\
\hline $\begin{array}{l}\text { Pest- } \\
\text { icide }\end{array}$ & Aldrin & 0.8 & $78.1^{*}$ & 0.0 & 67.7 & 31.3 & 1.0 & 0 \\
\hline
\end{tabular}

Table 21. Experimental and OLI model predicted organics distribution as a percentage of each species fed, with calculated evaporator condensor vent species concentrations.

Despite Quality Assurance qualification of some experimental values (in yellow/italic), the OLI model generally correctly predicted the relative partitioning of each target organic between condensate, concentrate and off-gas, with all volatiles and light semivolatiles (1,2,4trichlorobenzene and naphthalene) exiting the evaporator system through the off-gas and the heavier semi-volatiles examined remaining predominantly in the evaporator concentrate. The notable exceptions were pentachlorophenol, pyrene and Aldrin where the model predicted would mostly accumulate in the evaporator condensate. This is likely due to the model predicting a separate organic phase in all aqueous streams, and possibly not accounting for secondary interactions between water and acetone to assist in the dissolution of the heavier organic compounds into the Hanford waste simulant. The organic phase in the feed was predicted to consist mainly of aldrin, BEHP, pyrene, naphthalene, and 1,2,4-trichlorobenzene. The majority of the aldrin, pyrene, and some BEHP would evaporate to form the organic layer in the condensate, while pentachlorophenol was deposited in the condensate aqueous phase. Benzo[a]pyrene was predicted to not dissolve significantly, and flowed through the model evaporator mostly in the solid phase.

The experimentally determined quantity of 1,2,3-trichloropropane in the off-gas is again expected to be low as BWXT Services, Inc. expected chemical degradation on the sorbent material or during extraction from the sorbent material.

Another notable difference between OLI model predictions and experimental data is the quantity of BEHP in the condensate. As discussed earlier, regulatory data was used to the greatest extent possible when valid data existed, with the BWXT Services regulatory results not detecting BEHP in the condensate in 5 samples and slightly $(12 \mu \mathrm{g} / \mathrm{L})$ in 1 sample. However, in-house SRTC analysis of four other condensate samples taken throughout the experiment all showed significant BEHP concentrations $(320-360 \mu \mathrm{g} / \mathrm{L})$. If the in-house analytical results for condensate BEHP 
were used instead, the percentage of feed BEHP exiting the evaporator dissolved in the condensate would rise to approximately $10.2 \%$, similar to the $12.6 \%$ OLI model prediction. Unsuccessful attempts were made to identify potential causes for the discrepancy, such as sample preparation, sample storage containers, and analytical sample preparation. The only significant difference was that the in-house sample was refrigerated a few weeks longer than the regulatory sample prior to analysis, but BEHP contamination into a refrigerated sealed zero-headspace sample is not considered likely. As a result, both results are reported here.

Lastly for evaporator design purposes, total quantities of volatilized species detected in the offgas samplers were divided by the total mass of air in-leaked at $11.5 \mathrm{~mL} / \mathrm{min}$ for their respective sampling event to estimate the concentration of each target organic compound present in the evaporator condensor vent stream. The volatiles and light semi-volatile condensor vent concentrations are high due to the high input of these target organic compounds through the feed, the high degree of volatilization, and the low volume of air-inleakage.

\subsection{Conclusion/Summary}

The following was found from the regulatory off-gas sampling from the evaporation of Hanford RPP Tank AN-107 (Envelope C) simulated waste spiked with 14 (1.03 ppm theoretical concentration) volatiles, semi-volatiles, and pesticide target compounds:

- Steady state evaporation

- Volatiles and light semi-volatiles (1,2,4-trichlorobenzene and naphthalene) almost completely exit the evaporator system in the off-gas.

- Maximum target organic compound concentrations in the condensor vent gas were calculated to be approximately $130-970$ ppm for lighter volatile compounds such as benzene and methyl iso-butyl ketone (MIBK).

- Heavier semi-volatiles appear to remain in the evaporator concentrate, with slight quantities observed in the condensate and non-detection in the off-gas sampling

- Pesticides appear to behave as a heavier semi-volatile organic compound

- Final boildown

- At saturation, the bulk solubility of the waste was found to be approximately 94.6 $\mathrm{g}$ total salt (TS) per $100 \mathrm{~g}$ water at an estimated $10.1 \mathrm{M} \mathrm{Na}$, or equivalently 48.6 wt $\%$ total solids. 
- Insoluble solids increase only slightly during concentration from approximately $8.3 \mathrm{M} \mathrm{Na}$.

- Sodium oxalate is the initial insoluble solid, and is followed by sodium carbonate decahydrate formation during concentration before saturation.

- A very sharp transition to saturation at approximately $10.1 \mathrm{M} \mathrm{Na}$ concentrate concentration was observed, suggesting a major salt such as nitrate precipitated.

- OLI Modeling Results

- An OLI model used to simulate evaporation predicted the saturation endpoint reasonably and predicted solution behavior at saturation well.

- An OLI model incorporating the 14 target organic compounds predicted trends in the volatiles and semi-volatiles well, except pentachlorophenol, pyrene and aldrin. The model predicted a separate organic phase for all aqueous streams and nondissolution of benzo[a]pyrene into the simulated waste, possibly accounting for the prediction discrepancies.

- The ICP-ES analytical results from both steady-state evaporation and final boildown suggest Hanford RPP Tank AN-107 Envelope C waste simulant appears to behave as an ideal mixture. IC-Anion data for soluble species such as nitrate and formate appears to support this, but other species do not possibly due to precipitation of small quantities of solids.

- No anti-foaming agent was needed for the evaporation or boildown of the AN-107 waste simulant.

- No evaporator scaling was observed, and the salt solution behaved as a Newtonian fluid.

- A novel method was developed to produce and stably store a Hanford caustic waste simulant spiked with volatile and semi-volatile organic compounds. 


\subsection{Quality Assurance}

This work was carried out in accordance to the Task Technical and Quality Assurance Plan for Bench Scale LAW Evaporation with Simulants, T. B. Calloway, D. P. Lambert, BNF-003-990056, January 4, 2000. Other QA and QC programs applied to the testing described in this technical report include SRTC procedures for control of measurement and testing equipment (M\&TE), control of laboratory notebooks, and routine ADS QA and QC ${ }^{32,33,34}$. The QA program applied by SRTC for preparation and analysis of the AN-107 simulant evaporation samples complies with the requirements of NQA-1.

Analytic standards were required for all analyses performed for this study. Use of these standards is part of routine ADS QA and QC and are part of the procedures in Manual L16.1 for the operating the analytical instrument.

All M\&TE used to perform the evaporation and vitrification experiments was used within the specified calibration period. Calibrations were verified as required for each mass balance instrument. A record of the calibration was routinely maintained in the logbook designated for that piece of equipment.

All laboratory data obtained in the tasks described in this technical report are included as permanent record in Hiroshi Saito's WSRC laboratory notebook WSRC-NB-2000-00043. Regulatory analytical data received from BWXT Services, Inc. is kept as permanent record in the three-ring binders labeled as: Data Package for AN-107 Envelope C-Simulant Regulatory Evaporation, D. M. Ferrara, WSRC-TR-2000-00528, SRT-RPP-2000-00062, December, 2000. SRTC QC validation of the regulatory analytical data is recorded in Report of Analytical Data Validation of Regulatory Analyses for SRTC Contract WFO-98-003: Envelope C Simulant Samples; Rev. 0, Kubilius, W., ESH-EMS-2000761, August 24, 2000. SRTC QA also performed a surveillance of sample preparation and sample packaging of the Envelope $\mathrm{C}$ simulant samples for regulatory analysis at BWXT Services, Inc. (BNFL Envelope C Simulant Sample Preparation and Packaging (U), S. A. Martin, L. D. Prince, 2000-SUR-11-00015, June 22, 2000). No deviations from the Run Plan or Task Technical and Quality Assurance Plans were found.

\footnotetext{
${ }^{32}$ Westinghouse Savannah River Company, "WSRC 1Q Quality Assurance Manual”, Manual 1Q, current revision.

${ }^{33}$ Westinghouse Savannah River Company, "WSRC L1 Savannah River Technology Center Procedures Manual”, current revision.

${ }^{34}$ Westinghouse Savannah River Company, "WSRC L16.1 Analytical Development Section Analytical Operating Procedures Manual", current revision.
} 


\subsection{Acknowledgments}

The results presented in this report are the product of the efforts of a task team made up of over twenty individuals at the Savannah River Site, BWX Technologies, Inc. (BWXT) Y-12, L.L.C., BWXT Services, Inc. and the Southwest Research Institute (SWRI). The success of this program was only possible because of the exceptional teamwork of these individuals. The authors would like to thank: Frances Williams and Nick Odom (Immobilization Technology Section, ITS) for extraordinary efforts to obtain and organize critical resources and supplies; Mary Moss, Vicki Williams, Sammie King, John Duvall, Tony Burkhalter (ITS) for valuable help in executing the experiments and packaging samples for shipment; Bill Stagg and Paul Macek (BWXT Services, Inc.) for their critical help coordinating regulatory sample shipping and analysis, and resolving analytical issues; Chee-Kai Tan (SWRI) for his timely help preparing sorbent tubes; John Young and Steve Crump (Analytical Development Section) for valuable technical input for organic spike development and timely chemical analyses; Alfred "Boots" Camp and Susan Jergensen for their help resolving Hazardous Materials Transport issues; Gary Dobos and Curt Sexton (SRS Glass Shop) for valuable input enhancing glassware design and for supplying critical parts; and Brad Stinnett (BWXT Y-12) for assistance with the off-gas sampling. 


\section{Appendices}

\section{Appendix A - Envelope C (AN-107) Simulant Recipe}

\section{A. Supernate recipe}

\begin{tabular}{|c|c|c|c|}
\hline \multicolumn{3}{|c|}{ Complete Envelope C Supernate Recipe at 7 Molar Na+ } & \\
\hline (valid as of $6 / 22 / 99$ ) & & & \\
\hline Volume of Feed & & & Need, g \\
\hline 1000 & $\mathrm{~mL}$ & Fill the container with water & 200 \\
\hline
\end{tabular}

\begin{tabular}{|c|c|c|c|}
\hline Compounds & Formula & Conc., PPM & M \\
\hline Calcium Nitrate & $\mathrm{Ca}(\mathrm{NO} 3) 2.4 \mathrm{H} 2 \mathrm{O}$ & 2083 & $1.18 \mathrm{E}-02$ \\
\hline Cerium Nitrate & $\mathrm{Ce}(\mathrm{NO} 3) 3.6 \mathrm{H} 2 \mathrm{O}$ & 98 & 3.01E-04 \\
\hline Cesium Nitrate & $\mathrm{CsNO} 3$ & 14 & $9.58 \mathrm{E}-05$ \\
\hline Copper Nitrate & $\mathrm{Cu}(\mathrm{NO} 3) 2.2 .5 \mathrm{H} 2 \mathrm{O}$ & 66 & $3.78 \mathrm{E}-04$ \\
\hline Ferric Nitrate & $\mathrm{Fe}(\mathrm{NO} 3) 3.9 \mathrm{H} 2 \mathrm{O}$ & 7315 & $2.42 \mathrm{E}-02$ \\
\hline Lanthanum Nitrate & $\mathrm{La}(\mathrm{NO} 3) 3.6 \mathrm{H} 2 \mathrm{O}$ & 85 & $2.61 \mathrm{E}-04$ \\
\hline Lead nitrate & $\mathrm{Pb}(\mathrm{NO} 3) 2$ & 0 & $0.00 \mathrm{E}+00$ \\
\hline Magnesium Nitrate & $\mathrm{Mg}(\mathrm{NO} 3) 2.6 \mathrm{H} 2 \mathrm{O}$ & 158 & $8.21 \mathrm{E}-04$ \\
\hline Manganous Chloride & $\mathrm{MnCl} 2.4 \mathrm{H} 2 \mathrm{O}$ & 1213 & $8.18 \mathrm{E}-03$ \\
\hline Neodymium Nitrate & $\mathrm{Nd}(\mathrm{NO} 3) 3.6 \mathrm{H} 2 \mathrm{O}$ & 174 & $5.31 \mathrm{E}-04$ \\
\hline Nickel Nitrate & $\mathrm{Ni}(\mathrm{NO} 3) 2.6 \mathrm{H} 2 \mathrm{O}$ & 1571 & $7.21 \mathrm{E}-03$ \\
\hline Potassium Nitrate & KNO3 & 2755 & $3.64 \mathrm{E}-02$ \\
\hline Strontium Nitrate & $\mathrm{Sr}(\mathrm{NO} 3) 2$ & 8 & $5.16 \mathrm{E}-05$ \\
\hline Zinc Nitrate & $\mathrm{Zn}(\mathrm{NO} 3) 2.6 \mathrm{H} 2 \mathrm{O}$ & 123 & 5.53E-04 \\
\hline yyl Nitrate & & 114 & $6.13 \mathrm{E}-04$ \\
\hline EDTA $^{*}$ & Na2EDTA & 4343 & $1.56 \mathrm{E}-02$ \\
\hline HEDTA $^{*}$ & HEDTA & 1294 & $6.21 \mathrm{E}-03$ \\
\hline Sodium Gluconate & & 2349 & 1.44E-02 \\
\hline Glycolic Acid & & 16112 & 1.98E-01 \\
\hline Citric Acid & & 5648 & $3.59 \mathrm{E}-02$ \\
\hline Nitrilotriacetic Acid & & 341 & $2.38 \mathrm{E}-03$ \\
\hline Iminodiacetic Acid & & 3613 & $3.62 \mathrm{E}-02$ \\
\hline Boric acid & $\mathrm{H} 3 \mathrm{BO} 3$ & 120 & $2.58 \mathrm{E}-03$ \\
\hline Sodium Chloride & $\mathrm{NaCl}$ & 1088 & $2.48 \mathrm{E}-02$ \\
\hline Sodium Fluoride & $\mathrm{NaF}$ & 176 & $5.59 \mathrm{E}-03$ \\
\hline Sodium Chromate & $\mathrm{Na} 2 \mathrm{CrO} 4$ & 0 & $0.00 \mathrm{E}+00$ \\
\hline Sodium Sulfate & $\mathrm{Na2SO} 4$ & 7299 & $6.86 \mathrm{E}-02$ \\
\hline Potassium Molybdate & K2MoO4 & 53 & $2.98 \mathrm{E}-04$ \\
\hline
\end{tabular}

Need

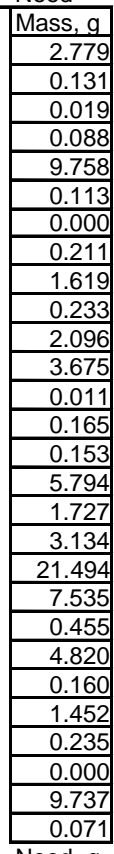

In separate container mix the following: Fill the container with water 200

\begin{tabular}{|c|c|c|c|c|}
\hline Add & Formula & Conc., PPM & $\mathbf{M}$ & Need, $\mathrm{g}$ \\
\hline Sodium Hydroxide & $\mathrm{NaOH}$ & 15047 & $5.02 \mathrm{E}-01$ & 20.073 \\
\hline Aluminum Nitrate & $\mathrm{Al}(\mathrm{NO} 3) 3.9 \mathrm{H} 2 \mathrm{O}$ & 3211 & $1.14 \mathrm{E}-02$ & 4.284 \\
\hline Sodium Phosphate & $\mathrm{Na3PO} 4.12 \mathrm{H} 2 \mathrm{O}$ & 2658 & 9.33E-03 & 3.546 \\
\hline Sodium Formate & $\mathrm{NaHCOO}$ & 9401 & $1.84 \mathrm{E}-01$ & 12.541 \\
\hline Sodium Acetate & $\mathrm{NaCH} 3 \mathrm{COO} .3 \mathrm{H} 2 \mathrm{O}$ & 1418 & 1.39E-02 & 1.891 \\
\hline Sodium Oxalate & \begin{tabular}{|l|l|}
$\mathrm{Na} 2 \mathrm{C} 2 \mathrm{O} 4$ & \\
\end{tabular} & 752 & $7.49 \mathrm{E}-03$ & 1.004 \\
\hline \multicolumn{5}{|c|}{ 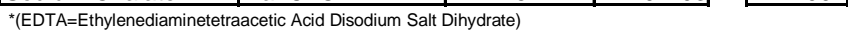 } \\
\hline \multicolumn{5}{|c|}{${ }^{*}(\mathrm{HETDA}=\mathrm{N}-(2-\mathrm{Hydroxyethyl)ethylenediaminetriacetic} \mathrm{Acid))}$} \\
\hline \multicolumn{5}{|c|}{ Mix thoroughly. Then add this solution to the container. Then } \\
\hline Add & Formula & Conc., PPM & $\mathbf{M}$ & Need, $\mathrm{g}$ \\
\hline Sodium Carbonate & $\mathrm{Na} 2 \mathrm{CO} 3$ & 88703 & $1.12 \mathrm{E}+00$ & 118.330 \\
\hline
\end{tabular}

Mix thoroughly. Then
\begin{tabular}{|l|l|c|c|r|}
\hline Add & Formula & Conc., PPM & M & \\
\hline Sodium Nitrate & NaNO3 & 178069 & $2.79 \mathrm{E}+00$ \\
\hline Sodium Nitrite & NaNO2 & 54741 & $1.06 \mathrm{E}+00$ \\
\cline { 1 - 3 } & 237.544 \\
\hline
\end{tabular}

Mix thoroughly and dilute to the mark.

The final addition of water would be $=385.02$ grams

(grams based upon a density of $1.334 \mathrm{~g} / \mathrm{mL}$ )

\begin{tabular}{|l|l|l}
\hline Final Weight, grams & 1334.00 \\
\hline
\end{tabular} 


\section{B. Entrained solids recipe}

\section{Envelope C Entrained Solids}

\begin{tabular}{|c|c|}
\hline Approximate Supernate Volume & $1000.0 \mathrm{~mL}$ \\
\hline Approximate Supernate Density & $1.334 \mathrm{~g} / \mathrm{mL}$ \\
\hline Approximate Supernate Mass & 1334.0 grams \\
\hline At 0.5 wt $\%$ solids loading & 6.70 grams \\
\hline Total Mass Supernate + Solids & 1340.7 grams \\
\hline
\end{tabular}

\begin{tabular}{|c|c|c|c|}
\hline Compound & Compound & Concentration & Needed \\
\hline Name & Formula & $\mathrm{g} / 100 \mathrm{~g}$ solids & grams \\
\hline Alumina & $\mathrm{Al} 2 \mathrm{O} 3$ & $5.10 \%$ & 0.34 \\
\hline Calcium Phosphate, tribasic & $\mathrm{Ca3}(\mathrm{PO} 4) 2$ & $0.10 \%$ & 0.01 \\
\hline Chromium Oxide & Cr2O3 & $0.40 \%$ & 0.03 \\
\hline Ferric Oxide & Fe3O2: 1-2 micron & $2.40 \%$ & 0.16 \\
\hline Ferric Oxide & Fe3O2: 5-10 micron & $2.40 \%$ & 0.16 \\
\hline Manganese Oxide & MnO2: 1-2 micron & $1.55 \%$ & 0.10 \\
\hline Manganese Oxide & MnO2: 5-10 micon & $1.55 \%$ & 0.10 \\
\hline Sodium Aluminosilicate & $\mathrm{Na} 2 \mathrm{OAl} 2 \mathrm{O} 3(\mathrm{SiO} 2) \cdot 2.5 \mathrm{H} 2 \mathrm{O}$ & $1.60 \%$ & 0.11 \\
\hline Sodium Oxalate & $\mathrm{Na2C2O4}$ & $34.20 \%$ & 2.29 \\
\hline Sodium Carbonate Monohydrate & $\mathrm{Na2CO3.H2O}$ & $32.30 \%$ & 2.17 \\
\hline Sodium Fluoride & $\mathrm{NaF}$ & $5.00 \%$ & 0.34 \\
\hline Sodium Sulfate Decahydrate & $\mathrm{Na2SO} 4.10 \mathrm{H} 2 \mathrm{O}$ & $4.10 \%$ & 0.27 \\
\hline Sodium Phosphate Dodecahydrate & $\mathrm{Na} 3 \mathrm{PO} 4.12 \mathrm{H} 2 \mathrm{O}$ & $9.30 \%$ & 0.62 \\
\hline
\end{tabular}

\begin{tabular}{|l|l|l|}
\hline Total & $100.00 \%$ & 6.70 \\
\hline
\end{tabular}




\section{Sr/TRU precipitation recipe}

1. In a container, place a fixed volume of $7 \mathrm{M} \mathrm{Na}$ Envelope $\mathrm{C}$ supernate with entrained solids, agitate, and raise solution temperature to $50 \pm 5^{\circ} \mathrm{C}$.

2. Add $166.7 \mathrm{~mL}$ de-ionized and filtered water per liter of $7 \mathrm{M} \mathrm{Na}$ supernate to dilute solution to $6 \mathrm{M} \mathrm{Na}$. Allow solution to mix 10-15 minutes.

3. Slowly add $55.6 \mathrm{~mL} 19 \mathrm{M} \mathrm{NaOH}$ solution per liter of $6 \mathrm{M} \mathrm{Na}$ supernate solution, and allow solution to mix 10-15 minutes.

4. Slowly add $90.5 \mathrm{~mL} 1 \mathrm{M} \mathrm{Sr}\left(\mathrm{NO}_{3}\right)_{2}$ solution per liter of $6 \mathrm{M}$ Na supernate solution, and allow solution to mix 10-15 minutes.

5. Slowly add $60.3 \mathrm{~mL} 1 \mathrm{M} \mathrm{NaMnO}_{4}$ solution per liter of $6 \mathrm{M} \mathrm{Na}$ supernate solution.

6. Continue agitation and maintain $50 \pm 5^{\circ} \mathrm{C}$ temperature for 4 hours.

7. Allow mixture to cool. 


\section{Appendix B - Regulatory Analysis Raw Data Summary}

This section contains the regulatory data from this study in two forms:

- Summary of raw data as received from BWXT Services, Inc. contained in reference:

Ferrara, D. M., “Data Package for AN-107 Env. C-simulant Regulatory Evaporation”, WSRC-TR-2000-00528, SRT-RPP-2000-00062, 2000.

- Data after validation by Savannah River Technology Center (SRTC) Quality Assurance and Quality Control (QA/QC) documented in reference:

Kubilius, W., "Report of Analytical Data Validation of Regulatory Analyses for SRTC Contract WFO-98-003: Envelope C Simulant Samples; Rev. 0", Internal memorandum, ESH-EMS-2000761, August 24, 2000

and correction by process, field, trip, and reagent blank data. 
WSRC-TR-2000-00486

SRT-RPP-2000-00047

A. Raw Data

\begin{tabular}{|c|c|c|c|c|c|c|c|c|c|c|c|c|c|c|c|c|c|c|c|c|c|c|c|c|}
\hline \multicolumn{2}{|c|}{ BWXT VOA Raw Data by Stream } & & & & & & & & & & & & & & & & & & & & & & & \\
\hline \multirow{3}{*}{\begin{tabular}{|l|} 
Hiroshi Saito \\
24-Aug-00
\end{tabular}} & & & & & & & & & & & & & & & & & & & \multirow{3}{*}{\multicolumn{2}{|c|}{ Data Qualifier Key }} & & & & \\
\hline & & & & & & & & & & & & & & & & & & & & & & & & \\
\hline & & & & & & & & & & & & & & & & & & & & & & & & \\
\hline & & & & & & & & \multirow{2}{*}{\multicolumn{2}{|c|}{\begin{tabular}{|c|}
\multicolumn{2}{|c|}{ Liquid 0 } \\
12-dibromo
\end{tabular}}} & \multirow{2}{*}{\multicolumn{2}{|c|}{$\begin{array}{l}\text { Concentration } \\
\text { chloro } \\
\text { benzene }\end{array}$}} & & \multirow{3}{*}{\multicolumn{3}{|c|}{\begin{tabular}{c|}
$1,2,4$-tri \\
chlorobenzene
\end{tabular}}} & \multirow{3}{*}{\multicolumn{2}{|c|}{\begin{tabular}{|l|} 
naphthalene \\
\end{tabular}}} & & \multirow{2}{*}{\multicolumn{6}{|c|}{$\begin{array}{l}=\text { Sample reanalyzed by dilution. Caution for dilutition error } \\
J=\text { estimated value (e.g. quantity between MDL and MRL) }\end{array}$}} \\
\hline Feed & & & & 4-methyl-2- & & & & & & & & $1,2,3-$ tri & & & & & & & & & & & & \\
\hline$\frac{\text { Sample Name }}{\text { RGNEVPVAfd1 }}$ & $\begin{array}{l}\text { Sample Description } \\
\text { Vanof }\end{array}$ & benzene & $\perp$ & pentanone & 工 & $\begin{array}{l}\text { toluene } \\
1110 \\
110\end{array}$ & 1 & ethane & I & benzene & 10 & chloropropane & & & & & & & \multirow{3}{*}{\multicolumn{5}{|c|}{$\begin{array}{l}\text { E = Quantity exceeds upper level of calibration range } \\
R=\text { = SRTC QA rejected result }\end{array}$}} & \\
\hline $\begin{array}{l}\text { RGNEVPAifd1 } \\
\text { RGNEVPVAfd2 }\end{array}$ & $\begin{array}{l}\text { VOA Feed Sample } \# 1(6 / 6 / 600,2300) \\
\text { VOA Feed Sample } \# 2(6 / 6 / 100,2300)\end{array}$ & $\begin{array}{l}1480 \\
1380\end{array}$ & & $\begin{array}{l}2440 \\
2410\end{array}$ & - & $\begin{array}{l}1110 \\
1020\end{array}$ & - & $\begin{array}{l}78.9 \\
66.3\end{array}$ & $\frac{2}{\mathrm{~J}}$ & $\begin{array}{l}1280 \\
1070\end{array}$ & + & $\begin{array}{l}800 \\
800\end{array}$ & $\frac{U}{U}$ & $\begin{array}{l}1170 \\
529\end{array}$ & & $\begin{array}{l}1580 \\
1080\end{array}$ & & & & & & & & \\
\hline 30014515 & pre-run feed sample $(7 E-15,665 / 00$, late $P M)$ & 200 & & 260 & & 170 & & 0 & 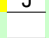 & 120 & & 130 & & & & & & & & & & & & \\
\hline 300145160 & mid-VOST feed sample $(6 / 7100,0300,24 \mathrm{hr})$ & 220 & & 270 & - & 150 & - & 1.4 & 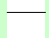 & 110 & - & 150 & & & & & & & \multirow{5}{*}{\multicolumn{5}{|c|}{$\begin{array}{l}\text { Data Guide } \\
\text { Italic tettrellow box = qualified data } \\
\text { Bold text/Green box = Significant/good data } \\
\text { Bold box/red box = corrected data }\end{array}$}} & \\
\hline 300145161 & mid-SVOST feed sample $(6 / 7 / 00,2210,7 \mathrm{hr})$ & 210 & & 280 & & 160 & & 0 & & 120 & & 130 & & & & & & & & & & & & \\
\hline & & & & & & & & & & & & & & & & & & & & & & & & \\
\hline & & & & & & & $\square$ & & 1 & & 1 & & & & & & & & & & & & & \\
\hline Concentrate & & & & 4-methyl-2- & & & & $\frac{\text { Liq }}{1 \text { 2-dibromo }}$ & & oncentratic & ion (ug/ & /L) & & & & & & & & & & & & \\
\hline Sample Name & Sample Description & benzene & ti & pentanone & & toluene & & ethane & (a & benzene & & chloropropopane & & $\frac{1,2,4-\mathrm{tr} I}{\text { chlorobenzene }}$ & & & & & & & & & & \\
\hline RGNEVPVAcc1 & VOA Concentrate Sample \#1 $(6 / 6 / 100,1600)$ & 20.9 & J & 54.5 & $\mathrm{~J}$ & 11.8 & 7 & & $u$ & 13.2 & J & 400 & $u$ & 19.1 & & $\begin{array}{ll}n \text { nappinalene } \\
21.6\end{array}$ & & & & & & & & \\
\hline RGNEVPVACC2 & VOA Concentrate Sample \#2 $(6 / 6 / 00,2230)$ & 400 & $\mathrm{U}$ & 400 & $\mathrm{U}$ & 400 & u & 400 & $\bar{u}$ & 13 & $\mathrm{~J}$ & 400 & II & 7.1 & & $\begin{array}{l}2.6 \\
17.3\end{array}$ & J & & & & & & & \\
\hline $\begin{array}{r}300145166 \\
\end{array}$ & 6-hr. VOST concentrate sample $(6 / 6 / 100,0907)$ & & & & & 8.2 & & & & 7.6 & & 170 & & & & & & & & & & & & \\
\hline 300145167 & mid-run VOST conc. sample $(6 / 6,2230,20 \mathrm{hr})$ & 2.2 & - & 48 & & 11 & & 1.9 & - & 5.8 & - & 160 & & & & & & & & & & & & \\
\hline 300145168 & end-run VOST conc. Sample $(6 / 7,1443,35.5 \mathrm{hr})$ & 5.3 & E & 26 & - & 11 & 二 & 1.8 & - & 5.4 & E & 190 & & & & & & & & & & & & \\
\hline 300145169 & mid-run. SVOST conc. Sample $(6 / 8,0927,18 \mathrm{hr})$ & 6.3 & & 120 & & 4.5 & $\overline{-}$ & 4.5 & - & 5.7 & E & 400 & & & & & & & & & & & & \\
\hline & & & & & & & 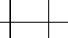 & & -1 & & & & & & & & & & & & & & & \\
\hline & & & & & & & & & guid C & oncentratic & $\frac{1}{\operatorname{ion}(\mathrm{ug} / \mathrm{l}}$ & & & & & & & & & & & & & \\
\hline Condensate & & & 4 & 4-methyl-2- & & & 1 & 1,2-dibromo & & chloro & L & $1,2,3$-tri & & $1,2,4$-tri & & & & & & & & & & \\
\hline $\begin{array}{l}\text { Sample Name } \\
\text { BGNEVPVACd1 }\end{array}$ & Sample Description & benzene & $\perp$ & pentanone & 1 & $\begin{array}{l}\text { toluene } \\
259 \\
9\end{array}$ & L & ethane & 1 & benzene & 10 & chloropropane & & chlorobenzene & & naphthalene & & & & & & & & \\
\hline $\mid \frac{\text { RGENVPVVAdd1 }}{\text { RGNEVPVAcd1DL }}$ & $\begin{array}{l}\text { VOA Condensate Sample \#1 } 16 / 6 / 00,1625) \\
\text { Aboveve with } 10 \text { dilution factor }\end{array}$ & $\begin{array}{l}32.7 \\
26.8\end{array}$ & $\overline{\mathrm{DJ}}$ & $\begin{array}{l}712 \\
688\end{array}$ & $\frac{\mathrm{E}}{\mathrm{D}}$ & $\begin{array}{l}25.9 \\
18.3\end{array}$ & $\overline{D .1}$ & $\begin{array}{r}41.6 \\
362\end{array}$ & $\overline{D J}$ & ${ }_{31}^{44}$ & $\overrightarrow{\mathrm{DJ}}$ & $\begin{array}{l}10 \\
100 \\
\end{array}$ & $\frac{U}{U}$ & $\begin{array}{l}60.8 \\
40.6\end{array}$ & 1. & ${ }_{200}^{257}$ & & & & & & & & \\
\hline GNEVPVACd2 & VOA Condensate Sample \#2 $(6 / 6 / 100,2230)$ & 12.9 & $\frac{\mathrm{Ju}}{\mathrm{J}}$ & $\begin{array}{l}000 \\
479\end{array}$ & & $\begin{array}{l}18.3 \\
10.9\end{array}$ & $\frac{\mathrm{DJ}}{\mathrm{D}}$ & $\begin{array}{l}36.2 \\
18.1\end{array}$ & & & $\frac{\mathrm{J}}{\mathrm{D}}$ & $\frac{100}{20}$ & & 25.5 & & & & & & & & & & \\
\hline RGNEVPVACd2MS & Method spike & 93.4 & & 484 & $E$ & 89.7 & & 17.8 & $\mathrm{~J}$ & 98.8 & & 62.1 & & & & 139 & & & & & & & & \\
\hline RGNEVPVAcd2MSD & Method spike duplicate & 93.5 & & 495 & E & 90.3 & & 19 & $\mathrm{~J}$ & 101 & & 62.4 & & 25.5 & & 152 & & & & & & & & \\
\hline $\begin{array}{r}300145162 \\
30145163 \\
\end{array}$ & 5.5-hr. VOST condensate sample $(6 / 6 / 100,0842)$ & 7.2 & - & 130 & $=$ & 26 & 二 & 2.8 & - & 5.5 & 二 & 120 & & & & & & & & & & & & \\
\hline $\begin{array}{l}300145163 \\
300145164 \\
3\end{array}$ & mid-run VOA cond. Sample $66 / 6,2330,20 \mathrm{hr})$ & 1.2 & - & 160 & — & 4.1 & - & 2.2 & - & $\begin{array}{l}6.6 \\
54\end{array}$ & — & 170 & & & & & & & & & & & & \\
\hline 300145165 & mid-run SVOST cond. Sample $(6 / 8,0840,17 \mathrm{hr})$ & $\begin{array}{l}0.5 \\
25\end{array}$ & & 340 & & 18 & 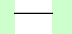 & $\begin{array}{l}1.0 \\
19\end{array}$ & & $\begin{array}{l}0.4 \\
28\end{array}$ & - & 200 & & & & & & & & & & & & \\
\hline & & & & & & & $\square$ & & & & $\square$ & & & & & & & & & & & & & \\
\hline & & & & & & & & & 1 & & $\frac{1}{10}$ & & & & & & & & & & & & & \\
\hline Pump Trap Liquids & & & & & & & & $\begin{aligned} \text { Liqi } \\
12 \text {-dibromo }\end{aligned}$ & quid & incentratic & 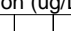 & ill) 123 -tri & & & & & & & & & & & & \\
\hline $\begin{array}{l}\text { Sample Name } \\
\text { Sames }\end{array}$ & Sample Description & benzene & & 4-methyl-2- & & toluene & & 1,2-dibromo & & $\begin{array}{l}\text { chloro } \\
\text { benzene }\end{array}$ & & $\frac{1,2,3 \text {-tri }}{\text { chlorome }}$ & & $\frac{1,2,4-\text {-ri }}{1}$ & & nanhthalene & & & & & & & & \\
\hline RGNEVPVATrap1 & Sample Pump Liquids Sample \#1 $(6 / 7 / 00,1500)$ & Denzene & $L_{E}$ & $\begin{array}{l}\text { pentanone } \\
28400\end{array}$ & & $\frac{\text { toluene }}{1200}$ & & $\frac{2 \text { ennane }}{2920}$ & & 272 & & $\frac{\text { chloropropane }}{10}$ & & Cniorobenzene & & nappinalene & & toluene-d8 & & & I. solit tota & ligyid with tw & two halow & \\
\hline RGNEVPVATrap1DL & Above, with 100 dilutution factor & 164 & $\frac{\mathrm{L}}{\mathrm{DJ}}$ & 年750 & $\frac{L}{D}$ & 115 & $\frac{{ }^{\mathrm{DJ}}}{\mathrm{s}}$ & 年39 & $\frac{\mathrm{L} . \mathrm{J}}{\mathrm{D}}$ & 212 & $\frac{\mathrm{L} . \mathrm{J}}{\mathrm{D}}$ & 1000 & & 烈 145 & D.ts & 年260 & $\bar{D}$ & & & & & 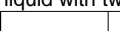 & 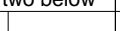 & \\
\hline RGNEVPVATrap2 & Sample Pump Liqu. Samp. \#2, 100X dil. (6/7,150 & & $\frac{J}{J}$ & & & & & 392 & & & & & & & & 2820 & & & benzene recc & & & & & \\
\hline RGNEVPVATrap2MS & Method spike & 4820 & 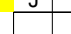 & 8010 & & 4750 & $\mathrm{~s}$ & 378 & $\frac{\mathrm{J}}{\mathrm{u}}$ & 4920 & 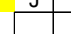 & 1000 & $\frac{U}{U}$ & 573 & $\frac{\mathrm{J}}{\mathrm{u}}$ & 2590 & & 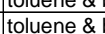 & benzene recc & & & o RPD's a & bithigh ver & \\
\hline RGNEVPVATrap2MSD & Method spike duplicate & 3940 & D & 7280 & $\square$ & 3870 & $\square$ & 336 & $\begin{array}{l}0 \\
\end{array}$ & 4160 & $\square$ & 1000 & $\frac{0}{u}$ & 482 & $\frac{7}{2}$ & 2350 & & & & & & & & \\
\hline 300145170 & in-house sample, no headspace $(6 / 7 / 00,1500)$ & 49 & & 1200 & & 33 & & 76 & & 35 & & 110 & & & & & & & & & & & & \\
\hline & & & & & & & & & & & & & & & & & & & & & & & & \\
\hline & & & & & & & & & Sol & ent & $(\mathrm{ng})$ & & & & & & & & & & & & & \\
\hline Sorbent Tubes & & & & 4-methyl-2- & & & & 1,2-dibromo & 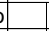 & chloro & 4 & $1,2,3$-tri & & $1,2,4$-tri & & & & & & & & & & \\
\hline 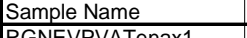 & Sample Description & benzene & $T_{F}$ & pentanone & 1 & toluene & 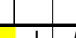 & ethane & 1 & benzene & 直 & chloropropane & & chlorobenzene & & naphthalene & & & & & & & & \\
\hline $\begin{array}{l}\text { RGNEVVVATTenax1 } \\
\text { RGNEVPVATenax2 }\end{array}$ & $\begin{array}{l}\text { Sample Tenax Tube \#1 }(6 / 7 / 700,1500) \\
\text { Sample Tenax Tube \#2 }(6 / 7 / 00,1500)\end{array}$ & $\frac{5000000}{1900}$ & $\mid \begin{array}{lll}U \\
E\end{array}$ & $\begin{array}{l}1160000 \\
230000\end{array}$ & $\frac{E}{3}$ & $\begin{array}{l}1140000 \\
25300\end{array}$ & $\frac{J}{E}$ & $\frac{5000000}{21700}$ & U & $\begin{array}{l}30000000 \\
658000\end{array}$ & $\frac{J}{E}$ & 5000000 & & $\begin{array}{l}48800000 \\
434\end{array}$ & & $\begin{aligned} 55900000 \\
2090\end{aligned}$ & & $\begin{array}{l}40 \% \text { recov } \\
\text { Thermald }\end{array}$ & $\begin{array}{l}\text { rise }, 1000 \\
\text { sorption res }\end{array}$ & & & & tector & \\
\hline RGNEVPVAAnasorb1 & & 24700000 & & 31500000 & & 10100000 & & 4600000 & & 5160000 & & & & & & 4500000 & & $20 \%$ re & & & dilution nee & & & \\
\hline
\end{tabular}


WSRC-TR-2000-00486

SRT-RPP-2000-00047

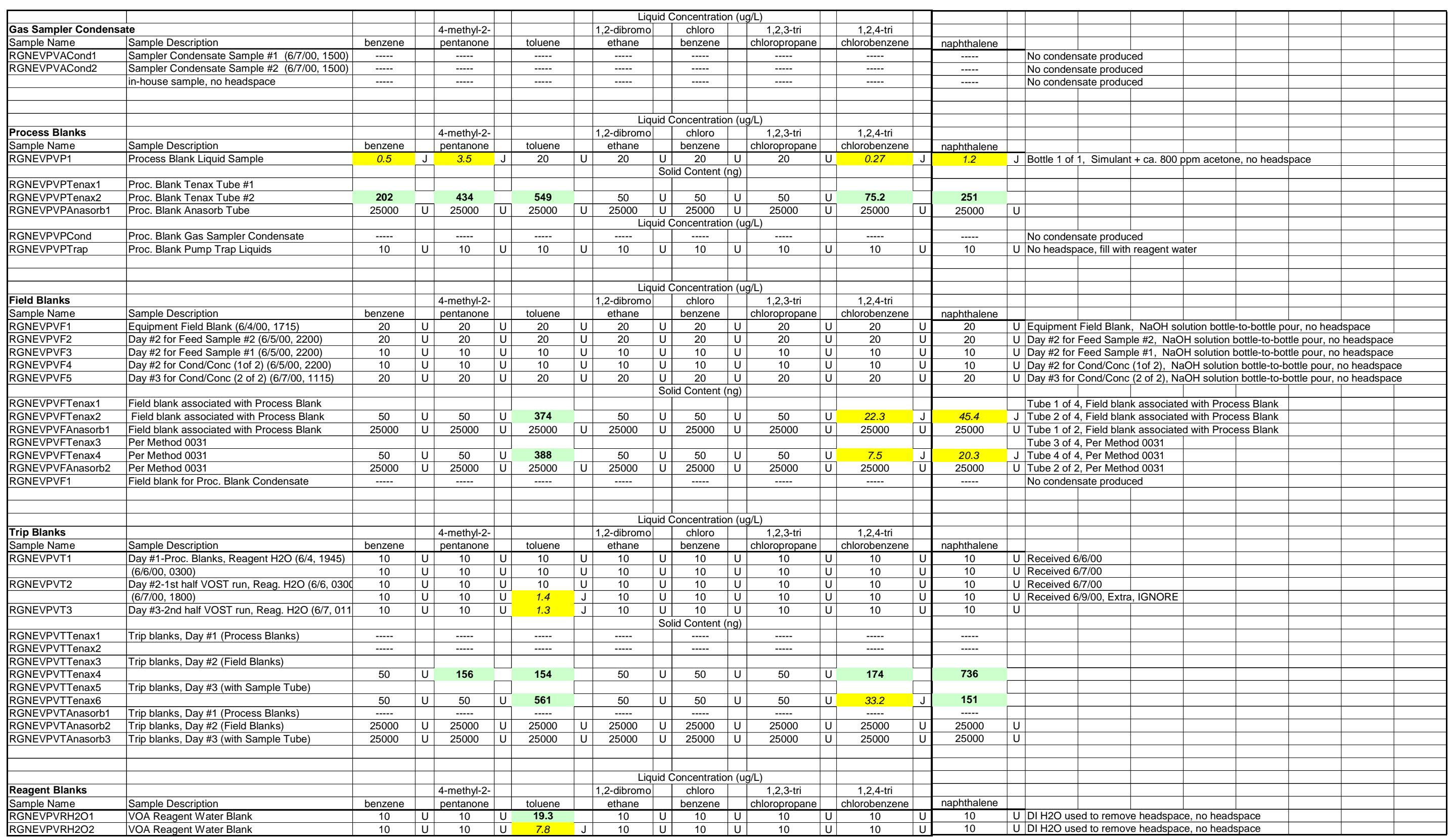


BWXT SVOA Raw Data by Stream

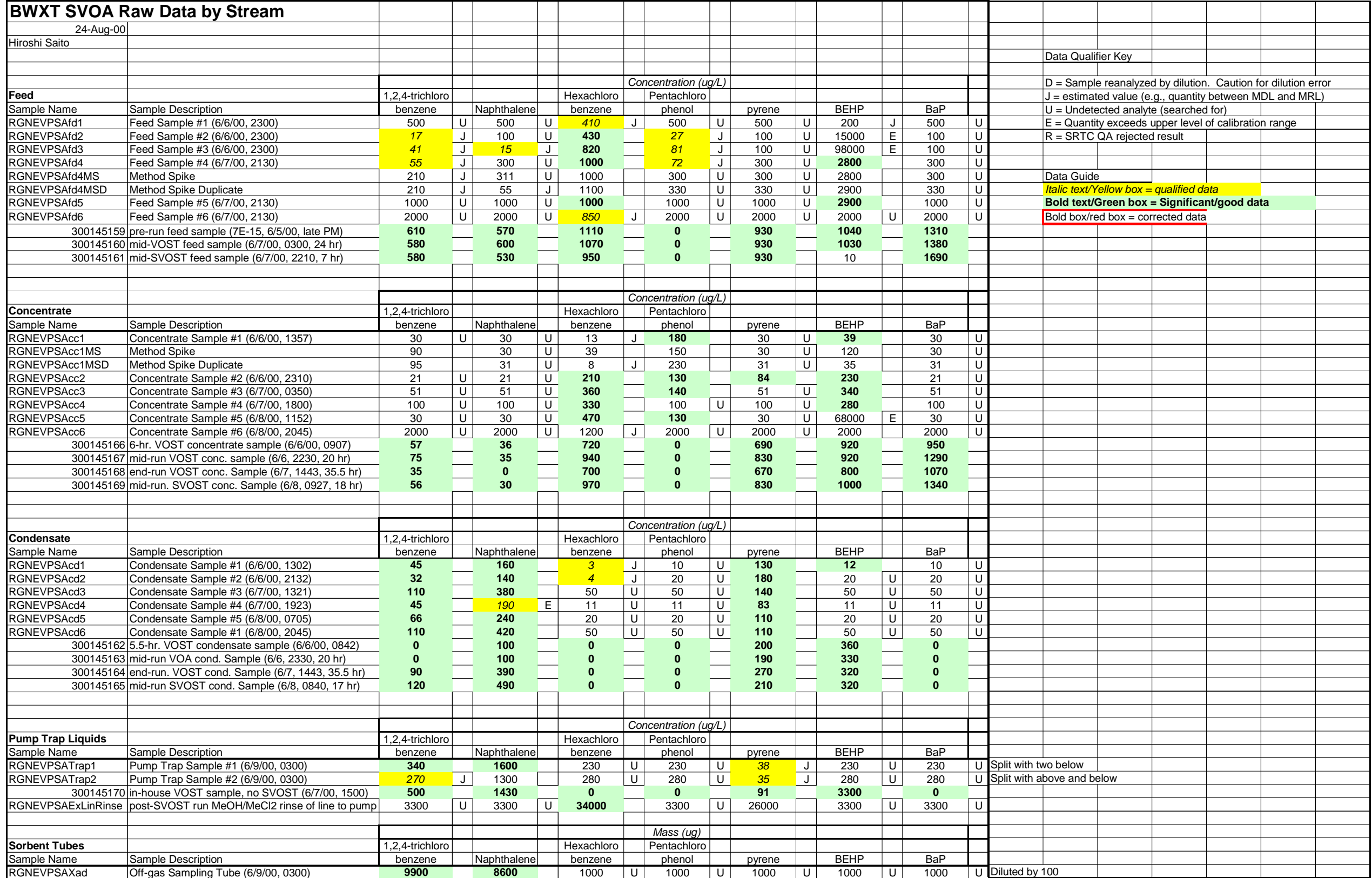


WSRC-TR-2000-00486

SRT-RPP-2000-00047

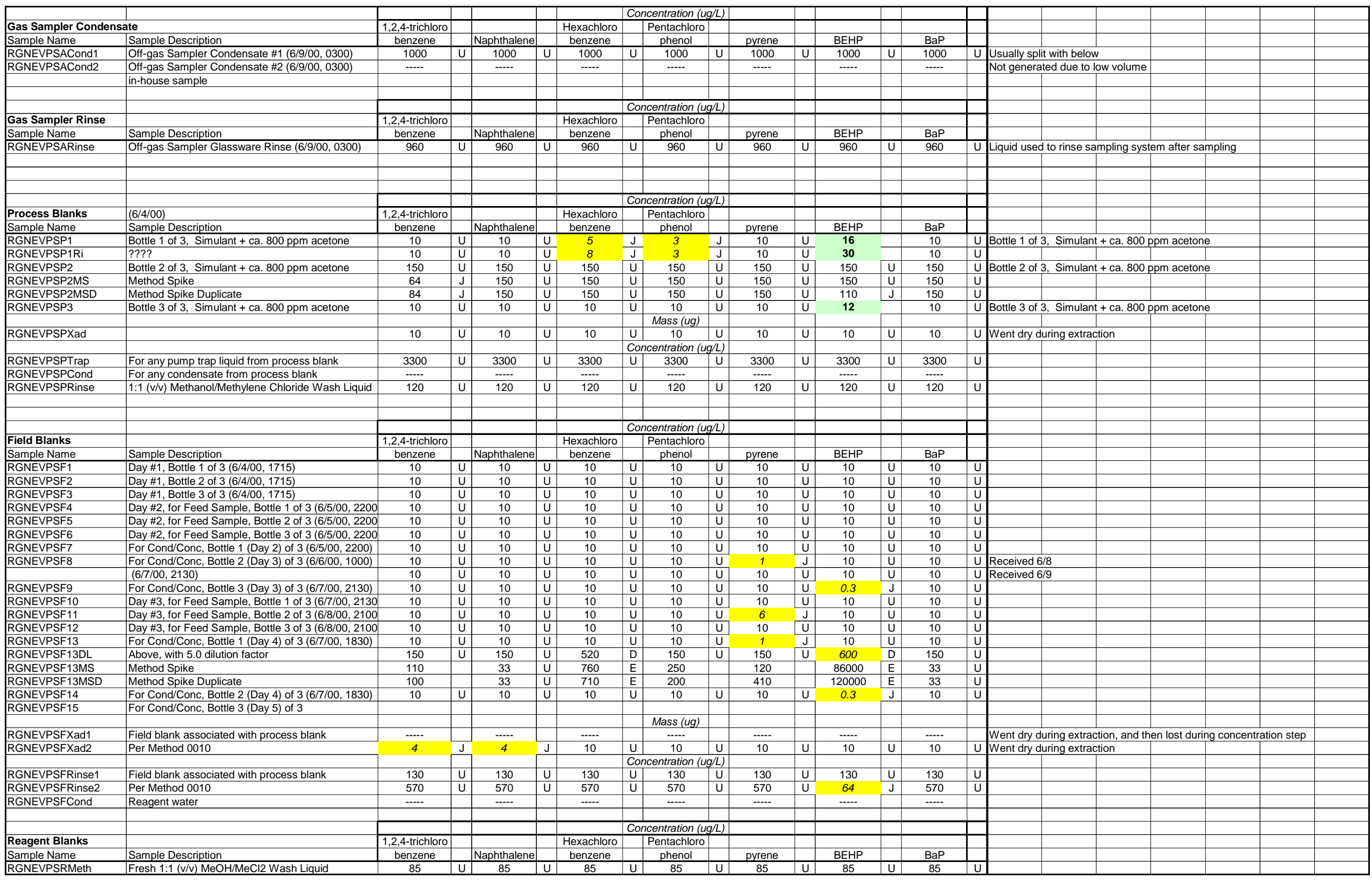




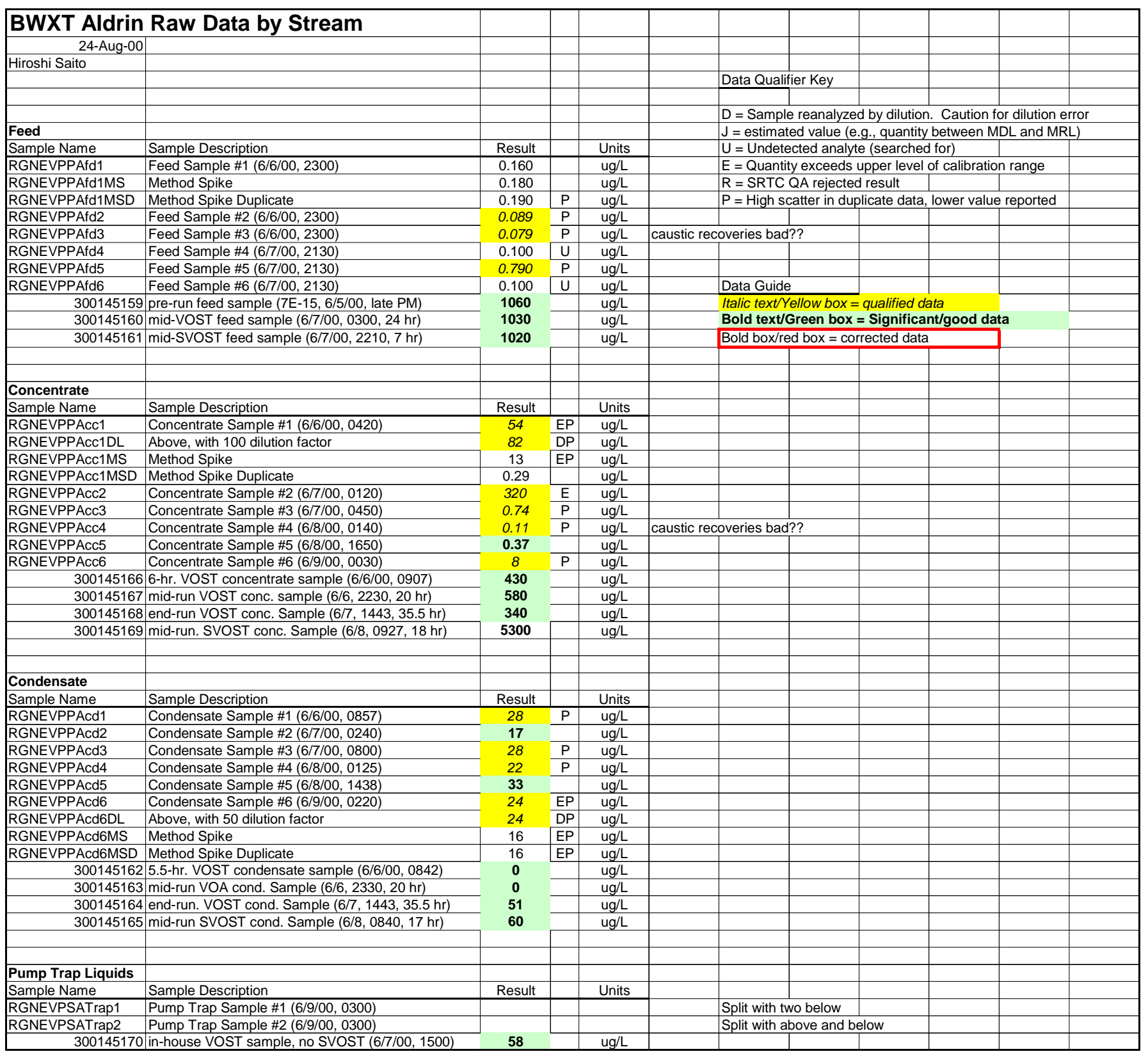


WSRC-TR-2000-00486

SRT-RPP-2000-00047

\begin{tabular}{|c|c|c|c|c|c|c|c|c|c|c|c|}
\hline \begin{tabular}{|l|} 
Sorbent Tubes \\
Sample Name \\
\end{tabular} & Sample Description & Result & & Units & & & & & & & \\
\hline RGNEVPSAXad & Off-gas Sampling Tube $(6 / 9 / 00,0300)$ & -..-- & & & & Went dry di & during extrac & ction, then Ic & 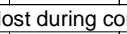 & oncentration & \\
\hline & & & & & & & & & & & \\
\hline & & & & & & & & & & & \\
\hline Gas Sampler Conde & sate & & & & & & & & & & \\
\hline $\begin{array}{l}\text { Sample Name } \\
\text { RGNEVPSACond1 }\end{array}$ & $\begin{array}{l}\text { Sample Description } \\
\text { Off-cas Sampler Condensate \#1 (6/9//00, 0300) }\end{array}$ & Result & & Units & & $\begin{array}{l}\text { Split with tw } \\
\end{array}$ & wo below & & & & \\
\hline RGNEVPSACond2 & Off-gas Sampler Condensate $\# 2(6 / 9 / 00,0300)$ & 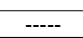 & & & & Split with ab & bove and be & elow & & & \\
\hline & in-house sample & & & & & & & & & & \\
\hline & & & & & & & & & & & \\
\hline Gas Sampler Rinse & & & & & & & & & & & \\
\hline $\begin{array}{l}\text { Sample Name } \\
\text { RGNEVPSARinse }\end{array}$ & $\begin{array}{l}\text { Sample Description } \\
\text { Off-gas Sampler Glassware Rinse }(6 / 9 / 00,0300)\end{array}$ & Result & & Units & & Liquid used & $\frac{d \text { to rinse sal }}{4}$ & ampling syst & tem after san & & \\
\hline & & & & & & & & & & & \\
\hline & & & & & & & & & & & \\
\hline & & & & & & & & & & & \\
\hline Process Blanks & $6(6 / 5 / 00)$ & & & & & & & & & & \\
\hline \begin{tabular}{|l} 
Sample Name \\
RGNEPPP1 \\
\end{tabular} & $\begin{array}{l}\text { Sample Description } \\
\text { Bottle 1 of } 3 \text { Simulant + ca. } 800 \text { pom acetone }\end{array}$ & $\frac{\frac{R}{2 e s u l t}}{0.050}$ & $u$ & $\frac{\text { Units }}{\text { nals }}$ & & Bottle 1 of 3 & 3, Simulant & $t+$ ca. 800 & opm acetone & & \\
\hline RGNEVPPP2 & Bottle 2 of 3 , Simulant + ca. 800 ppm acetone & 0.050 & $\mathrm{U}$ & ugh & & Bottle 2 of 3 & 3, Simulant & $t+$ ca. $800 \mathrm{r}$ & ppm acetone & & \\
\hline RGNEVPPP3 & Bottle 3 of 3, Simulant + ca. 800 ppm acetone & 0.050 & u & ugh & & Bottle 3 of 3 & 3, Simulant & $t+$ ca. $800 \mathrm{r}$ & ppm acetone & & \\
\hline $\begin{array}{l}\text { RGNEVPSPXad } \\
\text { BGNFVPSPTran }\end{array}$ & For any num tran liquid from nrocess hlank & & & & & & & & & & \\
\hline $\begin{array}{l}\text { RGNEVPSPIIrap } \\
\text { RGNEVPSPCond }\end{array}$ & 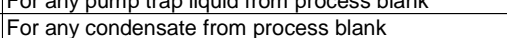 & $\ldots$ & & & & & & & & & \\
\hline RGNEVPSPRinse & 1:1 (v/v) Methanol/Methylene Chloride Wash Liquid & & & & & & & & & & \\
\hline & & & & & & & & & & & \\
\hline & & & & & & & & & & & \\
\hline $\begin{array}{l}\text { Field Blanks } \\
\text { Sample Name }\end{array}$ & Sample Description & Result & & Units & & & & & & & \\
\hline \begin{tabular}{|l|l|} 
RGNEVPPF1 \\
\end{tabular} & Day \#1, Bottle 1 of $3(6 / 4 / 400,1715)$ & 0.050 & $\mathrm{U}$ & uglil & & & & & & & \\
\hline RGNEVPPF2 & Day \#1, Bottle 2 of $3(6 / 4 / 400,1715)$ & & & & & & & & & & \\
\hline $\begin{array}{l}\text { RGNEVPPF3 } \\
\text { RGP }\end{array}$ & Day \#1, Bottle 3 of $3(6 / 4 / 00,1715)$ & 0.050 & $\mathrm{U}$ & ug/L & & & & & & & \\
\hline $\begin{array}{l}\text { RGNEVPPF4 } \\
\text { RGEVPPF5 }\end{array}$ & Day \#2, for Feed Sample, Bottle 1 of $3(6 / 5,2200)$ & 0.050 & $\mathrm{U}$ & ug/L & & & & & & & \\
\hline $\begin{array}{l}\text { RGNEVPPF5 } \\
\text { RGNEVPPF6 }\end{array}$ & 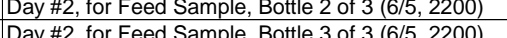 & 0.050 & $\frac{U}{u}$ & $\frac{\mathrm{ug} / \mathrm{L}}{\mathrm{ugh} / \mathrm{L}}$ & & & & & & & \\
\hline RGNEVPPF7 & For Cond/Conc, Bottle 1 (Day 2) of $3(6 / 5 / 00,2200)$ & 0.050 & $\mathrm{u}$ & ug/L & & & & & & & \\
\hline RGNEVPPF8 & For Cond/Conc, Bottle 2 (Day 3) of $3(6 / 6 / 100,1500)$ & 0.092 & & uggh & received 6 - & $8 / 00$ & & & & & \\
\hline RGNEVPPF9 & $(6 / 7 / 100,2130)$ & 0.050 & $\mathrm{U}$ & ug/L & & & & & & & \\
\hline $\begin{array}{l}\text { RGNEVPFY } \\
\text { RGNEVPPF } 10 \\
\end{array}$ & 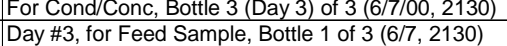 & 0.050 & $\mathrm{u}$ & $\frac{\lg / \mathrm{L}}{\mathrm{ug} / \mathrm{L}}$ & & & & & & & \\
\hline RGNEVPPF11 & Day \#3, for Feed Sample, Bottle 2 of 3 & & & & & & & & & & \\
\hline RGNEVPPF12 & Day \#3, for Feed Sample, Bottle 3 of $3(6 / 7,1830)$ & 0.050 & $\mathrm{U}$ & ug/L & & & & & & & \\
\hline $\begin{array}{l}\text { RGNEVPPF13 } \\
\text { RGNEVPPE14 }\end{array}$ & For Cond/Conc, Bottle 1 (Day 4) of $3(6 / 7,1830)$ & 0.050 & $\mathrm{U}$ & ug/L & & & & & & & \\
\hline $\begin{array}{l}\text { RRGEVPPF14 } \\
\text { RGNEVPPF15 }\end{array}$ & $\begin{array}{l}\text { For Cond/Conc, Bottle } 2 \text { (Day 5 5 of } 3 \\
\text { For Cond/Conc, Bottle } 3 \text { (Day) of } 3\end{array}$ & 0.050 & $\frac{u}{u}$ & $\frac{\lg / \mathrm{L}}{\mathrm{ug} / \mathrm{L}}$ & & & & & & & \\
\hline RGNEVPSFXad1 & Field blank associated with process blank & & & & & & & & & & \\
\hline RGNEVPSFXad2 & Per Method 0010 & & & & & & & & & & \\
\hline $\begin{array}{l}\text { RGNEVPSFRinse } 1 \\
\text { RGNEYSFRinse? }\end{array}$ & Field blank associated with process blank & & & & & & & & & & \\
\hline $\begin{array}{l}\text { RGGNEVSFFRinse2 } \\
\text { RGNEVPSFCond }\end{array}$ & $\begin{array}{l}\text { Per Metrod 00010 } \\
\text { Reagent water }\end{array}$ & $\ldots$ & & & & & & & & & \\
\hline & & & & & & & & & & & \\
\hline Reagent Blanks & & & & & & & & & & & \\
\hline Sample Name & Sample Description & Result & & Units & & & & & & & \\
\hline
\end{tabular}


WSRC-TR-2000-00486

SRT-RPP-2000-00047

B. Validated and Corrected Data

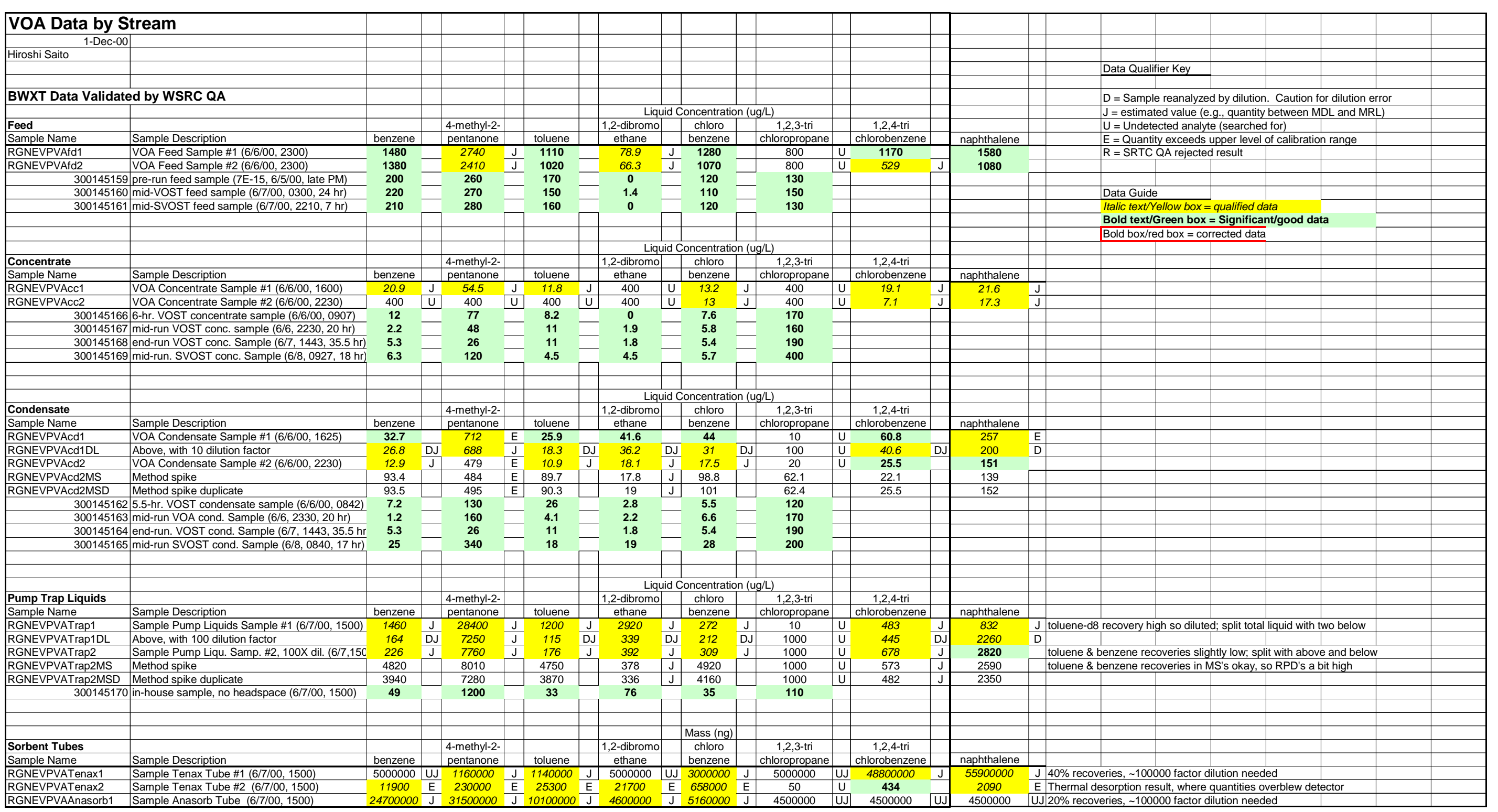


WSRC-TR-2000-00486

SRT-RPP-2000-00047

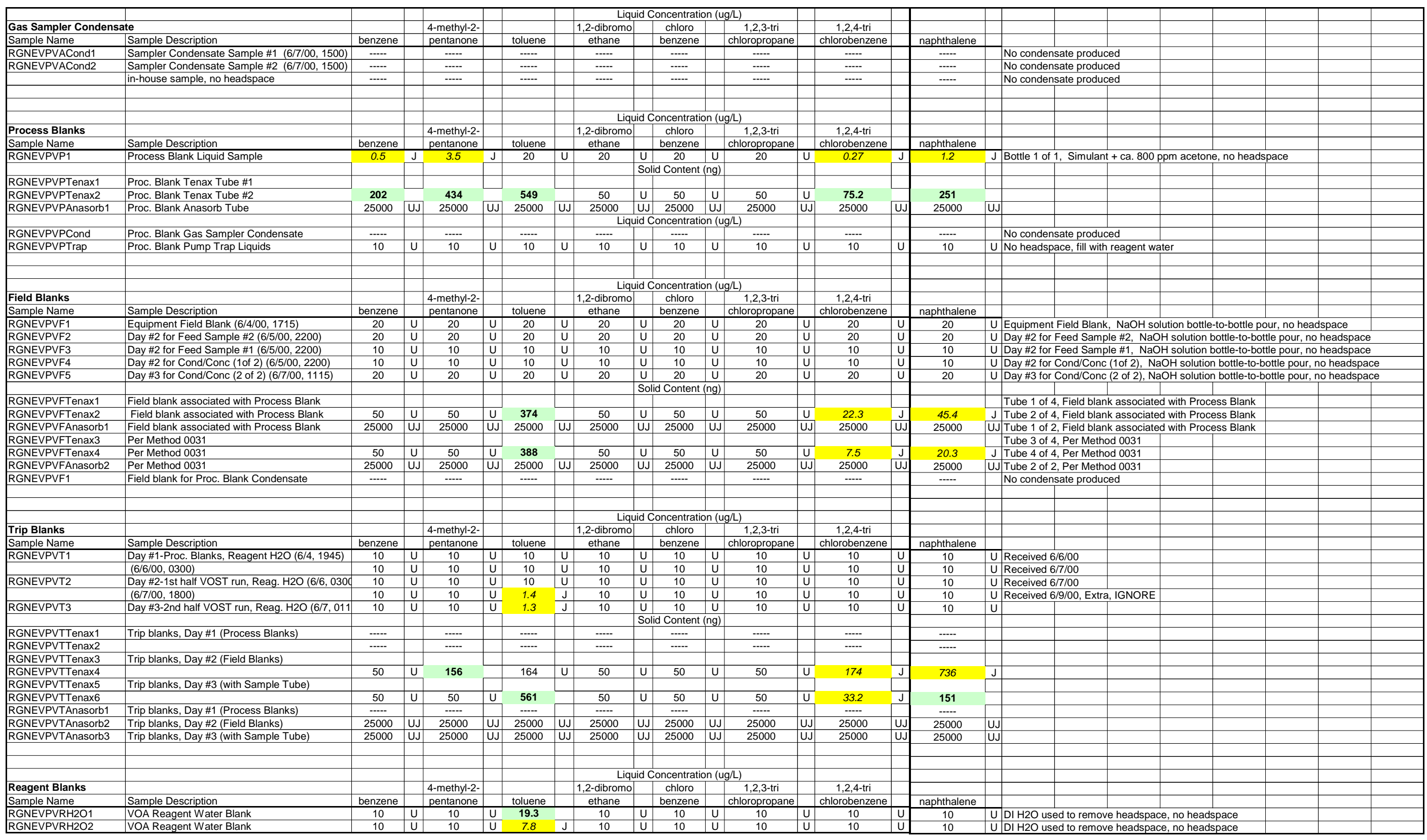


WSRC-TR-2000-00486

SRT-RPP-2000-00047

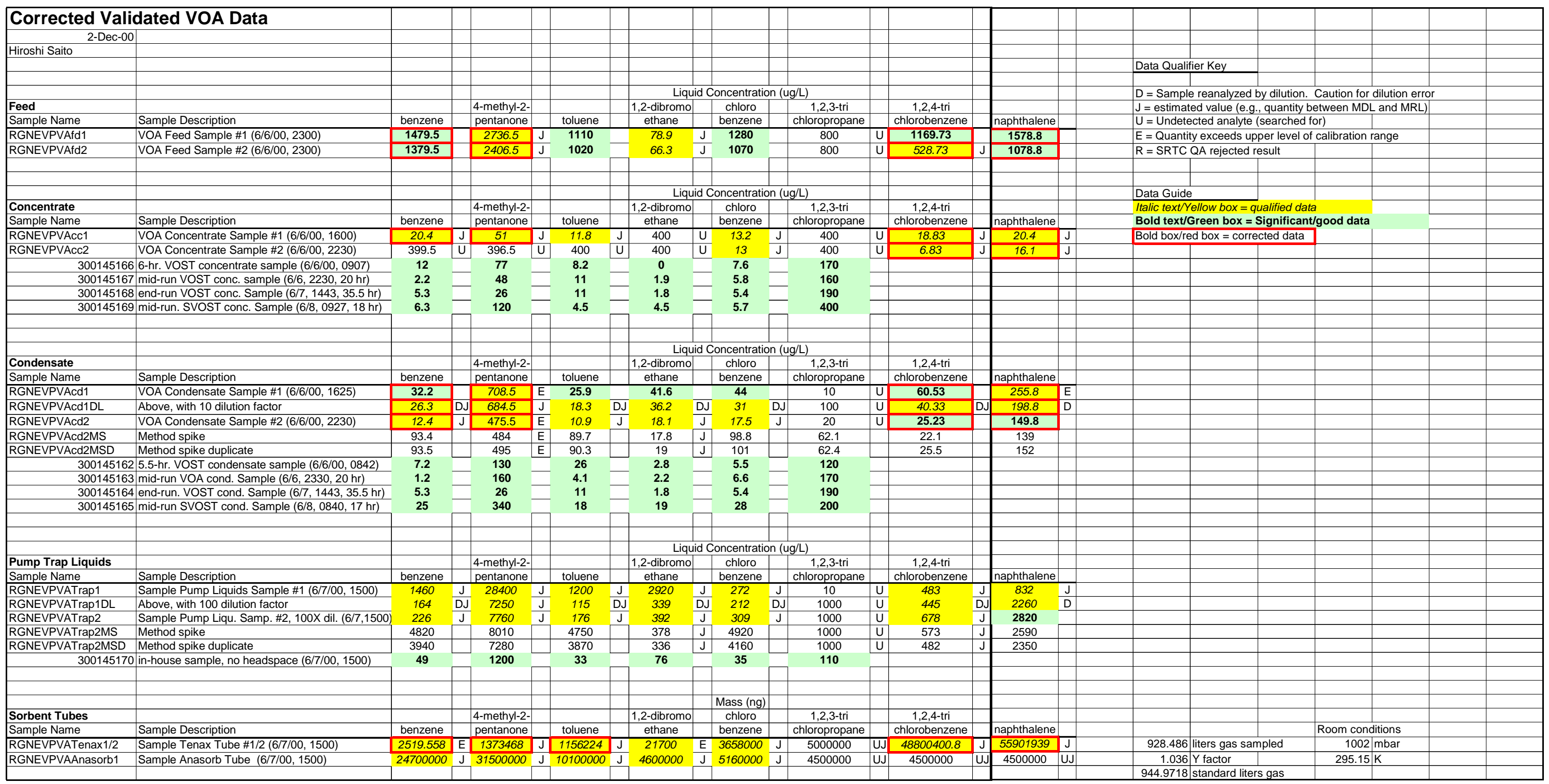


WSRC-TR-2000-00486

SRT-RPP-2000-00047

\begin{tabular}{|c|c|c|c|c|c|c|c|c|c|c|c|c|c|c|c|c|c|c|}
\hline Blank Corrections & & & & & Ligu & Concentratio & (ua/L) & & & & & & & & & & & \\
\hline & & & 4-methyl-2- & & 1,2-dibromo & chloro & $1,2,3$-tri & 1,2,4-tri & & & & & & & & & & \\
\hline & & benzene & pentanone & toluene & ethane & benzene & chloropropane & chlorobenzene & & naphthalene & & & & & & & & \\
\hline Day\#0 & Process Blank - Liquid Sample & & 3.5 & & & & & 0.27 & & 1.2 & & & & & & & & \\
\hline & Field Blank - Liquid Sample & & & & & & & & & & & & & & & & & \\
\hline Day\#1 & Field Blank - Liquid Samole & & & 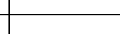 & & & & & & & & & & & & & & \\
\hline & Trip Blank - Liquid Sample & & & & & & & & & & & & & & & & & \\
\hline Day\#2 & Field Blank - Liquid Sample & & & & & & & & & & & & & & & & & \\
\hline & Trip Blank - Liquid Sample & & & 0 & & & & & & & Reagent cc & ontam. > trip & blank contam & & & & & \\
\hline & & & & & & & & & & & & & & & & & & \\
\hline Day\#3 & Field Blank - Liguid Sample & & & & & & & & & & & & & & & & & \\
\hline Day $¥ 3$ & $\begin{array}{l}\text { Flelal Blank - Liquid Sample } \\
\text { Trip Blank - Liquid Sample }\end{array}$ & & & 0 & & & & & & & Reagent cc & ontam. > trip $\mid$ & blank contam & & & & & \\
\hline & & & & & & & & & & & & & & & & & & \\
\hline & Reagent Blank - Liquid & & & 13.6 & & & & & & & & & & & & & & \\
\hline & & & & & & Mass (ng) & & & & & & & & & & & & \\
\hline & Trip Blank for Sample - Tenax & & 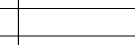 & 561 & & 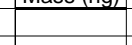 & & 33.2 & & 151 & & & & & & & & \\
\hline & Field Blank for Sample - Tenax & & 0 & 388 & & & & 0 & & 0 & & & & & & & & \\
\hline & Trip Blank for Sample Field Blank- Tenax & & 156 & & & & & 174 & & 736 & & & & & & & & \\
\hline & & & & & & & & & & & & & & & & & Room conc & tions \\
\hline & Process Blank - Tenax & 202 & 356 & 175 & & & & 0 & & 0 & Corrected $t$ & y field blank & $\mathrm{k} \&$ trip blank & 20.008 & liters gas : & ampled & & mbar \\
\hline & Field Blank for Process Blank- Tenax & & & 93.5 & & & & 22.3 & & 45.4 & & by trip blank & & 1.036 & & & & \\
\hline & Trip Blank for Process Blank- Tenax (Day 1) & & 18 & 280.5 & & & & 103.6 & & 443.5 & Average of & Days 2 and & & 20.34918 & & ers gas & & \\
\hline & Tenax tube corrections are for pairs of tubes & & & & & & & & & & & & & & & & & \\
\hline & Anasorb tube field and trip blanks all nondete & able & & & & & & & & & & & & & & & & \\
\hline
\end{tabular}




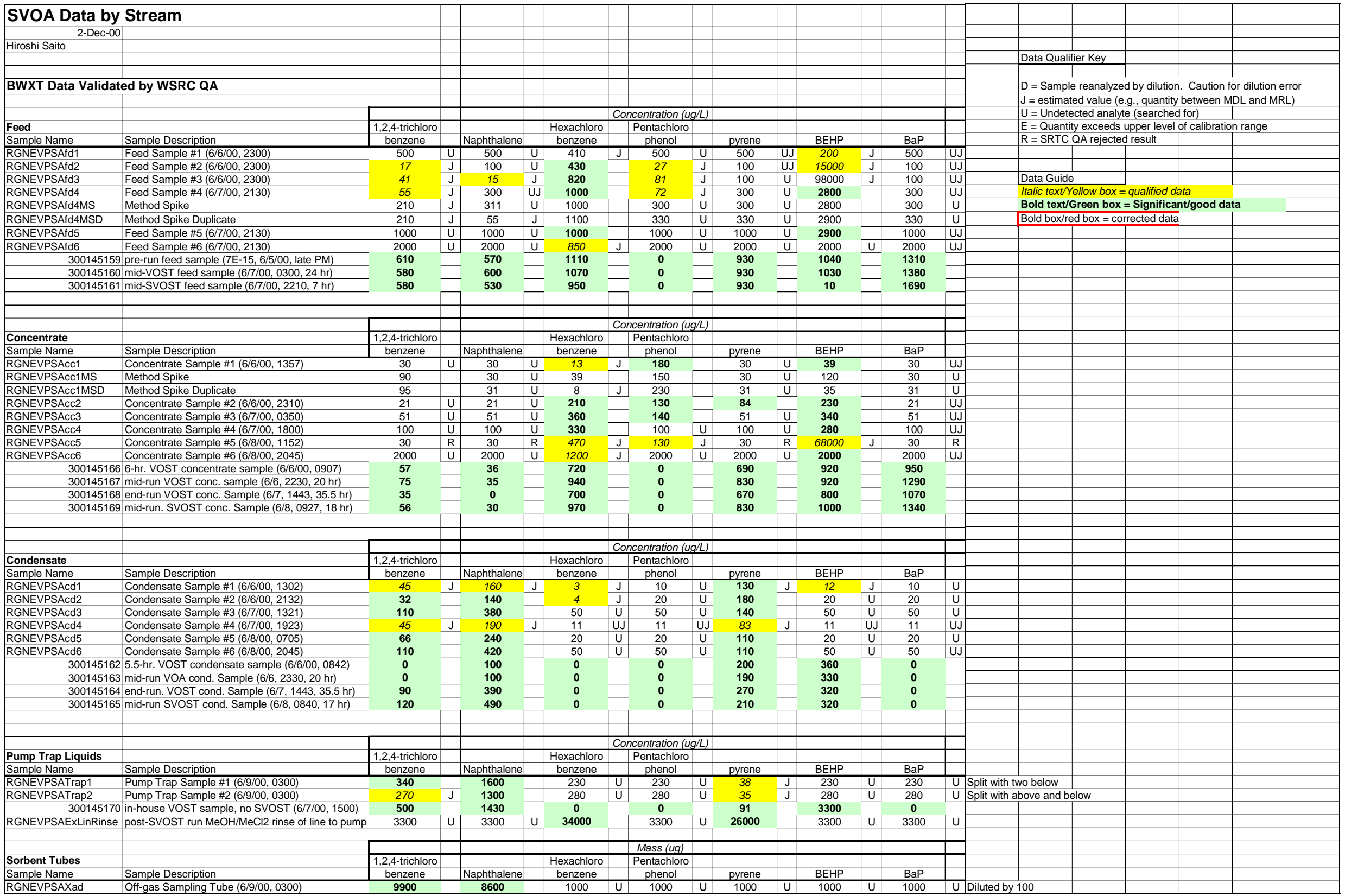


WSRC-TR-2000-00486

SRT-RPP-2000-00047

\begin{tabular}{|c|c|c|c|c|c|c|c|c|c|c|c|c|c|c|c|c|c|c|c|c|c|c|}
\hline & & & & & & & & icentration (L & & & & & & & & & & & & & & \\
\hline $\begin{array}{l}\text { Gas samplet Conden } \\
\text { Sample Name }\end{array}$ & & $\begin{array}{l}1,2,2, \text { tritrhiloro } \\
\text { benzen }\end{array}$ & & & & $\begin{array}{l}\text { Hexachloro } \\
\text { benzene }\end{array}$ & & $\begin{array}{l}\text { Pentachloro } \\
\text { phenol }\end{array}$ & & & & & & & & & & & & & & \\
\hline RGNEVPSACond1 & Offitgas Sampler Condensate \#1 (6/9/00, 0300) & 1000 & $\overline{U J}$ & 1000 & UJ & $\frac{1000}{100}$ & UJ & $\frac{1000}{1000}$ & $\overline{U J}$ & $\frac{1000}{1000}$ & UJ & $\frac{1000}{1000}$ & UJ & 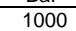 & UJ & & & & & & & \\
\hline RGNEVPSACond2 & 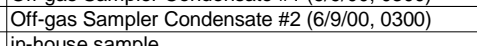 & & & $\cdots$ & & & 0 & & & $\cdots$ & $\infty$ & & 6 & & 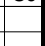 & Not generat & ted due to lov & ow volume & & & & \\
\hline & & & & & & & & & & & & & & & & & & & & & & \\
\hline & & & & & & & Col & centration (u & gg/L) & & & & & & ( & & & & & & & \\
\hline $\begin{array}{l}\text { Gas Sampler Rinse } \\
\text { Samplomen }\end{array}$ & & 1,2,4-trichloro & & & & $\begin{array}{l}\text { Hexachloro } \\
\text { henone }\end{array}$ & & $\begin{array}{c}\text { Pentachloro } \\
\text { nethen }\end{array}$ & & & & & & & & & & & & & & \\
\hline RGNEVPSARinse & $\begin{array}{l}\text { Sample Description } \\
\text { Off-gas Sampler Glassware Rinse }(6 / 9 / 00,0300)\end{array}$ & $\begin{array}{l}\text { benzene } \\
960\end{array}$ & $\mathrm{u}$ & $\frac{\text { Naphnthalen }}{960}$ & $\bar{u}$ & benzene & $\mathrm{U}$ & 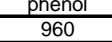 & u & yenene & $u$ & $\frac{B E P P}{960}$ & $\mathrm{u}$ & $\frac{\mathrm{BaP}}{960}$ & $u$ & Liquid used & to rinse sam & mpling syste & tem after sam & mpling & & \\
\hline & & & & & & & & & & & & & & & & & & & & & & \\
\hline & & & - & & & & 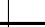 & & & & & & & & & & & & & & & \\
\hline Process Blanks & $6(6 / 400)$ & 1.24-4trichloro & & & & Hexachloro & Co & ceentration (u & gg/L) & & - & & - & & - & & & & & & & \\
\hline & & benzene & & & & benzene & & $\begin{array}{l}\text { phenol } \\
\text { phel }\end{array}$ & & pyrene & & BEHP & & $\mathrm{BaP}$ & & & & & & & & \\
\hline RGNEVPSP1 & Bottle 1 of 3, Simulant + ca. 800 ppm acetone & 10 & $\bar{U}$ & 10 & U & 5 & $\mathrm{~J}$ & 3 & $\mathrm{~J}$ & 10 & $\mathrm{U}$ & 16 & _ & 10 & Uu & Bottle 1 of 3 & 3 , Simulant + & $t+c a .800 \mathrm{p}$ & ppm acetone & & & \\
\hline $\begin{array}{l}\text { RGNEVPSP1Ri } \\
\text { RGNEPSP2 }\end{array}$ & ???? & $\frac{10}{150}$ & 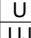 & $\frac{10}{150}$ & $\frac{u}{114}$ & $\stackrel{8}{150}$ & $\mathrm{~J}$ & $\stackrel{3}{150}$ & $\frac{\sqrt{14}}{2}$ & 10 & $u$ & $\begin{array}{c}30 \\
150\end{array}-10-10$ & HI & $\frac{10}{100}$ & Uu & & & & & & & \\
\hline $\begin{array}{l}\text { RGNEVPSP2 } \\
\text { RGNEVPSPMS }\end{array}$ & $\begin{array}{l}\text { Botle 2 o 3, Simulant + ca. } 800 \text { ppm acetone } \\
\text { Method Spike }\end{array}$ & $\frac{150}{64}$ & $\frac{\mathrm{J}}{\mathrm{U}}$ & $\begin{array}{l}150 \\
150\end{array}$ & $\frac{u}{U}$ & $\frac{150}{150}$ & $\frac{u}{u}$ & $\frac{150}{150}$ & $\frac{\mathrm{UJ}}{\mathrm{u}}$ & $\begin{array}{l}150 \\
150\end{array}$ & $\frac{u}{u}$ & $\frac{150}{150}$ & $\frac{u}{U}$ & $\frac{150}{150}$ & uJ & Bottle 2 of 3 & 3, Simulant + & itca. $800 \mathrm{p}$ & ppm acetone & & & \\
\hline RGNEVPSP2MSD & Method Spike Duplicate & 84 & J & 150 & $\mathrm{u}$ & 150 & u & $\frac{150}{150}$ & u & 150 & u & 110 & $\mathrm{~J}$ & 150 & $\mathrm{u}$ & & & & & & & \\
\hline RGNEVPSP3 & Bottle 3 of 3, Simulant + ca. 800 ppm acetone & & UJ & 10 & UJ & 10 & UJ & 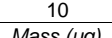 & UJ & 10 & UJ & & $\mathrm{J}$ & & UU & Bottle 3 of 3 & 3 , Simulant + & & ppm acetone & & & \\
\hline RGNEVPSPXad & & 10 & $\underline{U}$ & 10 & $\underline{U}$ & 10 & $u$ & $\frac{\text { Mass (lag) }}{10}$ & u & 10 & $\mathrm{U}$ & 10 & $\underline{U}$ & 10 & $\underline{U}$ & Went dry & ing extrat & ion & & & & \\
\hline RGNEVPSPTrap & For any pump trap liquid from process blank & 3300 & 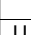 & 3300 & $\overline{I I}$ & & Co & $\begin{array}{ccc}\text { centration (L) } \\
3330\end{array}$ & $g / L)$ & 3300 & 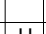 & & + & & & & & & & & & \\
\hline RGNEVPSPCond & 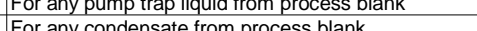 & 3300 & 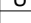 & & & 3300 & 0 & 3300 & 0 & 3300 & 0 & 3300 & 0 & 3300 & U & & & & & & & \\
\hline RGNEVPSPRinse & 1:1 (v/V) MethanolMethylene Chloride Wash Liquid & 120 & $\bar{u}$ & 120 & U & 120 & $\mathrm{U}$ & 120 & U & 120 & U & 120 & U & 120 & U & & & & & & & \\
\hline & & & & & & & & & & & & & & & & & & & & & & \\
\hline & & & & & & & $C_{0}$ & Icentration $(L)$ & ggll) & & - & & & & - & & & & & & & \\
\hline $\begin{array}{l}\text { Feld Blanks } \\
\text { Sample Name } \\
\end{array}$ & Sample Description & $\begin{array}{ll}1,2,4 \text {-trichloro } \\
\text { bezene }\end{array}$ & & Naphthalene & & $\begin{array}{l}\text { Hexachloro } \\
\text { benzene }\end{array}$ & - & 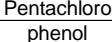 & & pyrene & & BEHP & & $\mathrm{BaP}$ & 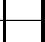 & & & & & & & \\
\hline 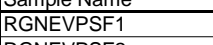 & Day $\# 1$, Bottle 1 of $3(6 / 4 / 00,1715)$ & 10 & $\mathrm{u}$ & 10 & $\mathrm{u}$ & $\frac{10}{10}$ & $\mathrm{u}$ & 10 & u & $\frac{10}{10}$ & $\mathrm{U}$ & $\frac{D L T h}{10}$ & $\bar{U}$ & $\frac{10 \mathrm{~d}}{10}$ & $\mathrm{U}$ & & & & & & & \\
\hline $\begin{array}{l}\text { RGENEPSSF } \\
\text { RGNEVPSF3 }\end{array}$ & $\begin{array}{l}\text { Day \#1, Bottle } 2 \text { of } 3(6 / 4 / 1 / 00,1715) \\
\text { Day \#1, Bottle } 3 \text { of } 3(6 / 400,1715)\end{array}$ & $\frac{10}{10}$ & $\frac{U}{u}$ & $\frac{10}{10}$ & $\frac{u}{u}$ & $\frac{10}{10}$ & u & $\begin{array}{l}10 \\
10\end{array}$ & u & $\begin{array}{l}10 \\
10 \\
10\end{array}$ & $\frac{U}{U}$ & $\frac{10}{10}$ & $\frac{u}{u}$ & $\frac{10}{10}$ & $\frac{u}{u}$ & & & & & & & \\
\hline RGNEVPSF4 & Day \#2, for Feed Sample, Bottle 1 of $3(6 / 5 / 00,2200$ & $\frac{10}{10}$ & u & 10 & u & 10 & u & 10 & u & 10 & u & 10 & u & 10 & Uu & & & & & & & \\
\hline RGNEVPSF5 & Day \#2, for Feed Sample, Bottle 2 of $3(6 / 5 / 00,2200$ & 10 & U & 10 & u & 10 & u & ${ }_{10}^{10}$ & U & 10 & u & 10 & U & 10 & $\bar{U}$ & & & & & & & \\
\hline RGNEVPSF6 & Day \#2, for Feed Sample, Bottle 3 of 3 (6/5/00, 2200 & 10 & $\begin{array}{l}u \\
\end{array}$ & 10 & U & 10 & U & 10 & $\mathrm{U}$ & 10 & U & 10 & U & 10 & U & & & & & & & \\
\hline $\begin{array}{l}\text { RGNEVPSF7 } \\
\text { RGNEVIPSE }\end{array}$ & For Cond/Conc, Bottle 1 (Day 2) of $3(6 / 5 / 1 / 00,2200)$ & 10 & u & 10 & u & $\frac{10}{10}$ & u & $\frac{10}{10}$ & $\mathrm{U}$ & 10 & u & 10 & $\begin{array}{l}u \\
1\end{array}$ & 10 & u & & & & & & & \\
\hline RGNEVPSF8 & $\begin{array}{l}\text { For Cond//Conc, Bottle } 2 \text { (Day 3) of } 3(6 / 6 / 100,1000) \\
(6 / 7 / 00,2130)\end{array}$ & $\frac{10}{10}$ & $\frac{U}{u}$ & $\frac{10}{10}$ & $\frac{\mathrm{u}}{\mathrm{u}}$ & $\frac{10}{10}$ & $\frac{u}{u}$ & $\begin{array}{l}10 \\
10\end{array}$ & $\frac{U}{u}$ & $\begin{array}{c}1 \\
10\end{array}$ & $\frac{u}{u}$ & $\frac{10}{10}$ & $\frac{u}{u}$ & $\frac{10}{10}$ & $\frac{\mathrm{u}}{\mathrm{u}}$ & Received 6 & & & & & & \\
\hline RGNEVPSF9 & For Cond/Conc, Bottle 3 (Day 3 & 10 & U & 10 & u & 10 & u & 10 & 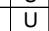 & 10 & & 0.3 & J & 10 & u & & & & & & & \\
\hline RGNEVPSF10 & Day \#3, for Feed Sample, Bottll & 10 & $\bar{U}$ & 10 & u & 10 & $U$ & 10 & U & 10 & u & 10 & U & 10 & U & & & & & & & \\
\hline RGNEVPSF11 & Day \#3, for Feed Sample, Bottle 2 of $3(6 / 8 / 800,2100$ & 10 & $\underline{U}$ & 10 & U & 10 & U & 10 & U & 6 & $\mathrm{~J}$ & 10 & U & 10 & U & & & & & & & \\
\hline RGENVPSF 12 & Day \#3, for Feed Sample, Bottle 3 of 3 (6/8/800, 2100 & 10 & UJ & 100 & UJ & 10 & UJ & 10 & UJ & 10 & UJ & 100 & 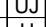 & 10 & $\begin{array}{lll}\mathrm{U} J \\
\end{array}$ & & & & & & & \\
\hline $\begin{array}{l}\text { RGINEVPSFIS } \\
\text { RGNEVPSF13DL }\end{array}$ & 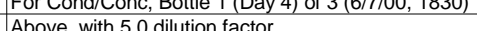 & $\frac{10}{150}$ & $\mathrm{u}$ & $\frac{10}{150}$ & u & 520 & D & $\frac{10}{150}$ & 0 & 150 & un & 600 & 菏 & $\frac{10}{150}$ & 要 & & & & & & & \\
\hline RGNEVPSF 13 MSS & Method Spike & $\frac{100}{110}$ & e & 33 & u & 760 & $\mathrm{E}$ & $\frac{250}{250}$ & 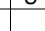 & $\frac{120}{120}$ & e & 86000 & E & $\frac{103}{33}$ & U & & & & & & & \\
\hline RGNEVPSF13MSD & Method Spike Duplicate & 100 & & 33 & $\bar{U}$ & 710 & $\mathrm{E}$ & 200 & & 410 & & 120000 & E & 33 & $\bar{U}$ & & & & & & & \\
\hline RGNEVPSF14 & For Cond/Conc, Bottle 2 (Day 4) of $3(6 / 7 / 00,1830)$ & 10 & u & 10 & U & 10 & & 10 & U & 10 & u & 0.3 & $J$ & 10 & u & & & & & & & \\
\hline RGNEVPSF15 & For Cond/Conc, Bottle 3 (Day 5) of 3 & & & & & & & & & & & & & & & & & & & & & \\
\hline RGNEVPSFXad1 & Field blank associated with process blank & $\cdots$ & & & & & & Mass (ug) & & & & & 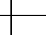 & & & & & & & & & \\
\hline RGNEVPSFXad2 & Per Method 0010 & 4 & & 4 & $\mathrm{~J}$ & 10 & U & 10 & $U$ & 10 & $\mathrm{U}$ & 10 & $\mathrm{U}$ & 10 & $\mathrm{U}$ & Went dry di & uring extractil & tion & & & & \\
\hline RGNEVPSFRinse1 & Field blank associated with process blank & & $\bar{U}$ & 130 & & 130 & U & 130 & $19(\mathrm{~L})$ & 130 & $U$ & 130 & u & 130 & u & & & & & & & \\
\hline RGNEVPSFRinse2 & Per Method 0010 & 570 & $\bar{U}$ & 570 & J & 570 & $\mathrm{U}$ & 570 & $\mathrm{u}$ & 570 & $\mathrm{U}$ & 64 & J & 570 & u & & & & & & & \\
\hline RGNEVPSFCond & Reagent water & & & & & & & & & & & & & & & & & & & & & \\
\hline & & & & & & & $C$ & & ug/L) & & & & & & & & & & & & & \\
\hline Reagent Blanks & & 1,2,4-trichloro & & & & Hexachloro & & $\begin{array}{l}\text { Pentachloro } \\
\end{array}$ & & & & & & & & & & & & & & \\
\hline RGNEVPSRMeth & $\begin{array}{l}\text { Fresh } 1: 1 \text { (1/v/v) MeOH/MeCl2 Wash Li } \\
\end{array}$ & 85 & $\bar{u}$ & 85 & $\bar{U}$ & benzene & U & $\begin{array}{c}\text { phenol } \\
85\end{array}$ & U & oyrene & $\mathrm{U}$ & $\frac{B E H P}{85}$ & $\bar{u}$ & $\frac{\mathrm{BaP}}{85}$ & $u$ & & & & & & & \\
\hline
\end{tabular}




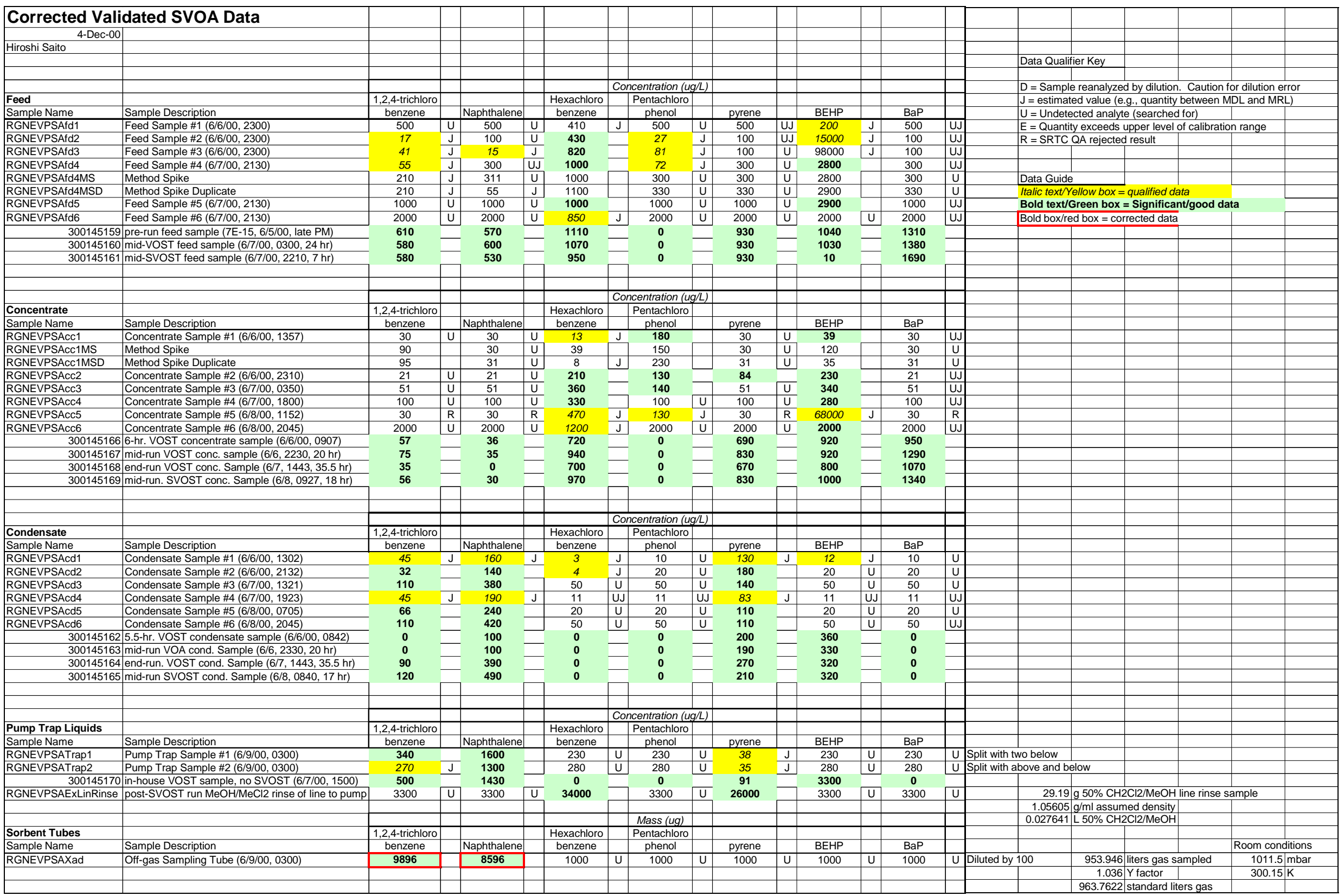


WSRC-TR-2000-00486

SRT-RPP-2000-00047

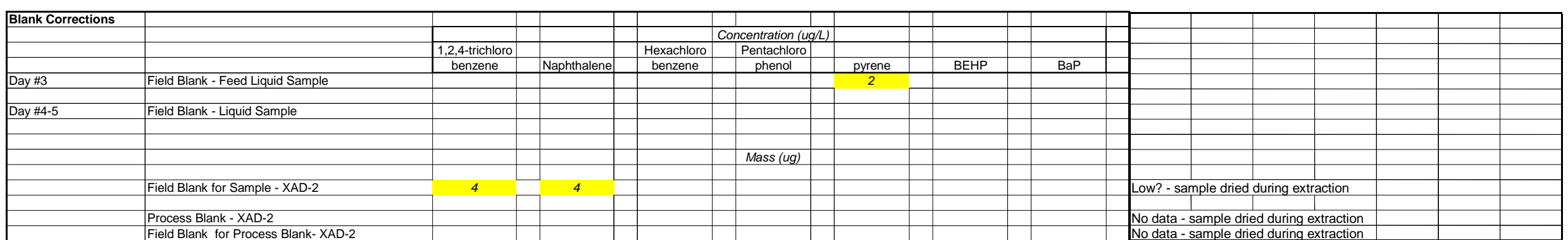




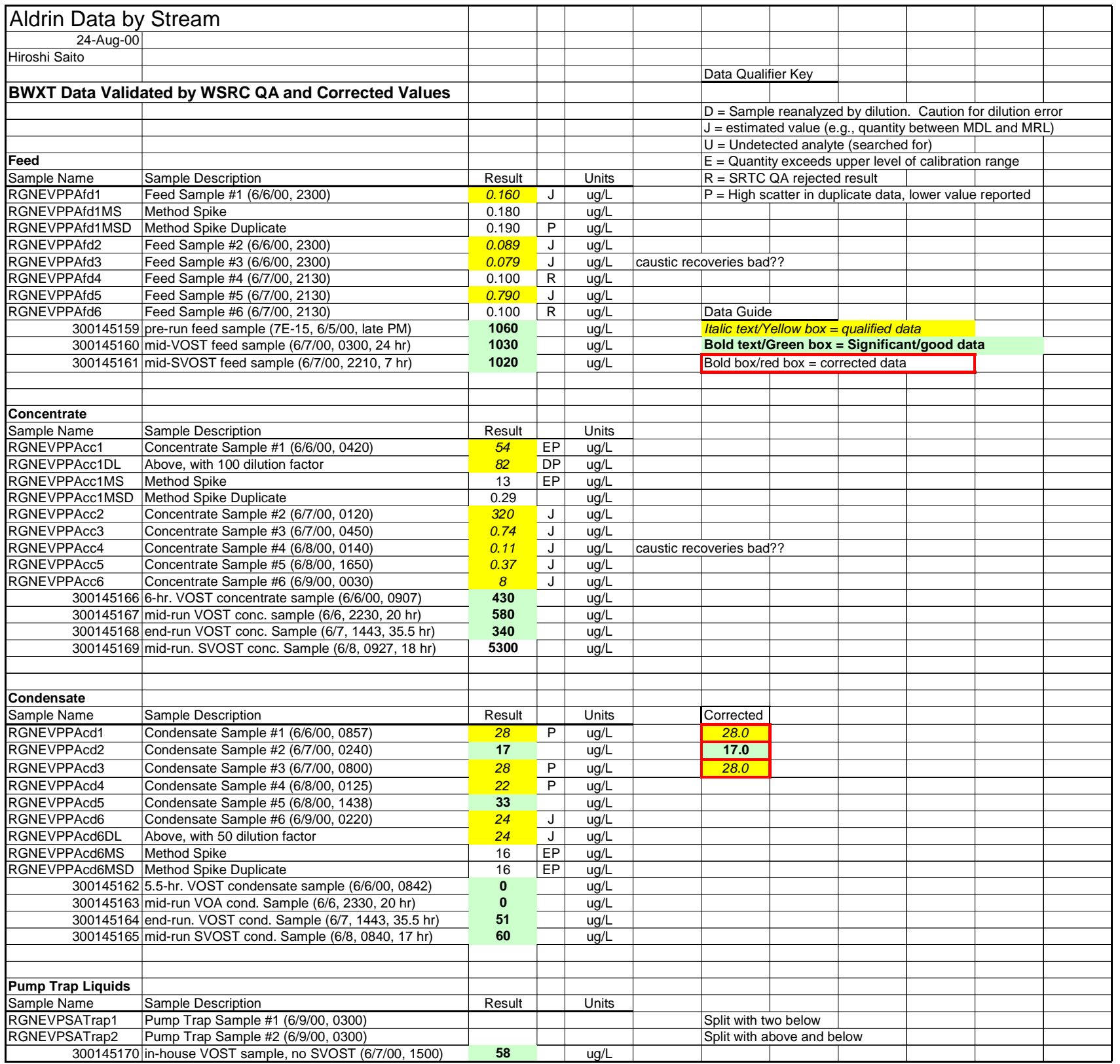


WSRC-TR-2000-00486

SRT-RPP-2000-00047

\begin{tabular}{|c|c|c|c|c|c|c|c|c|c|c|c|}
\hline \begin{tabular}{|l|} 
Sorbent Tubes \\
Sample Name \\
\end{tabular} & Sample Description & Result & & Units & & & & & & & \\
\hline RGNEVPSAXad & Off-gas Sampling Tube $(6 / 9 / 00,0300)$ & 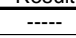 & & & & Went dry di & Uring extrac & tion, then lo & st during cor & oncentration & \\
\hline & & & & & & & & & & & \\
\hline & & & & & & & & & & & \\
\hline Gas Sampler Cond & ssate & & & & & & & & & & \\
\hline & Sample Description & Result & & Units & & & & & & & \\
\hline RGNEVPSACond1 & Off-gas Sampler Condensate \#1 (6/9/00, 0300) & & & & & Split with th & vo below & & & & \\
\hline RGNEVPSACond2 & Off-gas Sampler Condensate \#2 $(6 / 9 / 00,0300)$ & $\cdots$ & & & & Split with at & bove and be & & & & \\
\hline & in-house sample & & & & & & & & & & \\
\hline & & & & & & & & & & & \\
\hline \begin{tabular}{|l} 
Gas Sampler Rinse \\
Sample Name
\end{tabular} & & & & & & & & & & & \\
\hline \begin{tabular}{|l} 
Sample Name \\
RGNEVPARinse \\
\end{tabular} & $\begin{array}{l}\text { Sample Descrition } \\
\text { Off-gas Sampler Glassware Rinse }(6 / 9 / 00,0300)\end{array}$ & Result & 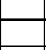 & Units & & Liquid used & to rinse sa & impling syste & em after sam & impling & \\
\hline & & & & & & & & & & & \\
\hline & & & 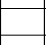 & & & & & & & & \\
\hline Process Blanks & $(6 / 5 / 00)$ & & & & & & & & & & \\
\hline \begin{tabular}{|l} 
Sample Name \\
RCNEVPD1
\end{tabular} & 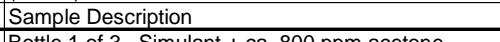 & $\begin{array}{ll}\text { Result } \\
0050\end{array}$ & $\square$ & Units & & & & & & & \\
\hline \begin{tabular}{|l} 
RGNEVPPP1 \\
RGEVPPP2
\end{tabular} & Bottle 1 of 3 , Simulant + ca. $800 \mathrm{ppm}$ acetone & 0.050 & $\frac{U}{4}$ & $\mathrm{ug} / \mathrm{L}$ & & Bottle 1 of 5 & 3, Simulant & $t+$ ca. $800 p$ & opm acetone & & \\
\hline $\begin{array}{l}\text { RGNENVPP2 } \\
\text { RGNEVPPP3 }\end{array}$ & $\begin{array}{l}\text { Bottle } 2 \text { o } 3 \text {, Simulant }+ \text { ca. } 800 \text { ppm acetone } \\
\text { Bottle } 3 \text { of } 3 \text {, Simulant }+ \text { ca. } 800 \text { ppm acetone }\end{array}$ & 0.050 & $\frac{u}{u}$ & $\frac{\mathrm{ugg} / \mathrm{L}}{\mathrm{ug} / \mathrm{L}}$ & & $\begin{array}{l}\text { Bottle } 2 \text { of } 3 \\
\text { Bottle } 3 \text { of } 3 \\
\end{array}$ & 3. Simulant & $\frac{t+\text { ca. } 800 p}{t+c .800 p}$ & opm acetone & & \\
\hline RGNEVPSPXad & & & & & & & & & & & \\
\hline $\begin{array}{l}\text { RGNEVPSPTrap } \\
\text { RGNEVPSPCond }\end{array}$ & $\begin{array}{l}\text { For any pump trap liquid from processs blank } \\
\text { For any condensate from process blank }\end{array}$ & 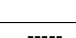 & & & & & & & & & \\
\hline RGNEVPSPRinse & 1:1 (v/V) Methanol/Methylene Chloride Wash Liquid & $\cdots$ & & & & & & & & & \\
\hline & & & - & & & & & & & & \\
\hline Field Blanks & 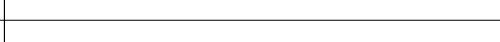 & & - & & & & & & & & \\
\hline $\begin{array}{l}\text { Sample Name } \\
\text { Samb }\end{array}$ & Sample Description & Result & & Units & & & & & & & \\
\hline $\begin{array}{l}\text { RGNEVPPF } 1 \\
\text { BGNEDPDE }\end{array}$ & Day \#1, Bottle 1 of $3(6 / 4 / 00,1715)$ & 0.050 & U & $\mathrm{ug} / \mathrm{L}$ & & & & & & & \\
\hline $\begin{array}{l}\text { RGNEEPPF } 2 \\
\text { RGNEVPPF3 }\end{array}$ & 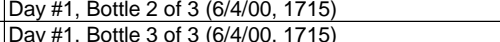 & 0.050 & $u$ & ug/L & & & & & & & \\
\hline RGNEVPPF4 & $\begin{array}{l}\text { Day } \# 2 \text {, for Feed Sample, Bottle } 1 \text { of } 3(6 / 5,2200) \\
\text { Def }\end{array}$ & 0.050 & $\mathrm{u}$ & $\mathrm{ug} / \mathrm{L}$ & & & & & & & \\
\hline RGNEVPPF5 & Day \#2, for Feed Sample, Bottle 2 of $3(6 / 5,2200)$ & 0.050 & $\mathrm{U}$ & $u g / L$ & & & & & & & \\
\hline $\begin{array}{l}\text { RGNEVYPF6 } \\
\text { RGNEPPF7 }\end{array}$ & Day \#2, for Feed Sample, Bottle 3 of $3(6 / 5,2200)$ & 0.050 & $\mathrm{U}$ & $\mathrm{ug} / \mathrm{L}$ & & & Correction & & & & \\
\hline $\begin{array}{l}\text { RGINEVPFF } \\
\text { RGNEVPPF8 }\end{array}$ & 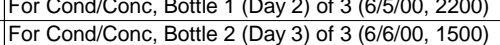 & $\begin{array}{l}0.050 \\
0.092\end{array}$ & 0 & $\frac{\mathrm{ugg} \mathrm{L}}{\mathrm{gg} / \mathrm{L}}$ & received $6 / / / 2,0$ & $8 / 00$ & Correction & & & & \\
\hline & $(6 / 7 / 00,2130)$ & 0.050 & U & $\mathrm{ug} / \mathrm{L}$ & received $6 /$ & & & & & & \\
\hline RGNEVPPF9 & For Cond/Conc, Bottle 3 (Day 3$)$ of $3(6 / 7 / 00,2130)$ & 0.050 & $\mathrm{R}$ & $\mathrm{ug} / \mathrm{L}$ & & & & & & & \\
\hline $\mid \frac{\text { RGNEVPPF10 }}{\text { RGNEVPPF11 }}$ & Day \#3, for Feed Sample, Bottle 1 of $3(6 / 7,2130)$ & 0.050 & $\mathrm{U}$ & ug/L & & & & & & & \\
\hline $\begin{array}{l}\text { RGNEVPFI11 } \\
\text { RGNEVPF12 }\end{array}$ & 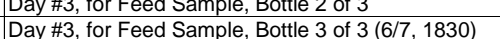 & 0.050 & $\bar{U}$ & $\mathrm{ug} / \mathrm{L}$ & & & & & & & \\
\hline RGNEVPPF13 & For Cond/Conc, Bottle 1 (Day 4) of $3(6 / 7,1830)$ & 0.050 & U & $\mathrm{ug} / \mathrm{L}$ & & & & & & & \\
\hline RGNEVPPF14 & For Cond/Conc, Bottle 2 (Day 5) of 3 & 0.050 & UJ & $u g / L$ & & & & & & & \\
\hline & For Cond/Conc, Bottle 3 (Day 5) of 3 & 0.050 & UJ & $u g / L$ & & & & & & & \\
\hline RGNEVPSFXad1 & Field blank associated with process blank & & & & & & & & & & \\
\hline RGNEVPSFXad2 & Per Method 0010 & & & & & & & & & & \\
\hline $\begin{array}{l}\frac{\text { RGNEVPSFRinse } 1}{\text { RGNEVPFFRinse2 }} \\
\text { RGE }\end{array}$ & Field blank associated with process blank & & & & & & & & & & \\
\hline RGNEVPSFCond & Reagent water & $\ldots$ & & & & & & & & & \\
\hline & & & & & & & & & & & \\
\hline Reagent Blanks & & & & & & & & & & & \\
\hline Sample Name & Sample Description & Result & & Units & & & & & & & \\
\hline RGNEVPSRMeth & Fresh 1:1 (v/v) MeOH/MeCl2 Wash Liquid & & & & & & & & & & \\
\hline
\end{tabular}




\section{Appendix C - Target Organic Compound Mass Balances}

This section presents mass balance information in four ways:

- Overall for the entire experiment, using volatiles off-gas sampling data to estimate volatiles emissions during semi-volatiles/pesticide off-gas sampling, and vice-versa.

- Using data obtained only during volatiles off-gas sampling (Method 0031)

- Using data obtained only during semi-volatiles off-gas sampling (Method 0010)

- OLI model results for predicting organics distribution among evaporator streams when concentrating from 5.8 to $8.0 \mathrm{M} \mathrm{Na}$ 
WSRC-TR-2000-00486

SRT-RPP-2000-00047

A. Overall Mass Balance

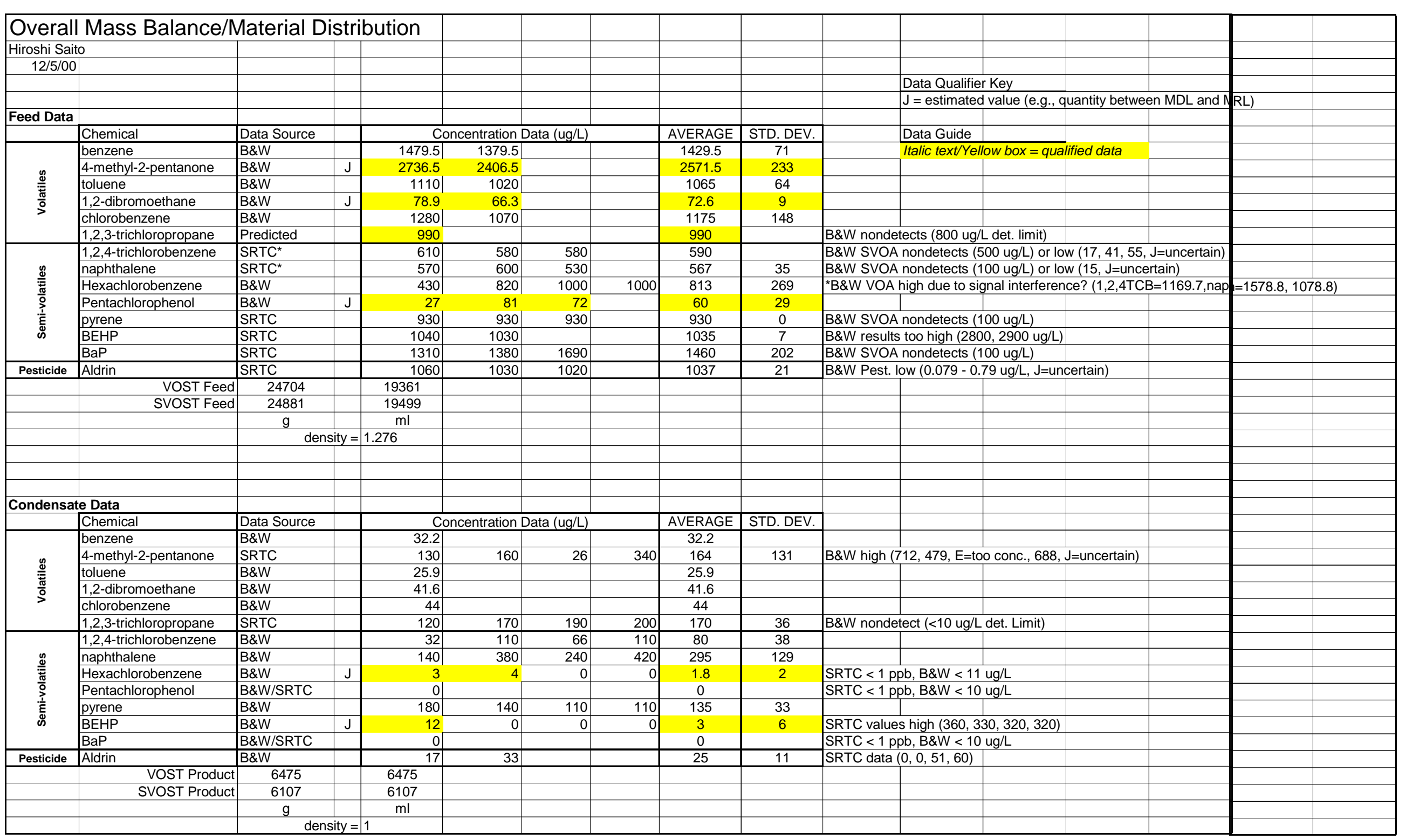


WSRC-TR-2000-00486

SRT-RPP-2000-00047

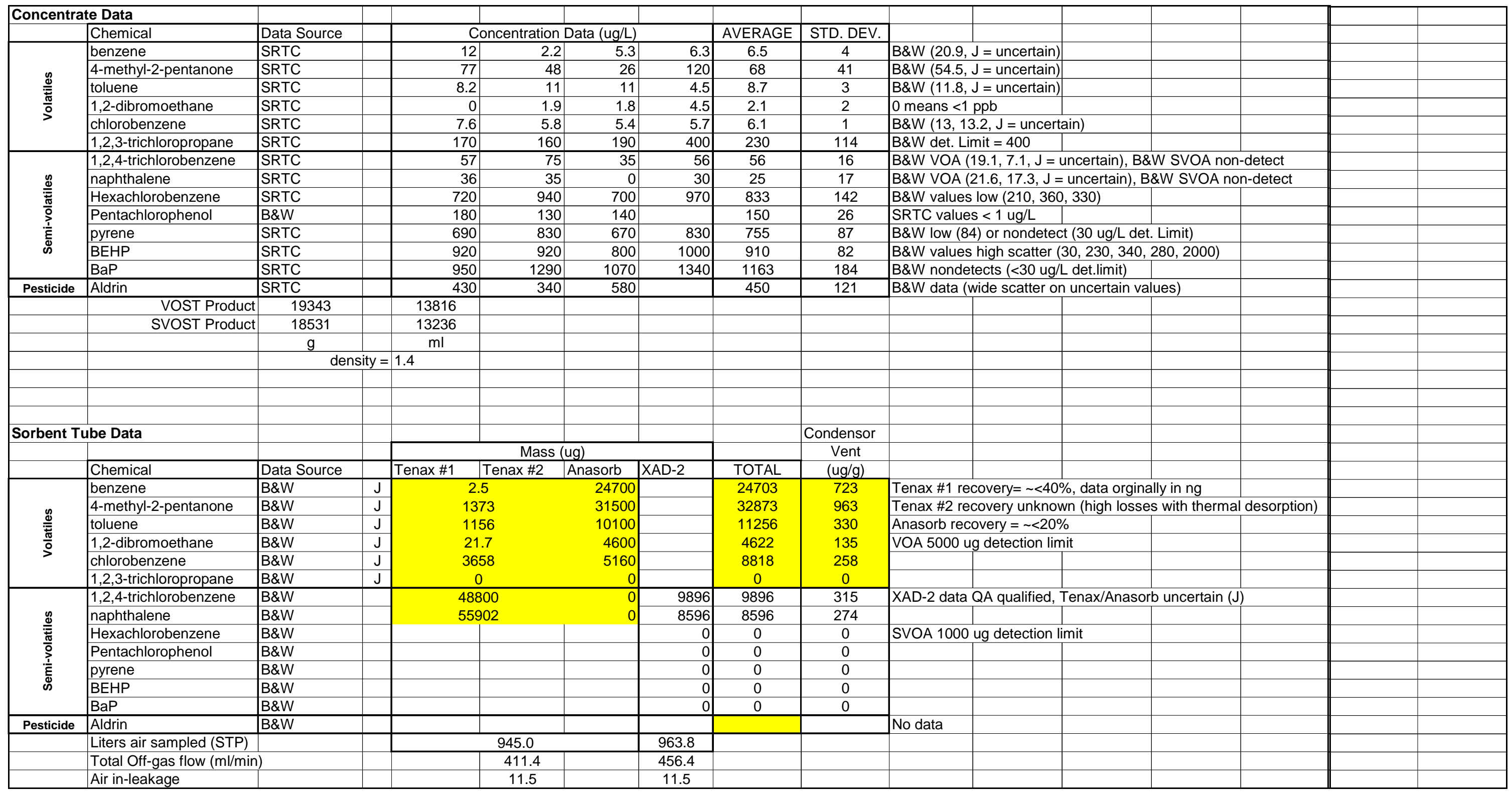


WSRC-TR-2000-00486

SRT-RPP-2000-00047

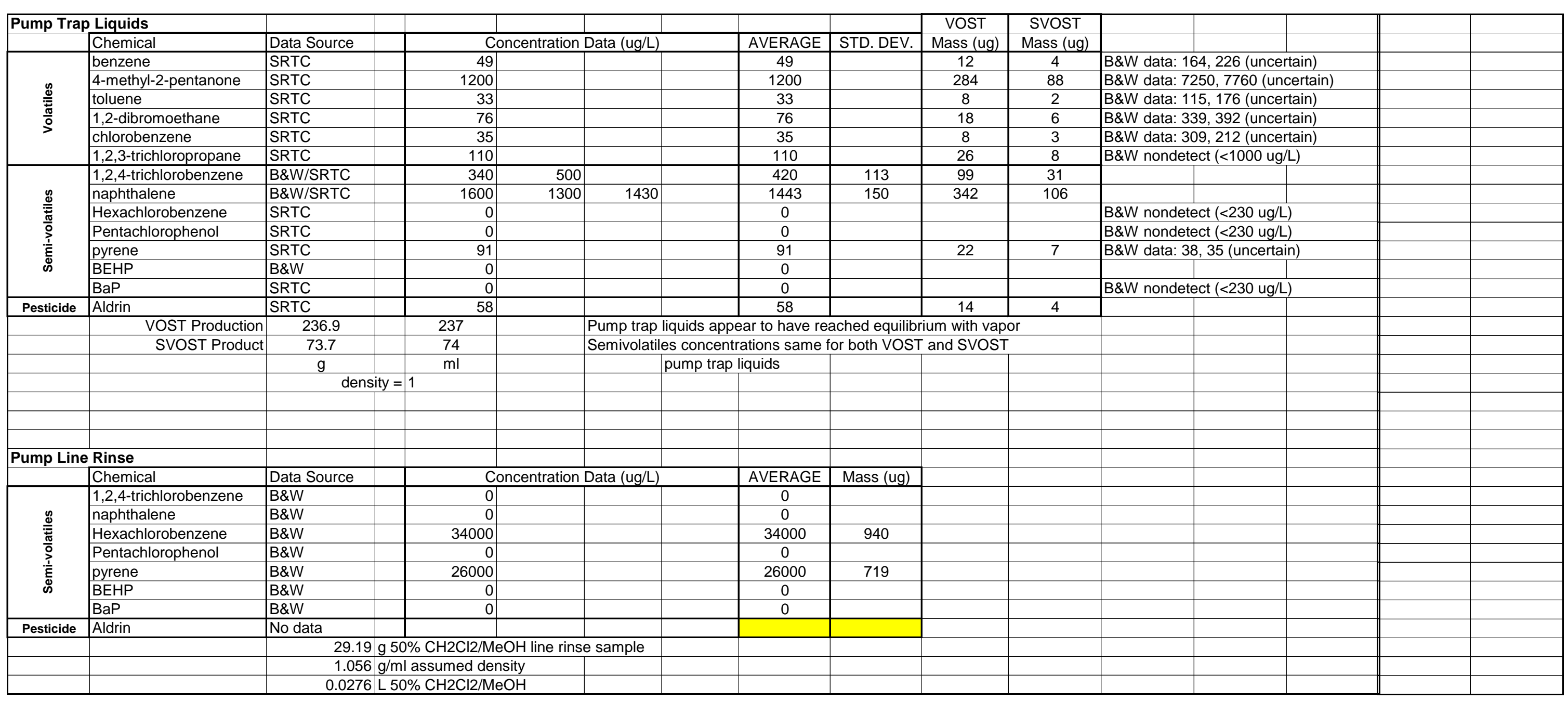


WSRC-TR-2000-00486

SRT-RPP-2000-00047

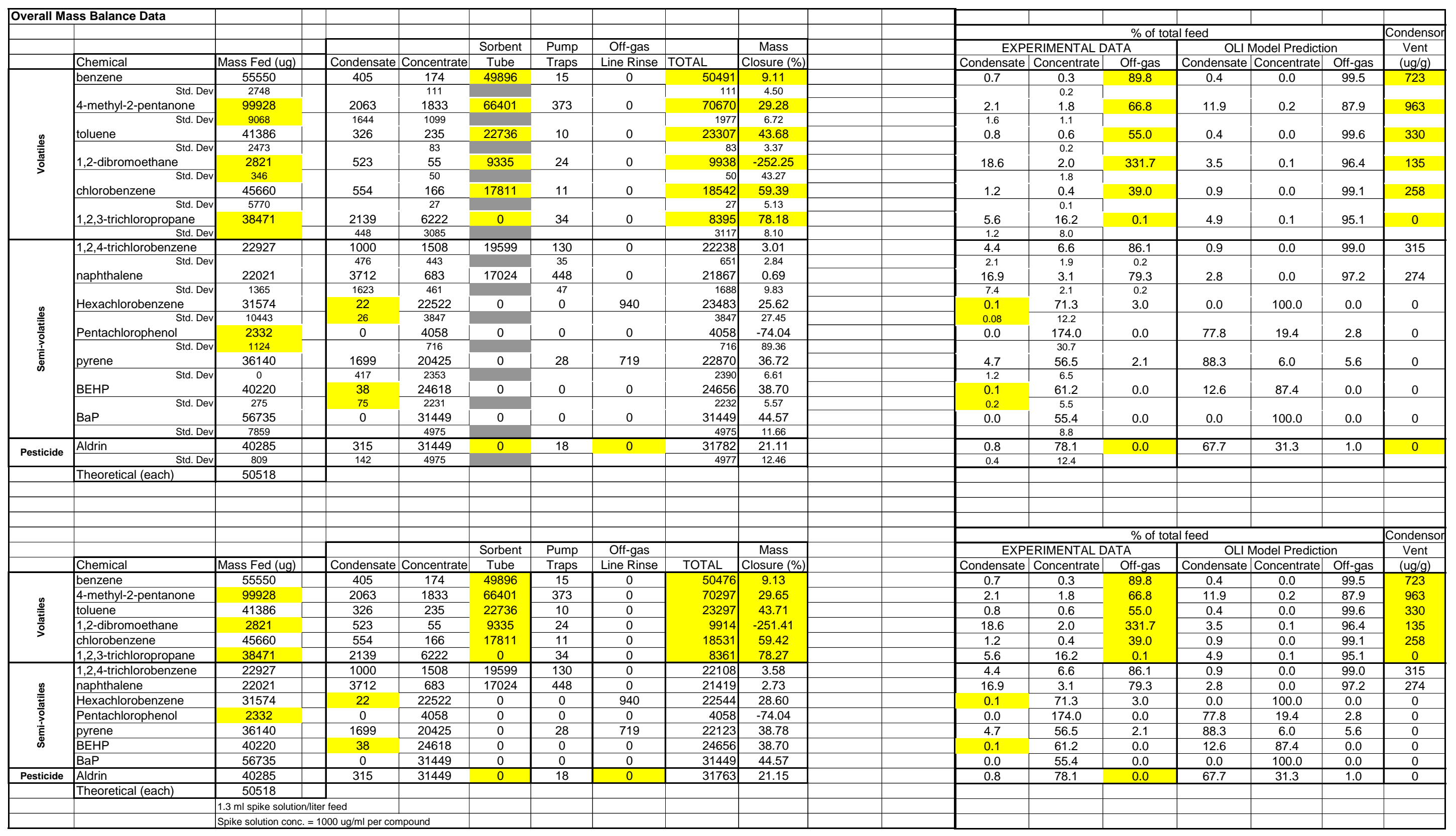


B. Volatiles Off-gas Sampling Mass Balance (VOST)

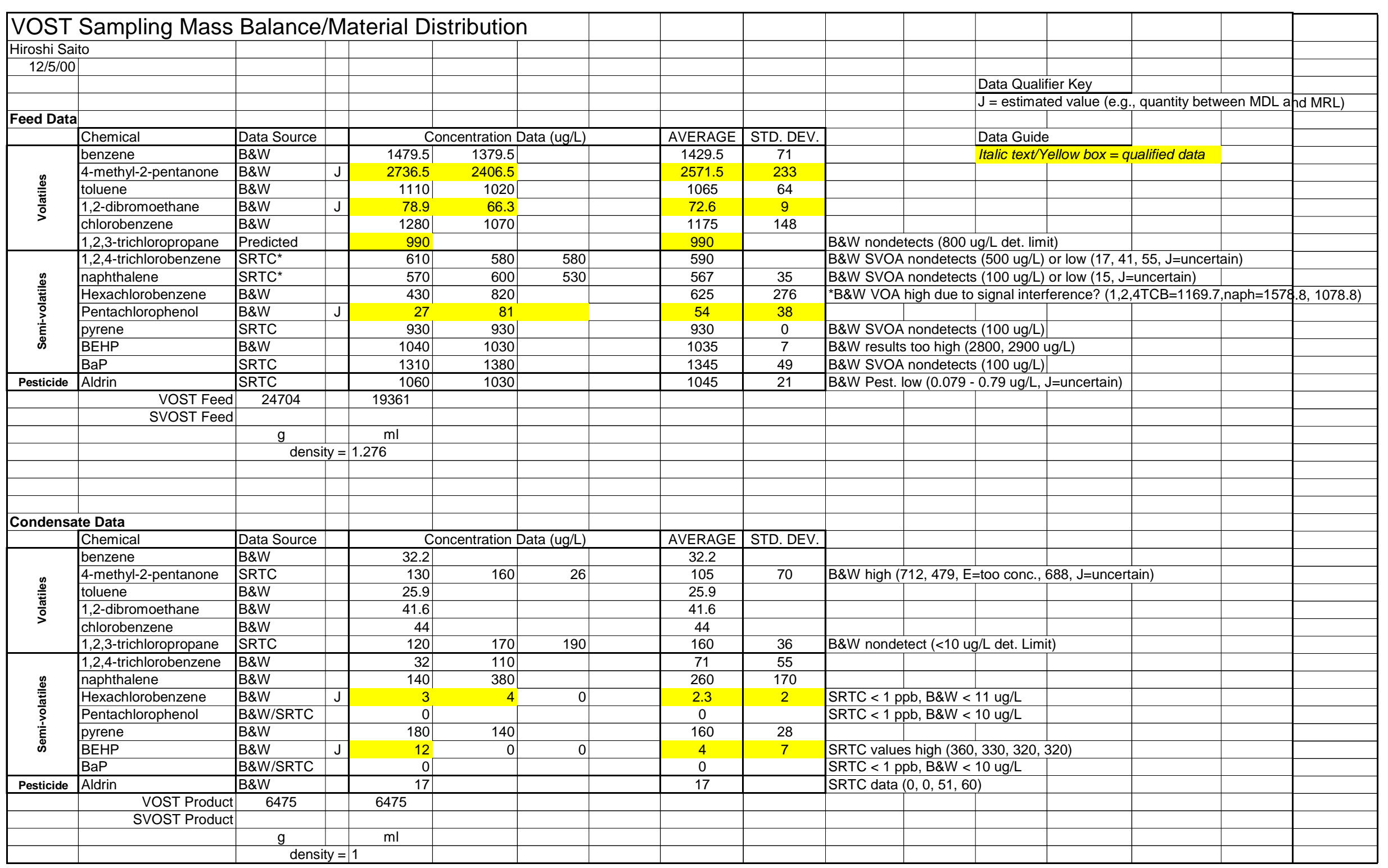


WSRC-TR-2000-00486

SRT-RPP-2000-00047

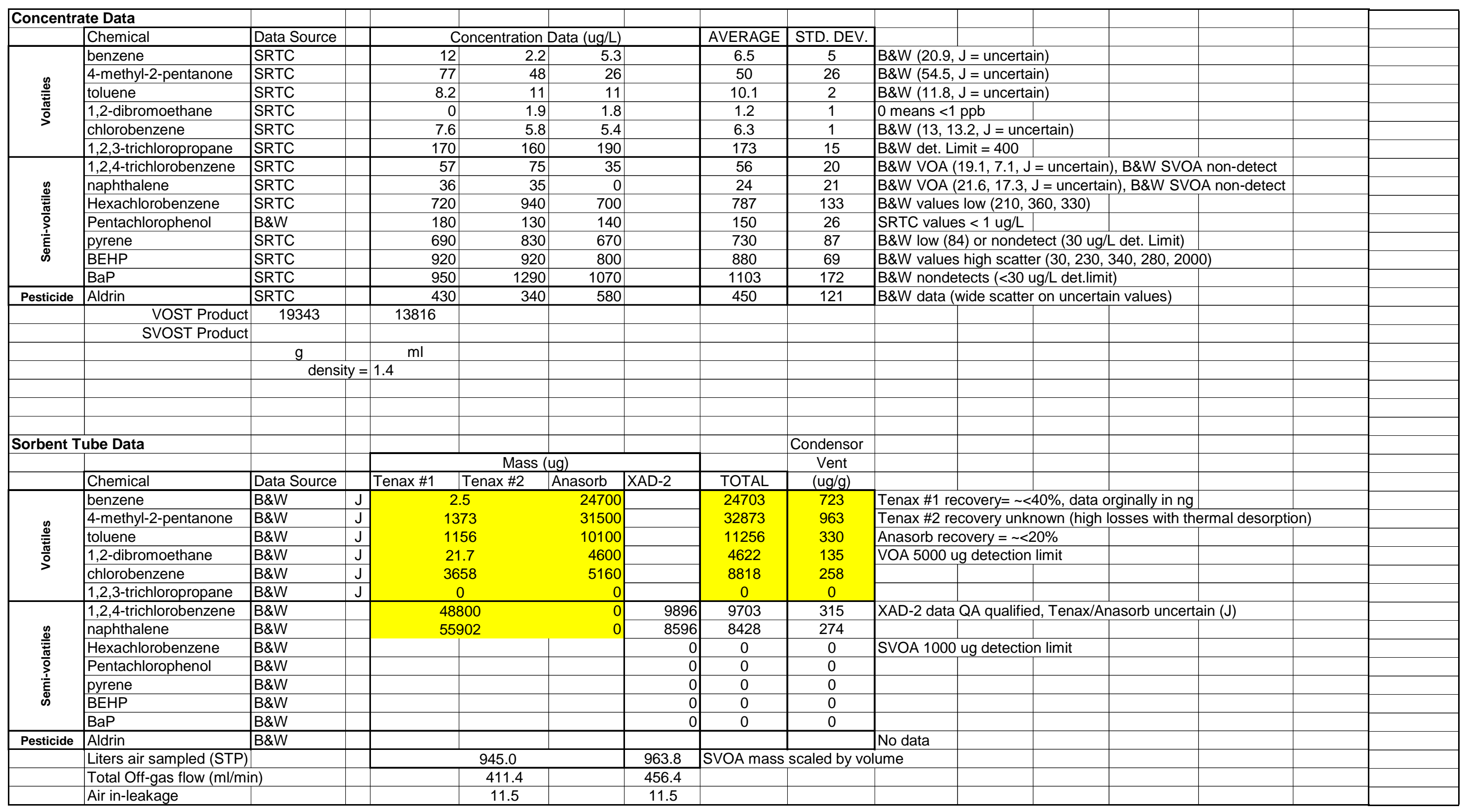


WSRC-TR-2000-00486

SRT-RPP-2000-00047

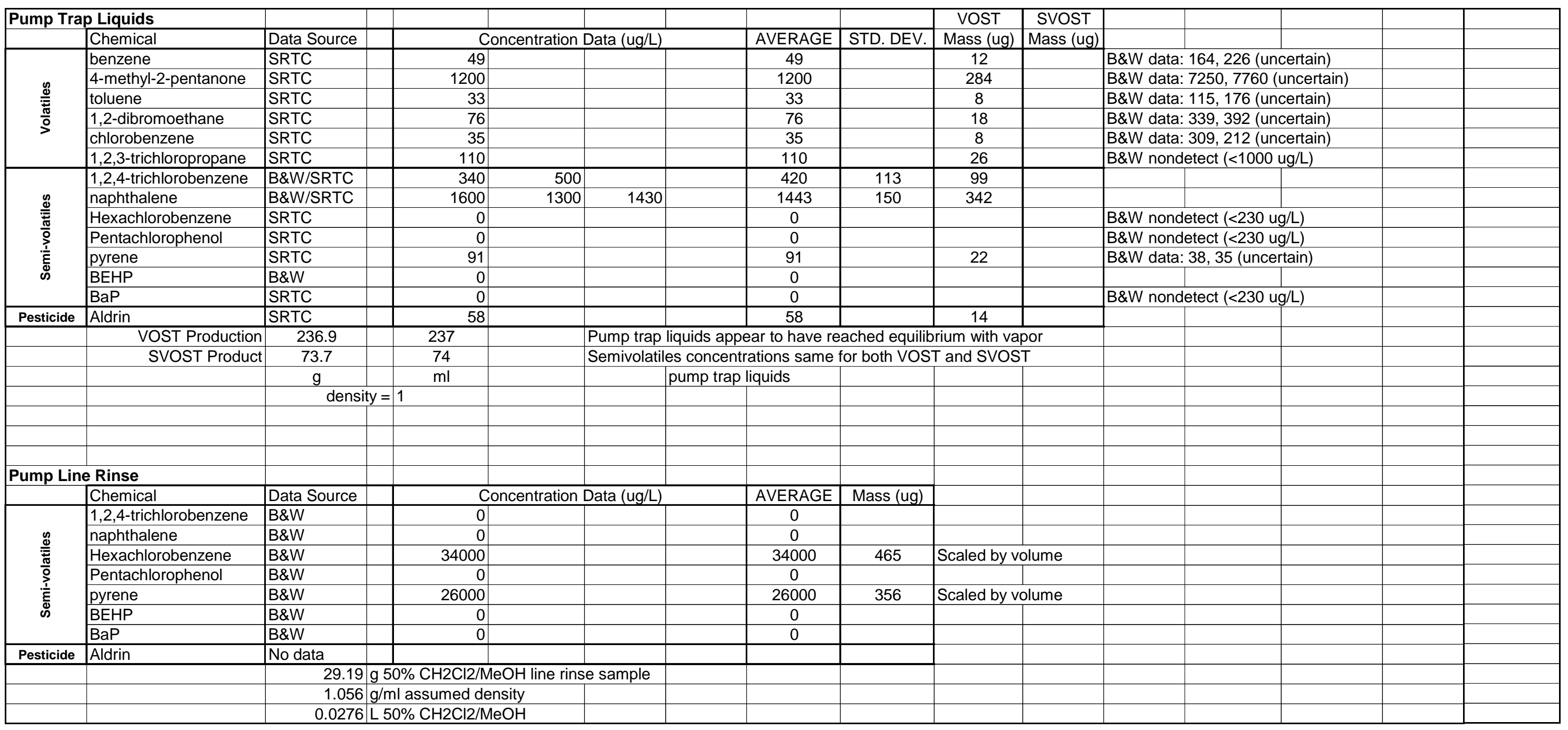


WSRC-TR-2000-00486

SRT-RPP-2000-00047

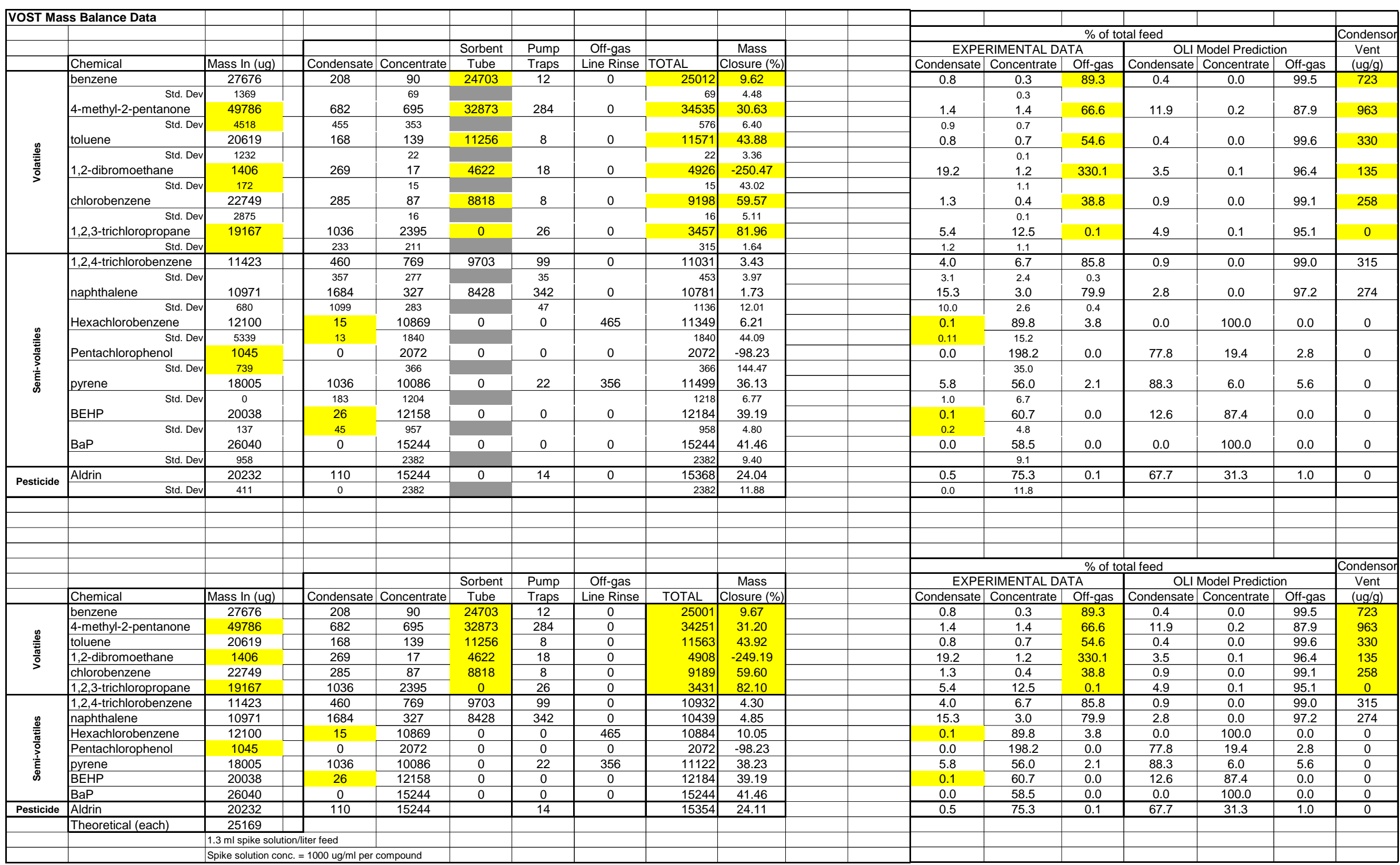


WSRC-TR-2000-00486

SRT-RPP-2000-00047

C. Semi-volatiles Off-gas Sampling Mass Balance (SVOST)

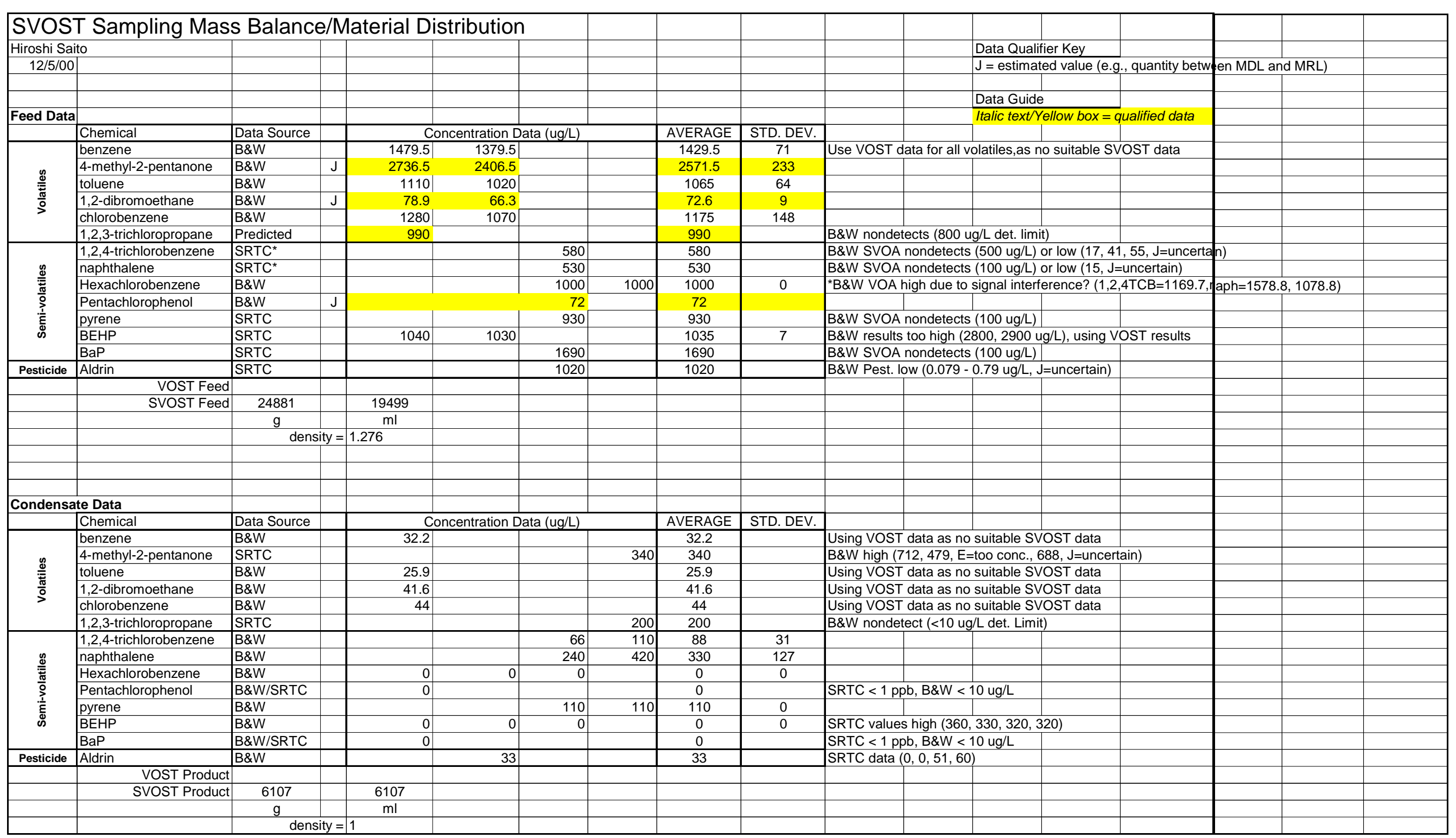


WSRC-TR-2000-00486

SRT-RPP-2000-00047

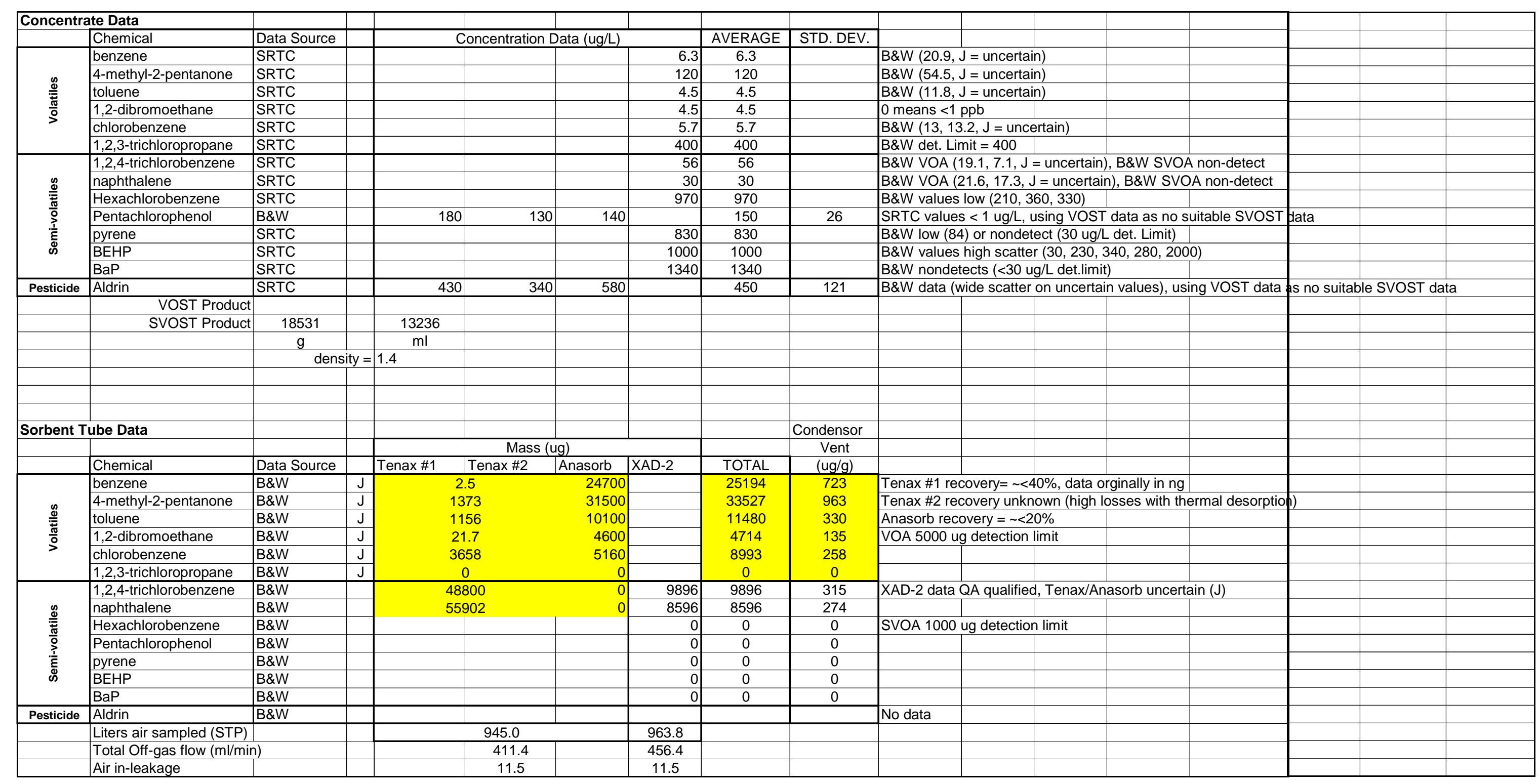


WSRC-TR-2000-00486

SRT-RPP-2000-00047

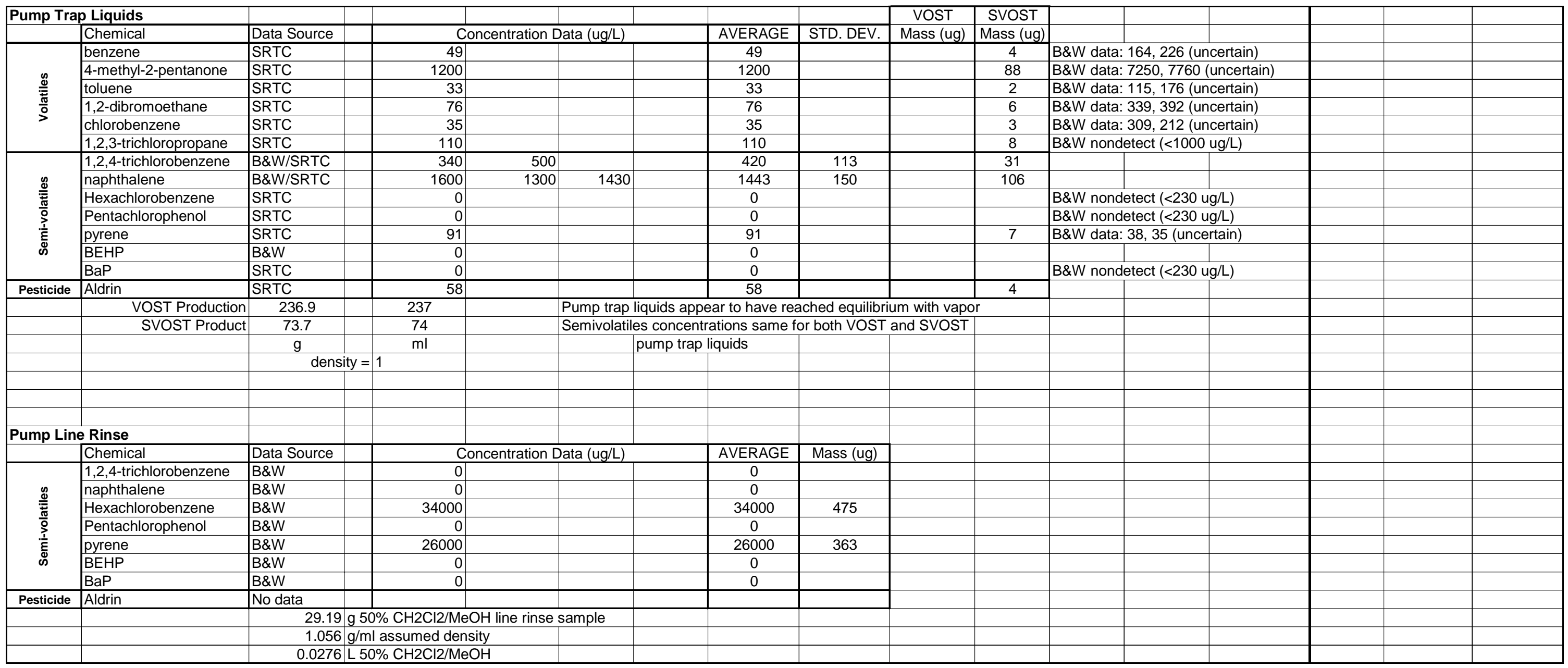


WSRC-TR-2000-00486

SRT-RPP-2000-00047

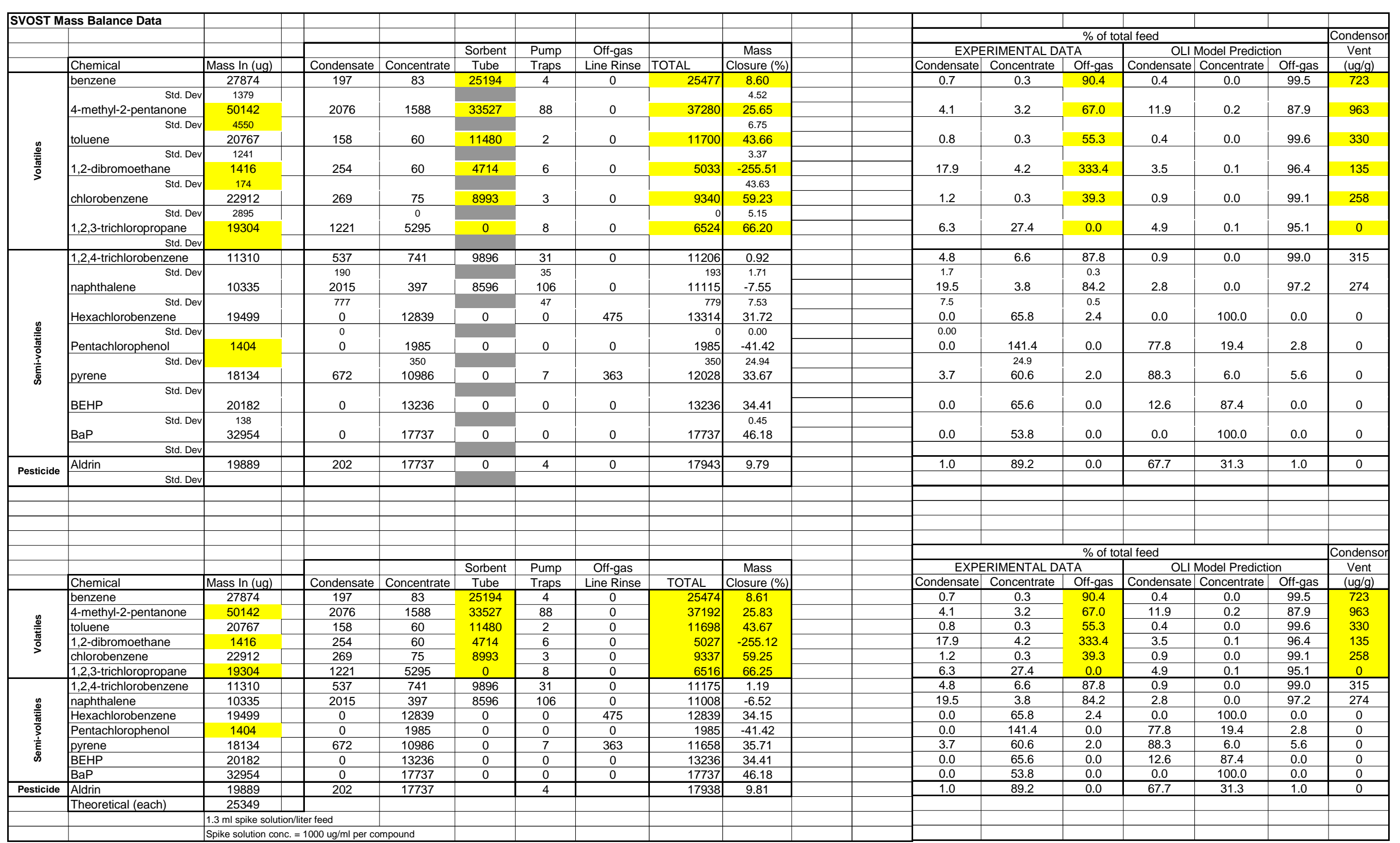


WSRC-TR-2000-00486

SRT-RPP-2000-00047

D. OLI Model Prediction - Concentration from 5.8 to $8.0 \mathrm{M} \mathrm{Na}$

\begin{tabular}{|c|c|c|c|c|c|c|c|c|c|c|}
\hline \multicolumn{11}{|c|}{ OLl Model Predictions (5.8 M to 8.0 M Na Evaporation) } \\
\hline \multirow{2}{*}{\multicolumn{11}{|c|}{\begin{tabular}{|r|l|l|l|l|l|} 
A. S. Choi & & & & & \\
$5 / 18 / 00$ & & & &
\end{tabular}}} \\
\hline & & & & & & & & & & \\
\hline & & & & & & & & & & \\
\hline & & & & & Sorbent & & Mass & Per & centage out as & \\
\hline & Chemical & Amt. In (mole) & Condensate & Concentrate & Tube & TOTAL & Closure (\%) & Condensate & Concentrate & Off-gas \\
\hline \multirow{6}{*}{$\frac{\stackrel{\mathscr{d}}{=}}{\frac{\bar{\pi}}{0}}$} & benzene & 0.019185 & 0.000085 & 0.000001 & 0.019098 & 0.019185 & 0.00 & 0.4 & 0.0 & 99.5 \\
\hline & 4-methyl-2-pentanone & 0.014962 & 0.001778 & 0.000025 & 0.013159 & 0.014962 & 0.00 & 11.9 & 0.2 & 87.9 \\
\hline & toluene & 0.016264 & 0.000063 & 0.000001 & 0.016200 & 0.016264 & 0.00 & 0.4 & 0.0 & 99.6 \\
\hline & 1,2-dibromoethane & 0.007977 & 0.000280 & 0.000004 & 0.007693 & 0.007977 & 0.00 & 3.5 & 0.1 & 96.4 \\
\hline & chlorobenzene & 0.013314 & 0.000115 & 0.000002 & 0.013197 & 0.013314 & 0.00 & 0.9 & 0.0 & 99.1 \\
\hline & 1,2,3-trichloropropane & 0.010165 & 0.000496 & 0.000007 & 0.009662 & 0.010165 & 0.00 & 4.9 & 0.1 & 95.1 \\
\hline \multirow{6}{*}{ 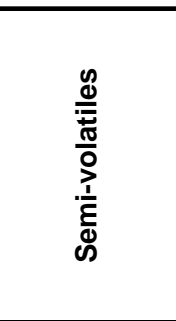 } & 1,2,4-trichlorobenzene & 0.008259 & 0.000078 & 0.000001 & 0.008180 & 0.008259 & 0.00 & 0.9 & 0.0 & 99.0 \\
\hline & naphthalene & 0.011692 & 0.000323 & 0.000005 & 0.011364 & 0.011692 & 0.00 & 2.8 & 0.0 & 97.2 \\
\hline & Hexachlorobenzene & 0.005262 & 0 & 0.005261 & 0 & 0.005261 & 0.02 & 0.0 & 100.0 & 0.0 \\
\hline & Pentachlorophenol & 0.005627 & 0.004380 & 0.001091 & 0.000155 & 0.005627 & 0.00 & 77.8 & 19.4 & 2.8 \\
\hline & pyrene & 0.007409 & 0.006540 & 0.000447 & 0.000412 & 0.007399 & 0.15 & 88.3 & 6.0 & 5.6 \\
\hline & BEHP & 0.003837 & 0.000483 & 0.003353 & 0.000001 & 0.003836 & 0.02 & 12.6 & 87.4 & 0.0 \\
\hline
\end{tabular}

